Prepared in cooperation with the Oregon Department of Transportation and the U.S. Department of Transportation Federal Highway Administration

\title{
Assessing Potential Effects of Highway Runoff on Receiving- Water Quality at Selected Sites in Oregon with the Stochastic Empirical Loading and Dilution Model (SELDM)
}

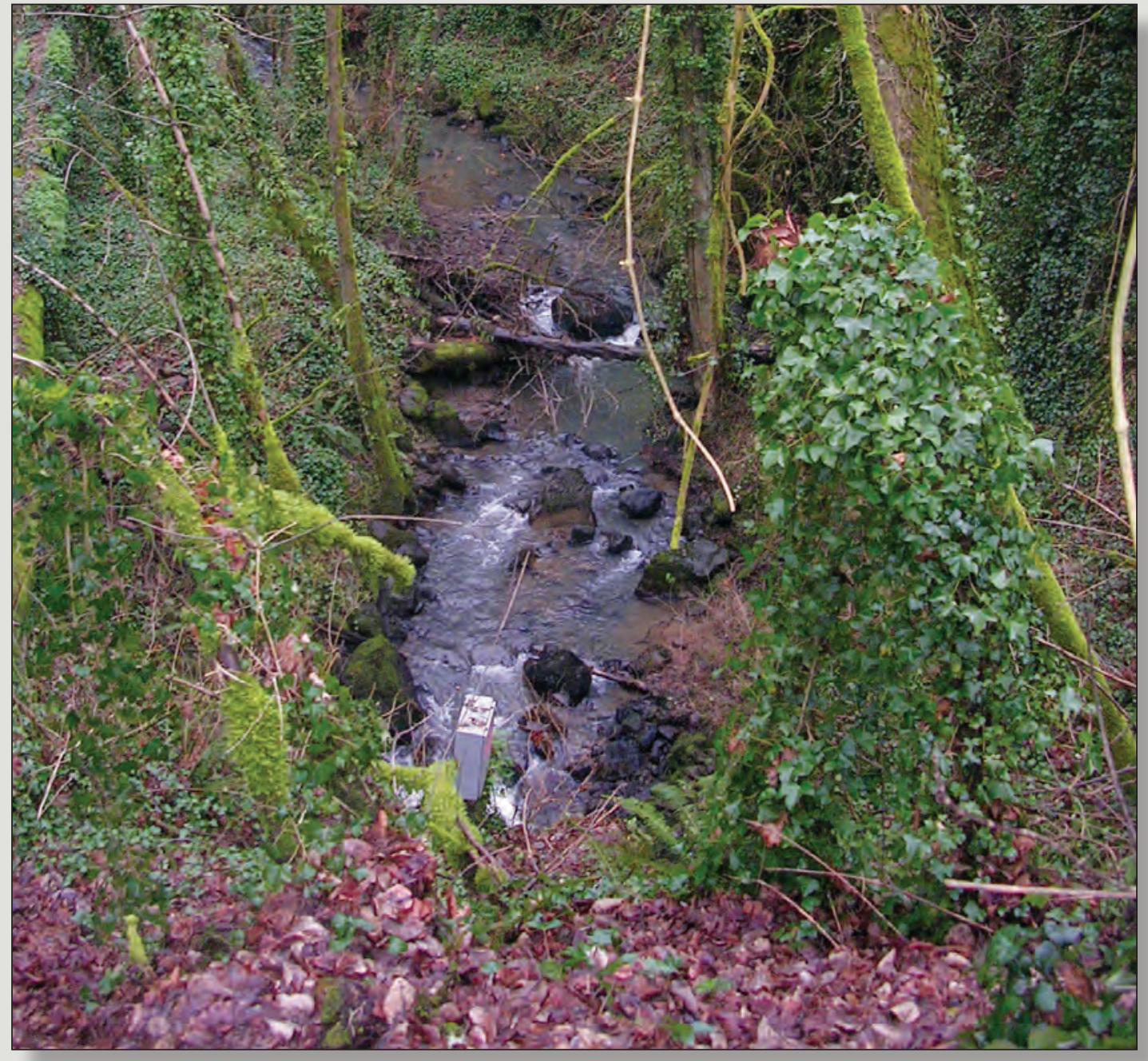

Scientific Investigations Report 2014-5099 
Cover: Photograph of Tryon Creek at Oregon Route 43, Lake Oswego, Oregon. Photograph taken by John Risley, U.S. Geological Survey, January 15, 2013. 


\section{Assessing Potential Effects of Highway Runoff on Receiving-Water Quality at Selected Sites in Oregon with the Stochastic Empirical Loading and Dilution Model (SELDM)}

By John C. Risley and Gregory E. Granato

Prepared in cooperation with the Oregon Department of Transportation and the U.S. Department of Transportation Federal Highway Administration

Scientific Investigations Report 2014-5099 


\title{
U.S. Department of the Interior SALLY JEWELL, Secretary
}

\section{U.S. Geological Survey \\ Suzette M. Kimball, Acting Director}

\author{
U.S. Geological Survey, Reston, Virginia: 2014
}

For more information on the USGS - the Federal source for science about the Earth, its natural and living resources, natural hazards, and the environment, visit http://www.usgs.gov or call 1-888-ASK-USGS.

For an overview of USGS information products, including maps, imagery, and publications, visit http://www.usgs.gov/pubprod

To order this and other USGS information products, visit http://store.usgs.gov

Any use of trade, firm, or product names is for descriptive purposes only and does not imply endorsement by the U.S. Government.

Although this information product, for the most part, is in the public domain, it also may contain copyrighted materials as noted in the text. Permission to reproduce copyrighted items must be secured from the copyright owner.

Suggested citation:

Risley, J.C., and Granato, G.E., 2014, Assessing potential effects of highway runoff on receiving-water quality at selected sites in Oregon with the Stochastic Empirical Loading and Dilution Model (SELDM): U.S. Geological Survey Scientific Investigations Report 2014-5099, 74 p., http://dx.doi.org/10.3133/sir20145099.

ISSN 2328-0328 (online) 


\section{Contents}

Abstract

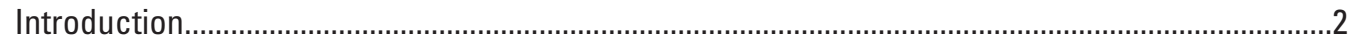

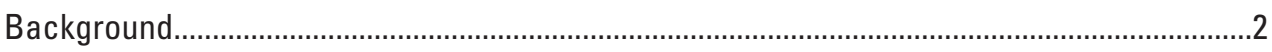

Purpose and Scope .......................................................................................................

Highway Water-Quality Constituents of Interest...................................................................

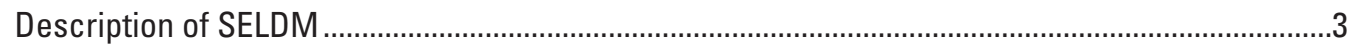

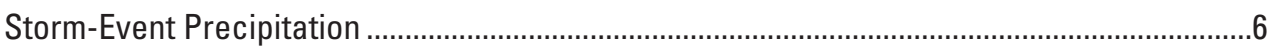

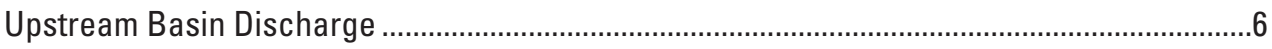

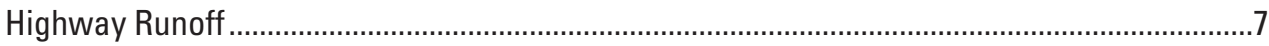

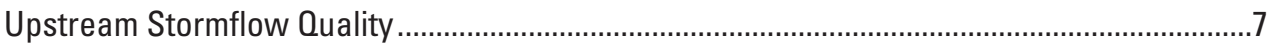

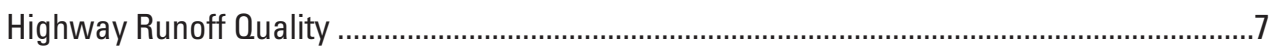

Best Management Practices..................................................................................................

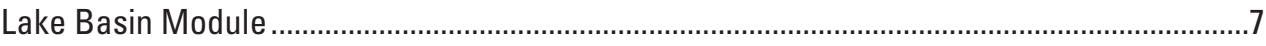

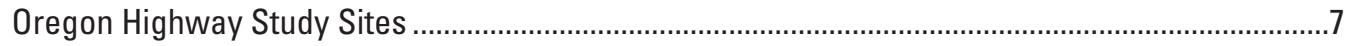

Miller Creek at U.S. Route 30, near Linnton, Oregon ..........................................................

Unnamed Creek at U.S. Route 30, at Portland, Oregon .........................................................12

Tryon Creek at Interstate 5, at Portland, Oregon ................................................................13

Tryon Creek at Oregon Route 43, at Lake Oswego, Oregon .................................................14

Murder Creek at Interstate 5, near Albany, Oregon.............................................................15

Wall Creek at Interstate 5, near Ashland, Oregon...............................................................16

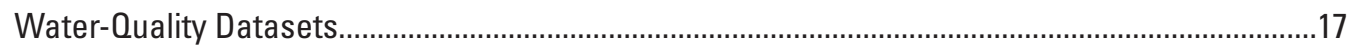

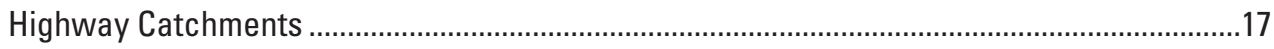

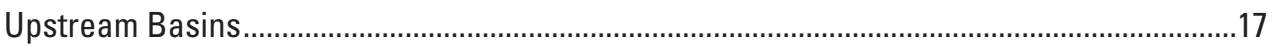

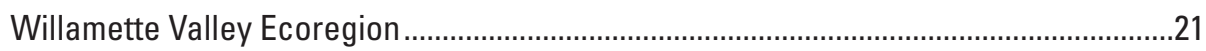

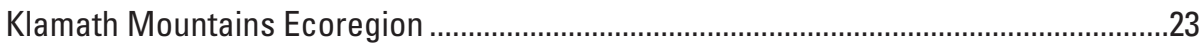

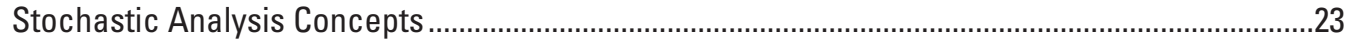

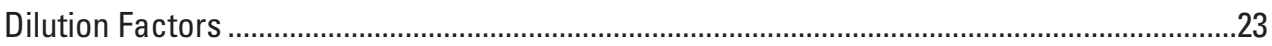

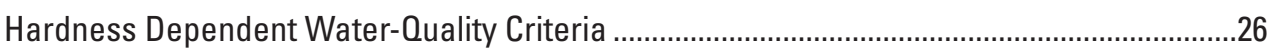

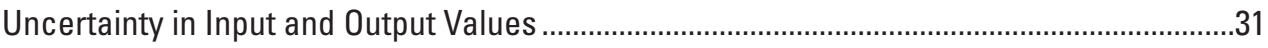

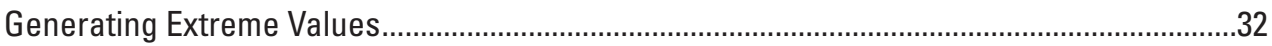

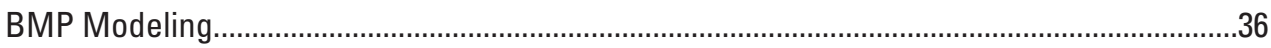

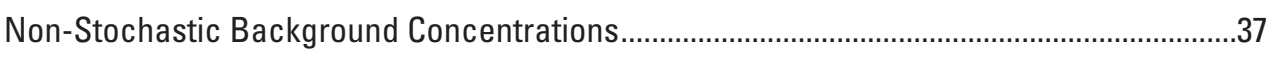

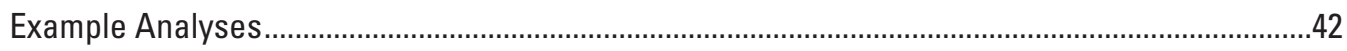

Miller Creek at U.S. Route 30, near Linnton, Oregon ............................................................42

Unnamed Creek at U.S. Route 30, at Portland, Oregon ........................................................46

Tryon Creek at Interstate 5, at Portland, Oregon ................................................................49

Tyron Creek at Oregon Route 43, at Lake Oswego, Oregon...............................................52

Murder Creek at Interstate 5, near Albany, Oregon..............................................................56

Wall Creek at Interstate 5, near Ashland, Oregon...............................................................59

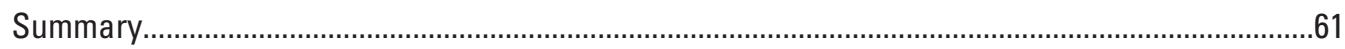

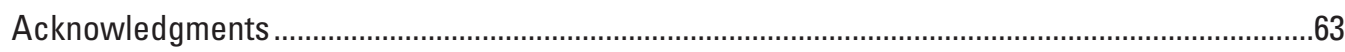




\section{Contents-Continued}

References Cited

Appendix A. Stochastic Empirical Loading and Dilution Model (SELDM) Related Products..........67

Appendix B. Spatial Data Layers Containing Storm-Event Precipitation and

Pre-Storm Streamflow Statistics. 69

Appendix C. Triangular Hydrograph Recession Ratios. 71

\section{Figures}

1. Schematic diagram showing components of the Stochastic Empirical Loading and Dilution Model.

2. Schematic diagram showing the upstream-flow and highway-runoff components that must be estimated for a mass-balance analysis of receiving-water quality...

3. Map showing locations of Oregon study sites used to evaluate potential effects of highway runoff on stormwater flows, concentrations, and loads in receiving waters with Stochastic Empirical Loading and Dilution Model.

4. Map showing Miller Creek at U.S. Route 30 study site (Lower Columbia River Highway), near Linnton, Oregon

5. Map showing Unnamed Creek at U.S. Route 30 (Lower Columbia River Highway), near St. John's Bridge at Portland, Oregon.

6. Map showing Tryon Creek at Interstate 5 (Pacific Highway), at Portland, Oregon.........13

7. Map showing Tryon Creek at Oregon Route 43 (Oswego Highway), at Lake Oswego, Oregon

8. Map showing Murder Creek at Interstate 5 (Pacific Highway), near Albany, Oregon ...15

9. Map showing Wall Creek at Interstate 5 (Pacific Highway), near Ashland, Oregon ......16

10. Graphs showing the stochastic populations of dilution factors for highway runoff or best management practices (BMP) discharge showing the effect of BMP treatments and upstream flow assumptions on the simulated dilution factors for Tryon Creek at Interstate 5, at Portland, Oregon, and Tryon Creek at Oregon Route 43, at Lake Oswego, Oregon

11. Graphs showing water-quality transport curves and stochastically generated data for Willamette Valley ecoregion and Klamath Mountains ecoregion generated by using concurrent upstream stormflows in Unnamed Creek at U.S. Route 30, Portland, Oregon, and Wall Creek at Interstate 5, near Ashland, Oregon, respectively

12. Boxplots showing total hardness concentrations in highway runoff, upstream stormflows, and downstream stormflows

13. Boxplots showing hardness-based total recoverable aquatic-life criteria for cadmium $(\mathrm{Cd})$, chromium $(\mathrm{Cr})$, copper $(\mathrm{Cu})$, lead $(\mathrm{Pb})$, Nickel $(\mathrm{Ni})$, and Zinc $(\mathrm{Zn})$ based on simulated stormflows and associated concentrations of total hardness in the Unnamed Creek study site in the Willamette Valley ecoregion and in Wall Creek study site in the Klamath Mountains ecoregion, Oregon...

14. Graph showing example of total recoverable lead exceedances in highway runoff in comparison with the Oregon Department of Environmental Quality hardness-based aquatic-life criteria as a function of the geometric mean lead concentration and the modeling method used. 


\section{Figures-Continued}

15. Graph showing example of total recoverable lead exceedances in the Unnamed Creek at U.S. Route 30, at Portland, Oregon, in comparison the Oregon Department of Environmental Quality hardness-based aquatic-life criteria as a function of the geometric mean lead concentration and the modeling method used.

16. Graph showing moving average values of total phosphorus concentrations for 22 stochastic samples generated with statistics from Interstate 5 at Mountain Gate Northbound, California...

17. Graph showing cumulative total phosphorus concentration-exceedances greater than 0.5 milligrams per liter in percent for 22 stochastic samples generated with statistics from Interstate 5 at Mountain Gate Northbound, California

18. Graph showing example analyses of the concentrations of chloride in highway runoff generated by using a log-Pearson type III distribution or a lognormal distribution

19. Graph showing example of total recoverable lead exceedances in relation to the geometric mean flow upstream and downstream of the highway discharge with various deterministic flow-reduction ratios indicating the potential effectiveness of infiltration without concentration reduction or flow extension for meeting the total lead criterion, not to exceed 1 event mean concentration during each 3-year period.

20. Graph showing measured suspended-sediment concentration, streamflow, two-segment water-quality transport curve, and stochastically generated suspended-sediment data calculated for each measured stormflow data point during water year October 1, 2010 to September 30, 2011.

21. Graphs showing suspended-sediment and total copper concentrations estimated by using the transport-curve sediment concentrations and the geometric mean concentration of copper in fine streambed sediment from sites in Willamette Basin, Oregon, with impervious areas less than 10 percent

22. Graph showing percentage of water-quality exceedances as a function of the average concentration, modeling method, and type of criteria applied for the upstream and the downstream water quality.....

23. Graph showing example analyses of stormflows including highway-runoff volumes and the concurrent upstream runoff, upstream stormflow, and downstream stormflow volumes in Miller Creek, at U.S. Route 30, near Linnton, Oregon..

24. Graph showing example analyses of the concentrations of total recoverable lead in highway runoff, upstream stormflows, and downstream stormflows concurrent to the period of highway runoff in Miller Creek at U.S. Route 30, near Linnton, Oregon....

25. Graph showing example analyses of the loads of total recoverable lead in highway runoff, upstream stormflows, and downstream stormflows concurrent to the period of highway runoff in Miller Creek at U.S. Route 30, near Linnton, Oregon..

26. Graph showing example analyses of stormflows including highway runoff volumes and the concurrent upstream runoff, upstream stormflow, and downstream stormflow volumes in Unnamed Creek at U.S. Route 30, at Portland, Oregon ....

27. Graph showing example analyses of the concentrations of total recoverable nickel in highway runoff, upstream stormflows, and downstream stormflows concurrent to the period of highway runoff in Unnamed Creek at U.S. Route 30, at Portland, Oregon. 


\section{Figures-Continued}

28. Graph showing example analyses of the loads of total recoverable nickel in highway runoff, upstream stormflows, and downstream stormflows concurrent to the period of highway runoff in Unnamed Creek at U.S. Route 30, at Portland, Oregon

29. Graph showing example analyses of stormflows including highway runoff volumes and the concurrent upstream runoff, upstream stormflow, and downstream stormflow volumes in Tryon Creek at Interstate 5, at Portland, Oregon.

30. Graph showing example analyses of the concentrations of total recoverable copper in highway runoff, upstream stormflows, and downstream stormflows concurrent to the period of highway runoff in Tryon Creek at Interstate 5, at Portland, Oregon

31. Graph showing example analyses of the loads of total recoverable copper in highway runoff, upstream stormflows, and downstream stormflows concurrent to the period of highway runoff in Tryon Creek at Interstate 5, at Portland, Oregon

32. Graph showing example analyses of stormflows including highway runoff volumes and the concurrent upstream runoff, upstream stormflow, and downstream stormflow volumes in Tryon Creek at Oregon Route 43, at Portland, Oregon

33. Graphs showing example analyses of the concentrations of total recoverable chromium and total recoverable copper in highway runoff, upstream stormflows, and downstream stormflows concurrent to the period of highway runoff in Tryon Creek at Oregon Route 43, at Portland, Oregon.

34. Graphs showing example analyses of the storm loads of total recoverable chromium and total recoverable copper in highway runoff, upstream stormflows, and downstream stormflows concurrent to the period of highway runoff in Tryon Creek at Oregon Route 43, at Portland, Oregon.

35. Graph showing example analyses of stormflows including highway runoff volumes and the concurrent upstream runoff, upstream stormflow, and downstream stormflow volumes in Murder Creek at Interstate 5, near Albany, Oregon

36. Graph showing example analyses of the concentrations of total recoverable zinc in highway runoff, upstream stormflows, and downstream stormflows concurrent to the period of highway runoff in Murder Creek at Interstate 5, near Albany, Oregon .....57

37. Graph showing example analyses of the loads of total recoverable zinc in highway runoff, upstream stormflows, and downstream stormflows concurrent to the period of highway runoff in Murder Creek at Interstate 5, near Albany, Oregon.

38. Graph showing example analyses of stormflows including highway runoff volumes and the concurrent upstream runoff, upstream stormflow, and downstream stormflow volumes in Wall Creek at Interstate 5, near Ashland, Oregon

39. Graph showing example analyses of the concentrations of chloride in highway runoff, upstream stormflows, and downstream stormflows concurrent to the period of highway runoff in Wall Creek at Interstate 5, near Ashland, Oregon. 


\section{Tables}

1. Highway runoff water-quality constituents of interest ....................................................

2. Selected highway sites with drainage-basin properties for the upstream basin and

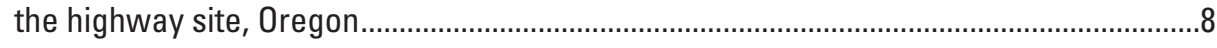

3. Storm-event precipitation statistics of selected study sites, Oregon ............................10

4. Pre-storm streamflow statistics of selected study sites, Oregon ...................................11

5. Surrogate streamflow sites used to select triangular hydrograph recession ratios for the Oregon study site upstream basins ..................................................................11

6. Surrogate water-quality data sites selected for the Oregon study site highway

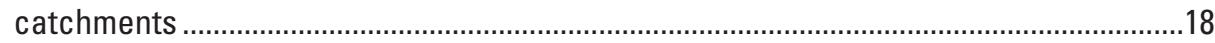

7. Surrogate highway water-quality statistics evaluated for use in example simulations

8. Surrogate water-quality data sites selected for the Oregon study site upstream basins.

9. Random water-quality statistics used to simulate upstream concentrations at non-urban sites in the Willamette Valley and Klamath Mountains ecoregions, Oregon

10. Water-quality transport curve statistics used to simulate upstream concentrations at sites in the Willamette Valley and Klamath Mountains ecoregions, California, Oregon, and Washington. 


\section{Conversion Factors, Datums, and Acronyms and Abbreviations}

\section{Conversion Factors}

Inch/Pound to SI

\begin{tabular}{|c|c|c|}
\hline Multiply & By & To obtain \\
\hline \multicolumn{3}{|c|}{ Length } \\
\hline inch (in.) & 25.4 & millimeter (mm) \\
\hline foot $(\mathrm{ft})$ & 0.3048 & meter $(\mathrm{m})$ \\
\hline mile (mi) & 1.609 & kilometer (km) \\
\hline \multicolumn{3}{|c|}{ Area } \\
\hline acre & 0.4047 & hectare (ha) \\
\hline acre & 0.004047 & square kilometer $\left(\mathrm{km}^{2}\right)$ \\
\hline square mile $\left(\mathrm{mi}^{2}\right)$ & 2.590 & square kilometer $\left(\mathrm{km}^{2}\right)$ \\
\hline \multicolumn{3}{|c|}{ Flow rate } \\
\hline foot per second (ft/s) & 0.3048 & meter per second (m/s) \\
\hline cubic foot per second $\left(\mathrm{ft}^{3} / \mathrm{s}\right)$ & 0.02832 & cubic meter per second $\left(\mathrm{m}^{3} / \mathrm{s}\right)$ \\
\hline $\begin{array}{l}\text { cubic foot per second per square } \\
\text { mile }\left[\left(\mathrm{ft}^{3} / \mathrm{s}\right) / \mathrm{mi}^{2}\right]\end{array}$ & 0.01093 & $\begin{array}{l}\text { cubic meter per second per square } \\
\text { kilometer }\left[\left(\mathrm{m}^{3} / \mathrm{s}\right) / \mathrm{km}^{2}\right]\end{array}$ \\
\hline \multicolumn{3}{|c|}{ Mass } \\
\hline pound, avoirdupois (lb) & 0.4536 & kilogram (kg) \\
\hline ton, short $(2,000 \mathrm{lb})$ & 0.9072 & megagram (Mg) \\
\hline \multicolumn{3}{|c|}{ Hydraulic gradient } \\
\hline foot per mile (ft/mi) & 0.1894 & meter per kilometer $(\mathrm{m} / \mathrm{km})$ \\
\hline
\end{tabular}

Temperature in degrees Celsius $\left({ }^{\circ} \mathrm{C}\right)$ may be converted to degrees Fahrenheit $\left({ }^{\circ} \mathrm{F}\right)$ as follows:

$$
{ }^{\circ} \mathrm{F}=\left(1.8 \times{ }^{\circ} \mathrm{C}\right)+32
$$

\section{Datums}

Vertical coordinate information is referenced to the North American Vertical Datum of 1988 (NAVD 88).

Horizontal coordinate information is referenced to the North American Datum of 1983 (NAD 83).

Altitude, as used in this report, refers to distance above the vertical datum. 


\section{Conversion Factors, Datums, and Acronyms and Abbreviations-Continued}

\section{Acronyms and Abbreviations}

$\begin{array}{ll}\text { 1B3 } & \text { 1-day 3-year biological flow } \\ \text { 4B3 } & \text { 4-day 3-year biological flow } \\ \text { 7010 } & \text { 7-day 10-year flow } \\ \text { ADT } & \text { average daily traffic } \\ \text { BDF } & \text { basin development factor } \\ \text { BMP } & \text { best management practices } \\ \text { EMCs } & \text { event mean concentrations } \\ \text { ESRI } & \text { Environmental Systems Research Institute } \\ \text { FHWA } & \text { Federal Highway Administration } \\ \text { GIS } & \text { Geographic Information System } \\ \text { GNWISO } & \text { Get NWIS WEB Streamflow Files software } \\ \text { HRDB } & \text { Highway-Runoff Database } \\ \text { I } & \text { Interstate } \\ \text { KTRLine } & \text { Kendall-Theil Robust Line software } \\ \text { log10 } & \text { common (base 10) logarithms } \\ \text { MkDF } & \text { Make DFLOW3 Input Files software } \\ \text { MkPP } & \text { Make Plotting Position file software } \\ \text { MPV } & \text { most probable value } \\ \text { NOAA } & \text { National Oceanic Atmospheric Administration } \\ \text { NPDES } & \text { National Pollutant Discharge Elimination System } \\ \text { ODEO } & \text { Oregon Department of Environmental Quality } \\ \text { ODOT } & \text { Oregon Department of Transportation } \\ \text { OWRD } & \text { Oregon Department of Water Resources } \\ \text { OSTATS } & \text { Streamflow (0) Statistics software } \\ \text { RMSE } & \text { root mean square error } \\ \text { ROS } & \text { Robust Regression on Order Statistics } \\ \text { SELDM } & \text { Stochastic Empirical Loading and Dilution Model } \\ \text { SPAF } & \text { Synoptic Precipitation Analysis Facilitator software } \\ \text { SR } & \text { State Route } \\ \text { SREF } & \text { Streamflow Record Extension Facilitator software } \\ \text { SWODM } & \text { Surface Water Quality Data Miner database } \\ \text { TMDL } & \text { Total Maximum Daily Load } \\ \text { EPA } & \text { U.S. Environmental Protection Agency } \\ \text { USGS } & \text { U.S. Geological Survey } \\ \text { WSDOT } & \text { Washington State Department of Transportation } \\ \text { WY } & \text { water year } \\ & \end{array}$





\title{
Assessing Potential Effects of Highway Runoff on Receiving-Water Quality at Selected Sites in Oregon with the Stochastic Empirical Loading and Dilution Model (SELDM)
}

\author{
By John C. Risley and Gregory E. Granato
}

\section{Abstract}

In 2012, the U.S. Geological Survey and the Oregon Department of Transportation began a cooperative study to demonstrate use of the Stochastic Empirical Loading and Dilution Model (SELDM) for runoff-quality analyses in Oregon. SELDM can be used to estimate stormflows, constituent concentrations, and loads from the area upstream of a stormflow discharge site, from the site of interest and in the receiving waters downstream of the discharge. SELDM also can be used to assess the potential effectiveness of best management practices (BMP) for mitigating potential effects of runoff in receiving waters. Nominally, SELDM is a highway-runoff model, but it is well suited for analysis of runoff from other land uses as well.

This report provides case studies and examples to demonstrate stochastic-runoff modeling concepts and to demonstrate application of the model. Basin characteristics from six Oregon highway study sites were used to demonstrate various applications of the model. The highway catchment and upstream basin drainage areas of these study sites ranged from 3.85 to 11.83 acres and from 0.16 to 6.56 square miles, respectively. The upstream basins of two sites are urbanized, and the remaining four sites are less than 5 percent impervious.

SELDM facilitates analysis by providing precipitation, pre-storm streamflow, and other variables by region or from hydrologically similar sites. In Oregon, there can be large variations in precipitation and streamflow among nearby sites. Therefore, spatially interpolated geographic information system data layers containing storm-event precipitation and pre-storm streamflow statistics specific to Oregon were created for the study using Kriging techniques.

Concentrations and loads of cadmium, chloride, chromium, copper, iron, lead, nickel, phosphorus, and zinc were simulated at the six Oregon highway study sites by using statistics from sites in other areas of the country. Water-quality datasets measured at hydrologically similar basins in the vicinity of the study sites in Oregon were selected and compiled to estimate stormflow-quality statistics for the upstream basins. The quality of highway runoff and some upstream stormflow constituents were simulated by using statistical moments (average, standard deviation, and skew) of the logarithms of data. Some upstream stormflow constituents were simulated by using transport curves, which are relations between stormflow and constituent concentrations.

Stochastic analyses were done by using SELDM to demonstrate use of the model and to illustrate the types of information that stochastic analyses may provide:

1. An analysis was done to demonstrate use of dilution factors as an initial reconnaissance tool for comparing relative risk among sites.

2. An analysis of hardness-dependent, water-quality criteria was done to illustrate the effects of variations in hardness and flow on the application and interpretation of such criteria. This analysis shows that hardness-dependent criteria can vary by an order of magnitude among storm events because hardness is diluted by stormflows.

3. An analysis of uncertainties in input and output values was done to demonstrate that properly selected robust datasets are needed to represent conditions at a site of interest. This analysis shows that the rate of water-quality exceedances that are measured or simulated may depend on sample size and the luck of the draw.

4. An analysis was done to demonstrate that SELDM and other Monte Carlo models may generate extreme values from input statistics, which may or may not be feasible based on physicochemical or hydrological limits.

5. An analysis of BMP modeling methods was done to demonstrate use of the model for estimating treatment requirements for meeting water-quality objectives.

6. An analysis of the use of grab sampling and nonstochastic upstream modeling methods was done to evaluate the potential effects on modeling outcomes. 
Additional analyses using surrogate water-quality datasets for the upstream basin and highway catchment were provided for six Oregon study sites to illustrate the risk-based information that SELDM will produce. These analyses show that the potential effects of highway runoff on receiving-water quality downstream of the outfall depends on the ratio of drainage areas (dilution), the quality of the receiving water upstream of the highway, and the concentration of the criteria of the constituent of interest. These analyses also show that the probability of exceeding a water-quality criterion may depend on the input statistics used, thus careful selection of representative values is important.

\section{Introduction}

\section{Background}

Water-resource managers are concerned about the frequencies, magnitudes, and durations of concentrations and loads (the products of measured stormflow and concentration) that may have an adverse effect on the quality of receiving waters. Runoff from impervious areas, such as parking lots, local roads, and highways, can increase stormflows and increase concentrations of sediment, nutrients, deicers, trace elements, and organic constituents in receiving water bodies (Athayde and others, 1983; Driscoll and others, 1990b; U.S. Environmental Protection Agency, 2005; National Cooperative Highway Research Program, 2006; Smith and Granato, 2010). Evaluating the potential effects of stormwater, however, poses many unique challenges (Athayde and others, 1983; Granato, 2013). Intermittent and highly variable concentrations, flows, and loads complicate the monitoring, characterization, and evaluation of potential effects of runoff on receiving waters. These factors also affect efforts to evaluate runoff-mitigation measures. Application of results from best management practices (BMP) monitoring studies is highly uncertain; few studies provide reliable predictions of treatment performance even with large datasets and complex models (Strecker and others, 2001; National Cooperative Highway Research Program, 2006; Wong and others, 2006; Park and others, 2011). Therefore, decision makers need tools to help transform complex scientific data into meaningful information about the risk of adverse effects of runoff on receiving waters, the potential need for mitigation measures, and the potential effectiveness of such management measures for reducing these risks.

The U.S. Geological Survey (USGS) in cooperation with the Federal Highway Administration (FHWA) developed the Stochastic Empirical Loading and Dilution Model (SELDM) to provide the tools and techniques necessary for doing stormwater-quality simulations (Granato, 2013). SELDM uses a stochastic mass-balance approach to estimate combinations of flows, concentrations, and loads of stormwater constituents from the site of interest, often highway catchments, and the basin upstream of the stormwater outfall to assess the risk for adverse effects of runoff. SELDM also can be used to simulate the effectiveness of volume reduction, flow extension, and concentration reductions by stormwater BMPs, which can be used to help mitigate the effects of runoff on the receiving water body. SELDM also produces a stochastic population of annual flows and loads that can be used to evaluate potential effects of runoff from a site of interest. SELDM is described as a highway-runoff model, but also can be used to simulate runoff discharges from various land uses.

The Oregon Department of Transportation (ODOT) entered a cooperative agreement with the USGS in 2012 to evaluate SELDM as a decision-making tool for the State. ODOT needs tools to evaluate potential effects of runoff to help focus limited resources for mitigation at sites where mitigation measures are needed and where they can improve receiving-water quality. The potential need for such mitigation measures in Oregon is driven by the Endangered Species Act of 1973 (ESA) and by water quality regulations that are implemented and enforced by the Oregon Department of Environmental Quality (ODEQ). Section 303(d) of the 1972 Clean Water Act requires States to identify waters not meeting water-quality standards, and to apply a Total Maximum Daily Load (TMDL) plan for water-quality limited resources (Oregon Department of Environmental Quality, 2007). ODOT has been identified by ODEQ as a "designated management agency" in many TMDLs but not as a stakeholder (American Association of State Highway and Transportation Officials, 2010). National Pollutant Discharge Elimination System (NPDES) permits also are required for stormwater discharges that reach streams through a point source, which is any conveyance of water, including pipes, culverts, and ditches. The ODEQ and ODOT have a memorandum of understanding to work together to develop and implement the information and methods needed to protect water quality while efficiently implementing ODOT and ODEQ missions (Weick and Brindle, 2011).

\section{Purpose and Scope}

The purpose of the study was to demonstrate how SELDM can be used as a decision-making tool to evaluate the potential effects of runoff on receiving streams. This report documents methods for estimating the quantity and quality of runoff and potential effects of runoff on downstream water quality. This report illustrates the model's capability for simulating the quality and quantity of stormflows and the potential effectiveness of mitigation measures to reduce or eliminate risks for adverse effects of runoff. The study 
was designed to apply the model by using datasets, example sites, and information specific to local conditions in Oregon. Because surrogate water-quality datasets were selected for these examples sites, these analyses were hypothetical. Rather than representing a complete characterization of the sites, they were provided only as a demonstration of the model capability.

The scope of the study was limited to applications within Oregon. However, information provided in this report should be beneficial to potential model users elsewhere in the Pacific Northwest or nationally. This report provides examples for using SELDM, but is not intended to be a supplementary "how to" manual for using the model. Numerous references to the manual (Granato, 2013) and other supporting documents are included throughout the report. Specifically, this report includes:

1. A brief description of the model;

2. An overview of the publications and software that are available to support advanced modeling efforts;

3. Suggestions for defining highway-site and upstream-basin characteristics necessary for modeling sites in Oregon;

4. Creation of spatial data layers that geographically cover Oregon and contain model input statistics that characterize storm-event precipitation and pre-storm streamflow statistics;

5. Selection of surrogate highway water-quality datasets for selected study sites;

6. Development of water-quality statistics and transport curves from available stream water-quality data measured at sites in Oregon that are nearby and hydrologically similar to the selected study sites;

7. Examples of stochastic analysis of runoff-quality data including use of dilution factors, application of waterquality criteria to stormwater, uncertainty in inputs and outputs, and BMP modeling methods; and

8. Hypothetical simulations of flow, concentration, and load at selected study sites.

\section{Highway Water-Quality Constituents of Interest}

Many potential highway study sites in Oregon suitable for SELDM analyses are located in western Oregon and within and near urban areas with high traffic volume. Highway and urban runoff constituents in these areas typically include sediment, nutrients, and trace metals, as well as natural and anthropogenic organic compounds. Although trace metals have been monitored at numerous highway study sites outside of Oregon, datasets within Oregon are limited (Herrera Environmental Consultants, 2011b). It was possible to select surrogate highway water-quality datasets monitored in other States that could be used to characterize the highway runoff water quality of the six Oregon study sites. Although highways are, in theory, a source of anthropogenic organic compounds, data show that concentrations of many of these constituents in highway runoff are near or below detection limits during most storm events (Granato and Cazenas, 2009; Smith and Granato, 2010). When these constituents are detected, they commonly are measured in the nanogram per liter range at sites in ultraurban areas where imperviousness exceeds 50 percent (Lau and others, 2009). Chloride also is a highway constituent of interest in Oregon. In 2013, ODOT began a program of winter weather road salt application on a limited number of mountainous highways.

For SELDM applications, it was necessary to use waterquality datasets from monitoring at the upstream basins or at similar streams in the vicinity of the study sites; those data could be paired with highway-runoff-quality datasets. For example, to quantify the effect of copper loading from highway runoff on a receiving water body, it is necessary to simulate background copper data from the upstream basin. Based on the availability of highway catchment and upstream basin water-quality datasets, nine constituents of interest (mostly trace metals) were selected for the study (table 1). Total phosphorus (TP) was selected as an example constituent because nutrients are a common concern throughout the Nation, and data for receiving waters, highway runoff, and the performance of BMPs are readily available for this constituent (Athayde and others, 1983; Granato and Cazenas, 2009; Granato and others, 2009; Leisenring and others, 2010; U.S. Environmental Protection Agency, 2013).

\section{Description of SELDM}

As a planning model, rather than a physically based water-quality model, SELDM uses Monte Carlo methods with statistics derived from local or regional hydrologic and water-quality data (Granato, 2013). SELDM uses widely accepted stochastic mass-balance methods to simulate the flows, concentrations, and loads of runoff-quality constituents from the site of interest and the upstream basin (Driscoll and others, 1979; Warn and Brew, 1980; Di Toro, 1984; Driscoll and others 1989; Driscoll and others, 1990a, 1990b).

In this report, a highway site of interest can be defined as the catchment that includes the road surface and shoulders that all drain to a receiving stream or lake. The upstream basin is defined as the watershed of the receiving stream, upstream of the outfall of the highway catchment. 
Table 1. Highway runoff water-quality constituents of interest.

[ODEQ Criteria: Oregon Department of Environmental Quality (ODEQ) criteria from http://www.deq.state.or.us/wq/standards/toxics.htm\#Cur (accessed August 1, 2013), table 20, enclosure 1, Aquatic life fresh chronic. Oregon data in NWIS: USGS National Water Information Systems (NWIS), September 2012. Highway runoff data in HRDB: Highway Runoff database (HRDB) from Granato and Cazenas (2009) and Smith and Granato (2010). Abbreviations: Pcode, U.S. Environmental Protection Agency (EPA) parameter code; $\mu$ g/L, micrograms per liter; mg/L, milligrams per liter; na, not available]

\begin{tabular}{|c|c|c|c|c|c|c|c|c|}
\hline \multirow[b]{2}{*}{ Constituent } & \multirow[b]{2}{*}{ Pcode } & \multirow[b]{2}{*}{ Pcode definition } & \multicolumn{2}{|c|}{ ODEO criteria } & \multicolumn{2}{|c|}{ Oregon data in NWIS } & \multicolumn{2}{|c|}{$\begin{array}{l}\text { Highway runoff data } \\
\text { in the HRDB }\end{array}$} \\
\hline & & & $\begin{array}{c}\text { Willamette } \\
\text { Valley } \\
\text { ecoregion }\end{array}$ & $\begin{array}{c}\text { Klamath } \\
\text { Mountains } \\
\text { ecoregion }\end{array}$ & Sites & Samples & Sites & Samples \\
\hline $\mathrm{Cd}$ & p01027 & Cadmium, water, unfiltered, $\mu \mathrm{g} / \mathrm{L}$ & ${ }^{1} 0.79$ & ${ }^{2} 1.42$ & 84 & 4,074 & 98 & 1,459 \\
\hline $\mathrm{Cl}$ & p00940 & Chloride, water, filtered, $\mathrm{mg} / \mathrm{L}$ & 230 & 230 & 145 & 12,156 & 45 & 2,179 \\
\hline $\mathrm{Cu}$ & p01042 & Copper, water, unfiltered, recoverable, $\mu \mathrm{g} / \mathrm{L}$ & ${ }^{1} 4.65$ & 27.58 & 79 & 4,045 & 116 & 2,153 \\
\hline $\mathrm{Fe}$ & p01045 & Iron, water, unfiltered, recoverable, $\mu \mathrm{g} / \mathrm{L}$ & 1,000 & 1,000 & 121 & 4,284 & 50 & 787 \\
\hline $\mathrm{Pb}$ & p01051 & Lead, water, unfiltered, recoverable, $\mu \mathrm{g} / \mathrm{L}$ & ${ }^{1} 13.4$ & ${ }^{2} 1.42$ & 89 & 3,949 & 115 & 2,050 \\
\hline $\mathrm{Ni}$ & p01067 & Nickel, water, unfiltered, recoverable, $\mu \mathrm{g} / \mathrm{L}$ & ${ }^{1} 0.79$ & ${ }^{2} 25.9$ & 72 & 3,617 & 75 & 1,105 \\
\hline TP & p00665 & Phosphorus, water, unfiltered, $\mathrm{mg} / \mathrm{L}$ & na & na & 114 & 25,207 & 94 & 1,439 \\
\hline $\mathrm{Zn}$ & p01092 & Zinc, water, unfiltered, recoverable, $\mu \mathrm{g} / \mathrm{L}$ & ${ }^{1} 35.9$ & ${ }^{2} 55.8$ & 78 & 4,045 & 117 & 2,119 \\
\hline
\end{tabular}

${ }^{1}$ Willamette Valley ecoregion hardness dependent criteria (average is $24.2 \mathrm{mg} / \mathrm{L}$ total hardness).

${ }^{2}$ Klamath Mountains ecoregion hardness dependent criteria (average is $40.6 \mathrm{mg} / \mathrm{L}$ total hardness).

For every storm event, SELDM generates an event mean concentration (EMC) and a concurrent stormflow volume for the upstream basin and the highway site (fig. 1). The downstream concentration and stormflow volume for that event are then computed by simple mass balance. The statistics describe the frequency distributions of the precipitation event, stormflow volumes, concentrations, and loads of the contributing components (highway catchment and upstream basin), which are used by SELDM to stochastically generate a distribution of stormflow volumes, concentrations, and loads in the receiving downstream water body. The model also can be used to simulate the effects of structural BMPs. In SELDM, BMP treatment mechanisms can include flow reduction, highway storm hydrograph extension, water-quality treatment, or combinations of these. By varying permutations and combinations of upstream basin and highway runoff concentrations and loads, the potential risk of exceeding water-quality standards at a location downstream of the highway outfall can be assessed. The required treatment for minimizing the number of exceedances can be simulated and used as design goals for construction of actual BMPs.

By facilitating scenario simulation and sensitivity analysis, SELDM can determine the potential risk of downstream water-quality exceedances resulting from highway runoff. A typical SELDM application might involve the intersection of a single roadway with a stream. However, SELDM applications are not restricted to this scenario. The model can be used to characterize the cumulative load of runoff constituents from a highway that is parallel to a stream by simulating the entire contributing area as if it was discharging to a single point. SELDM also can be used for mass balance analyses for runoff-generating areas that do not include a highway. For example, with representative water-quality statistics, SELDM can be used to simulate the effects of runoff from a commercial development on a stream by using the site characteristics of the contributing area and water-quality statistics that are representative of the runoff quality of commercial land uses.

Throughout this report the following terminology is used:

Highway runoff is the volume of runoff from the highway catchment area during a storm event.

Concurrent upstream runoff is the volume of runoff from the upstream drainage basin, without pre-storm streamflow, that occurs during the same time period as highway runoff during a storm event.

Concurrent upstream stormflow is the combined volume of upstream runoff and upstream pre-storm streamflow during the same time period as highway runoff (or BMP discharge) during a storm event.

Concurrent downstream stormflow is the combined volume of highway runoff and upstream stormflow during the same time period as highway runoff (or BMP discharge) during a storm event. 


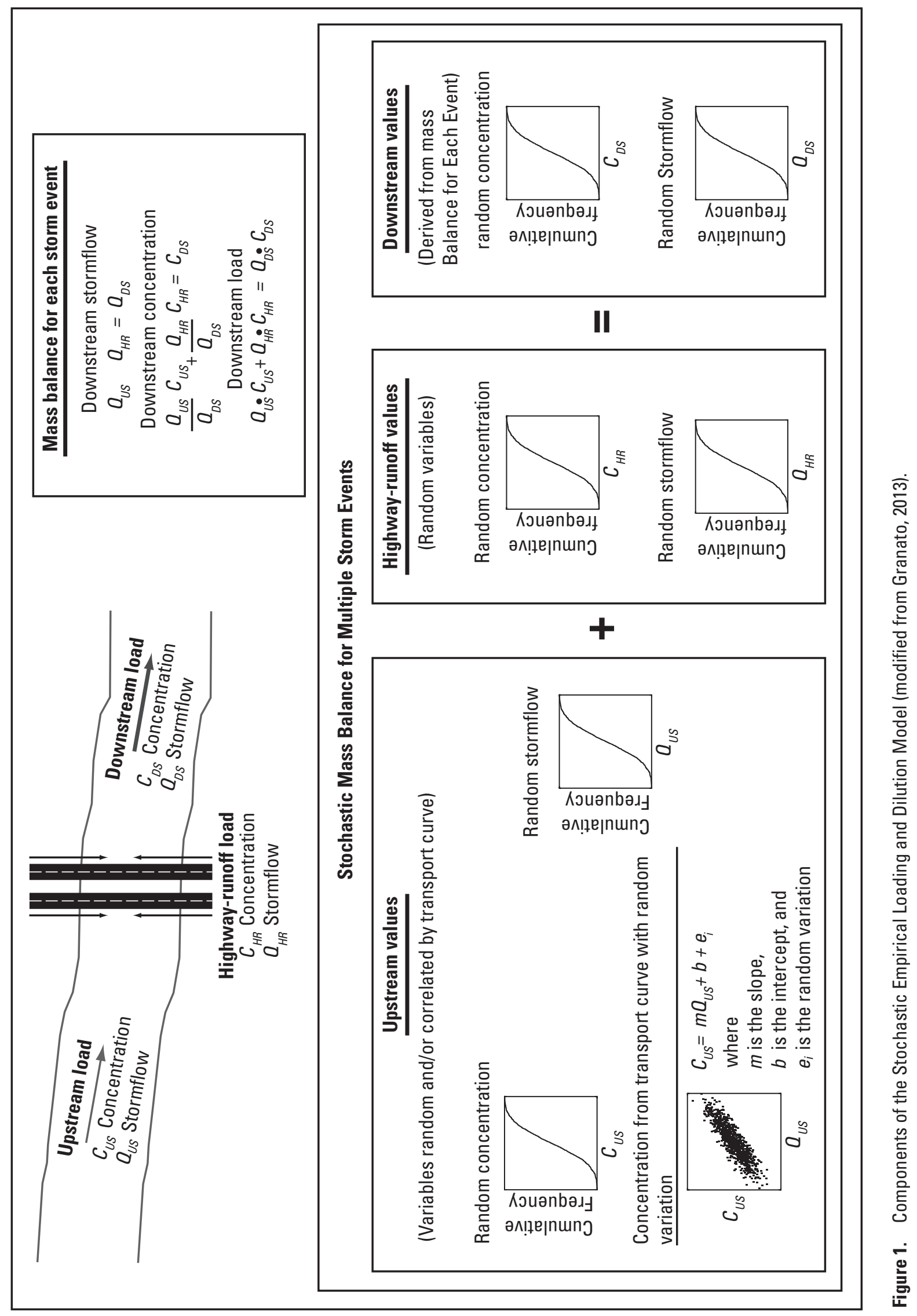




\section{Storm-Event Precipitation}

Storm-event precipitation statistics define the characteristics of each storm event and the number of events in the simulation. Storm-event precipitation statistics are used with runoff coefficient statistics to generate the upstream basin and the highway catchment storm discharges (fig. 2). Required storm-event statistics include the event volume (in inches), event duration (in hours), the time between event mid-points (in hours), the number of events per year, and total annual precipitation (in inches). The SELDM database application includes these statistics, which are based on data from 2,610 National Oceanic Atmospheric Administration (NOAA) weather stations located in 15 rain zones covering the conterminous U.S., with at least 25 years of record during 1965-2006. In SELDM, precipitation statistics are available and can be selected by rain zone, by ecoregion, or by proximity to one or more of the NOAA weather stations. Oregon model users have an additional option of using storm-event precipitation statistics that are derived from the same database of the NOAA weather stations but are spatially interpolated using a Geographic Information System (GIS) Kriging algorithm (appendix B). These statistics may be entered into SELDM as user-defined statistics.

\section{Upstream Basin Discharge}

Components of upstream basin discharge include pre-storm streamflow and storm runoff (fig. 2). Pre-storm streamflow is defined by statistical moments that characterize the logarithms of daily-mean streamflows and the proportion of zero-flow days in the record of the upstream basin. SELDM also has data-entry fields for the arithmetic statistical moments of streamflow, the 7-day 10-year flow (7Q10), the 1-day 3-year biological flow (1B3), and the 4-day 3 -year biological flow (4B3), but these statistics are included to facilitate evaluation of hydrologic similarity among nearby streamgages rather than for generating pre-storm streamflows. The statistics are in units of cubic feet per second per square mile. In SELDM, pre-computed, pre-storm streamflow statistics are available and can be selected by ecoregion or by proximity to a site of interest. Pre-storm streamflow statistics also can be computed by the user from flow records measured at the study site or estimated using a number of standard interpretive techniques. These statistics also can be selected within SELDM from a database of statistics derived from 2,873 USGS streamgaging stations with at least 20 years of record during 1960-2004. Oregon SELDM users have an additional option of using pre-storm streamflow statistics computed from a larger pool of streamflow sites in Oregon and neighboring States, and spatially interpolated using a GIS Kriging algorithm (appendix B). These statistics may be entered into SELDM as user-defined statistics.

\section{Storm-event statistics}

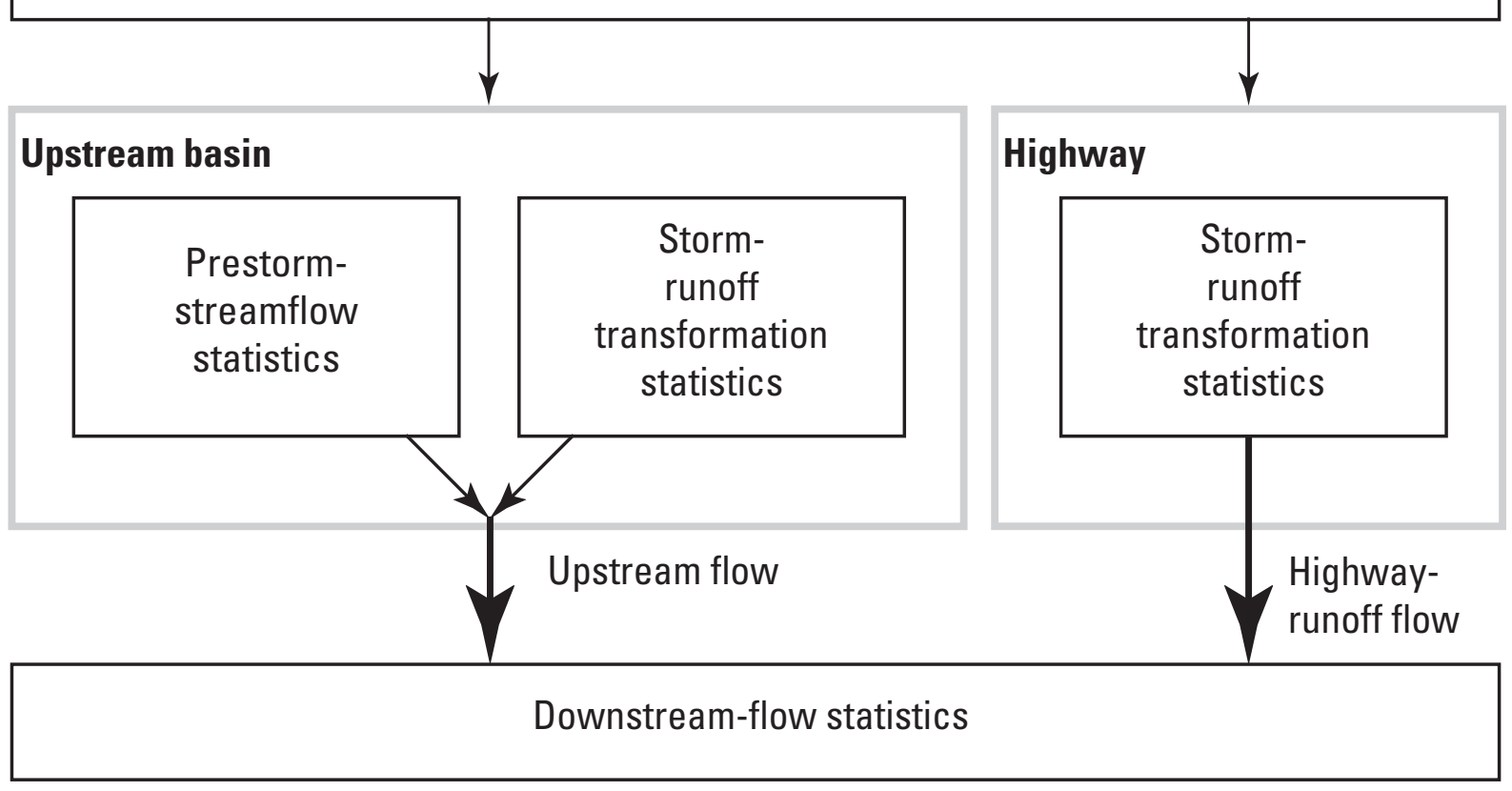

Figure 2. Upstream-flow and highway-runoff components that must be estimated for a mass-balance analysis of receiving-water quality (modified from Granato, 2013). 
The storm runoff volume for each event is defined by a volumetric runoff coefficient, which is computed from the user-entered, impervious fraction of the upstream basin drainage area. Factors controlling the timing of storm runoff volume for each event, while it is discharged to the downstream water body, include basin length, mean basin slope, development characteristics, and a triangular stormevent hydrograph. The ratio of the falling limb to the rising limb of the hydrograph is entered by the user to characterize the runoff properties that are unique to the upstream basin. The volume of upstream flow that is concurrent to the highway or BMP discharge is the proportion of total upstream flow that occurs during the period of discharge

\section{Highway Runoff}

Similar to the upstream basin, the volume of highway runoff for each storm event also is defined by a volumetric runoff coefficient, which is computed from the user-entered, impervious fraction of the highway catchment. Factors controlling the timing of storm runoff for each event, as it is discharged to the downstream water body, include the highway catchment area, length, mean slope, and development characteristics.

\section{Upstream Stormflow Quality}

Upstream-stormflow-quality constituents can be defined using either three methods: (1) random, (2) dependent, or (3) a transport curve. The random definition is based on statistical moments (mean, standard deviation, and coefficient of skew) computed from monitoring data for one or more constituents. A dependent water-quality definition is based on a relationship between the concentration of a constituent and the concentration of a related constituent. As an example, a suspended-sediment concentration can be defined as an independent constituent used to predict a dependent trace metal constituent. A water-quality transport curve is a relation between streamflow and the concentration of a constituent.

\section{Highway Runoff Quality}

Highway-runoff-quality constituents can be specified in SELDM as random or dependent (as previously defined). The user specifies the statistical moments of the constituent computed from data monitored at the site or using surrogate data monitored at a highway having similar highway traffic, pavement, and climatic conditions.

\section{Best Management Practices}

In SELDM, the user is allowed to specify the performance criteria for a highway-runoff BMP. BMP capabilities in SELDM include flow reduction, extending the highway storm hydrograph, water-quality treatment, or combinations of these. Flow reduction is primarily achieved through infiltration and absorption (for inter-storm evapotranspiration). This technique does not decrease the concentration of a constituent discharging to the receiving water body. However, it does decrease the total load. Extending the highway hydrograph can increase the amount of dilution in receiving waters. More of the highway runoff is distributed over a greater proportion of the upstream basin stormflow hydrograph. With the water-quality BMP option, the concentration of the discharging flow will be reduced by a specified amount.

\section{Lake Basin Module}

In addition to computing the mass balance of concentration and storm runoff discharging to a receiving stream, SELDM also can compute the concentration and storm runoff discharging to a lake basin or the combination of a lake basin and a receiving stream. SELDM uses an annual mass-balance model commonly known as the Vollenweider lake model to simulate almost any water-quality constituent (Granato, 2013). However, the lake basin module was not used in this study.

\section{Oregon Highway Study Sites}

Six highway sites within Oregon were selected for the study to demonstrate SELDM capabilities (table 2). Although most of the sites are located in the Portland and Albany area, one site is close to the California state line on the Siskiyou Pass near Ashland (fig. 3). All six sites were selected by ODOT based on data availability and their relevance to concurrent ODOT monitoring activities and interests. For each study site, the highway crosses a stream at a single location as opposed to a highway crossing a stream at several locations, which would make the delineation of the upstream basin and the highway catchment more challenging. All upstream basin drainage areas were relatively small $\left(<10 \mathrm{mi}^{2}\right)$. Larger drainage areas in western Oregon are less ideal for SELDM applications because the highway constituents become diluted or "swamped out" by the greater magnitude of upstream basin streamflow. 


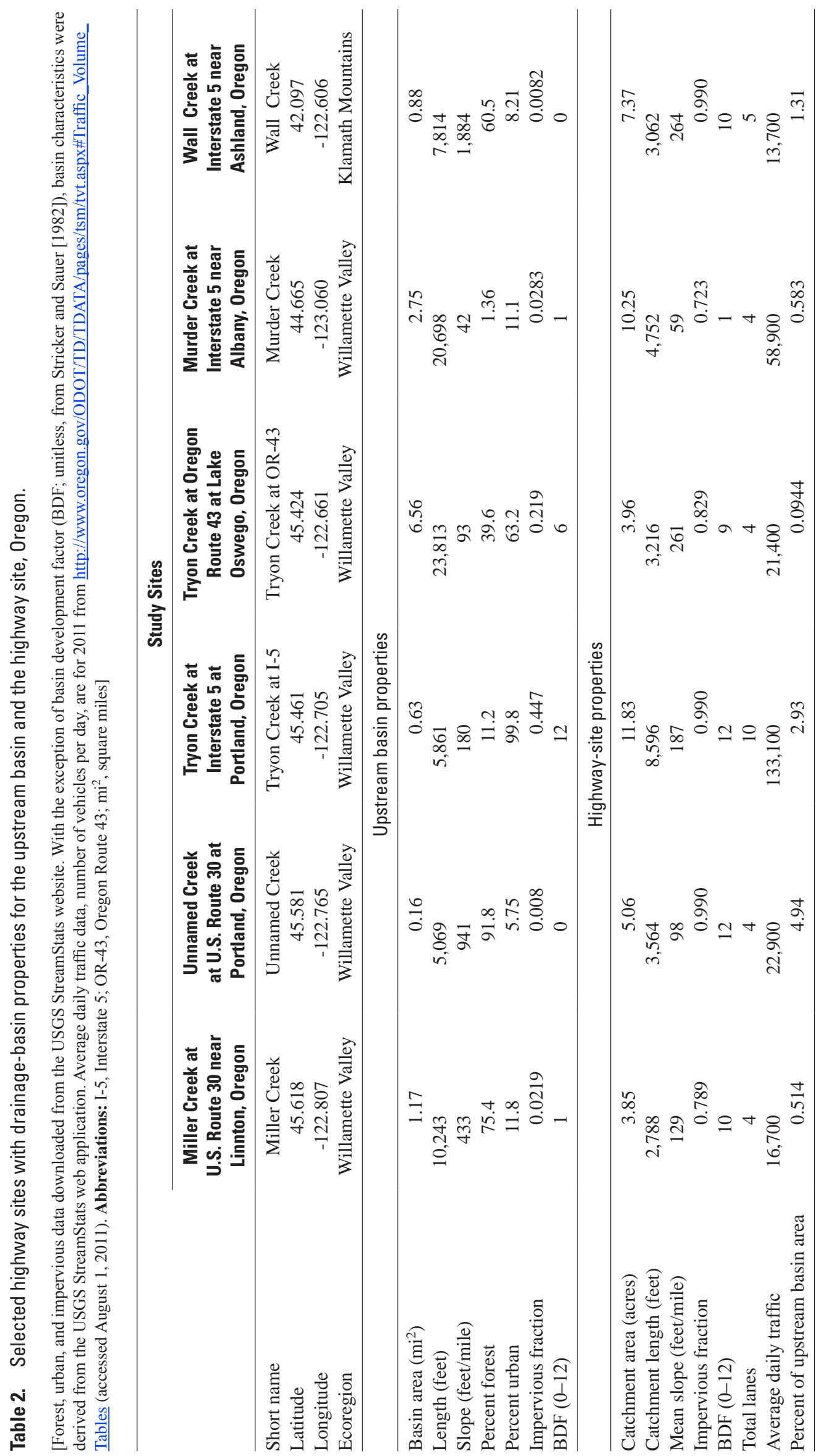




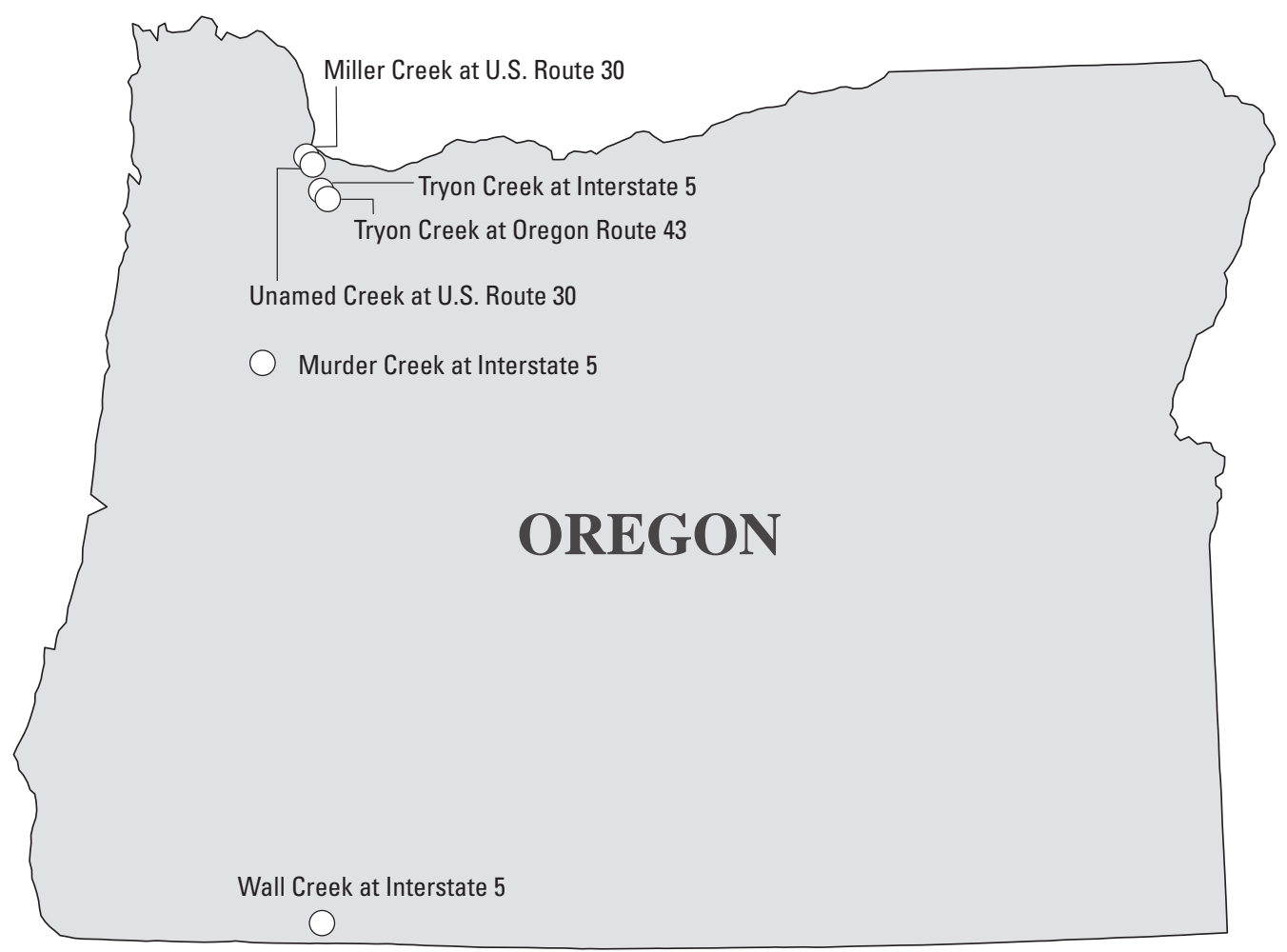

Figure 3. Locations of Oregon study sites used to evaluate potential effects of highway runoff on stormwater flows, concentrations, and loads in receiving waters with Stochastic Empirical Loading and Dilution Model.

\section{Miller Creek at U.S. Route 30, near Linnton, Oregon}

The Miller Creek site is located on U.S. Route 30, north of Portland. Miller Creek drains into Multnomah Channel and the Willamette River near the southern end of Sauvie Island (fig. 4). The Miller Creek site is of interest to ODOT because of its proximity to the U.S. Environmental Protection Agency (EPA) Willamette River Superfund cleanup effort. Characteristics of the Miller Creek highway catchment, such as drainage area, drainage length, slope, impervious fraction, basin development factor (BDF), number of lanes, and average daily traffic are shown in table 2. The characteristics were determined from measurements and photographs from a field visit, the USGS StreamStats web application (Ries and others, 2008), and Google Earth ${ }^{\mathrm{TM}}$. The highway catchment area was defined as the cumulative sum of areas of pavement, shoulders, median, and any side roads that drain to the stream at the highway crossing. The drainage length was defined as the total distance between the two highway divides located northwest and southeast of the stream. The basin development factor is a numerical classification system of human development and alteration in a drainage basin ranging from 0 to 12 , where a value of 0 is a basin that is completely undeveloped and 12 is a basin that is fully developed (Stricker and Sauer, 1982). Additional information about how BDFs are determined and their relevance in SELDM applications is provided in Granato (2012).

Characteristics of the Miller Creek drainage basin are shown in table 2. The basin is mostly forested, although it includes a few roads with residences. With the exception of the BDF value, all characteristics were determined using StreamStats. Specific details regarding how drainage length and mean basin slope need to be computed for SELDM applications are provided in Granato (2012). Additional required input data for SELDM include statistics for stormevent precipitation, pre-storm streamflow, and the triangular hydrograph recession ratio. Details describing how these statistics were computed for the Oregon study sites are provided in appendixes B and $\underline{\mathrm{C}}$. Storm-event precipitation, pre-storm streamflow, and triangular hydrograph recession ratio statistics specific to the Miller Creek site are shown in tables 3 , $\underline{4}$, and $\underline{5}$. 


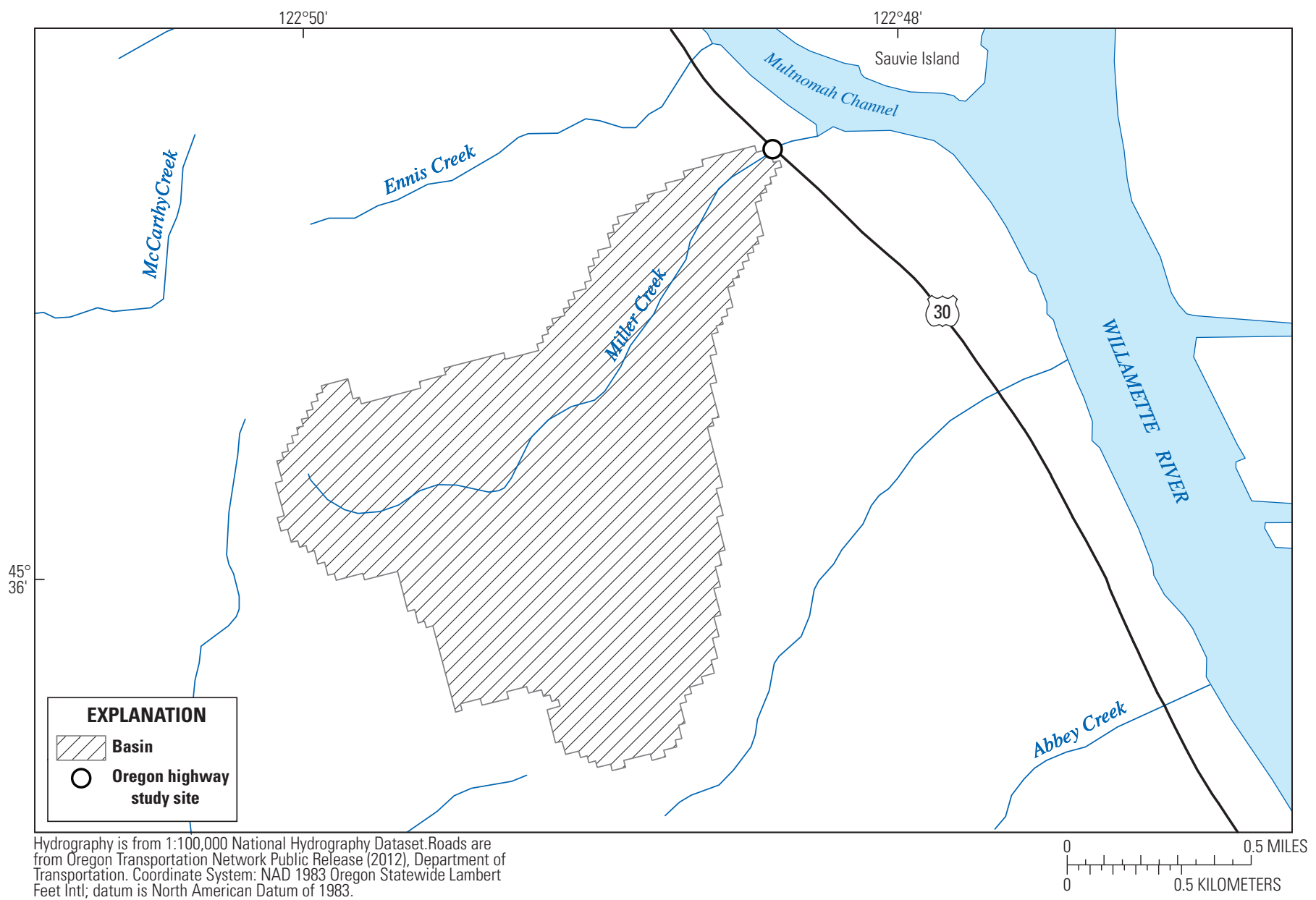

Figure 4. Miller Creek at U.S. Route 30 study site (Lower Columbia River Highway), near Linnton, Oregon.

Table 3. Storm-event precipitation statistics of selected study sites, Oregon.

[COV is the coefficient of variation which is computed by dividing the standard deviation by the average. Statistics downloaded from data layers in table B1. Abbreviations: I-5, Interstate 5; OR-43, Oregon Route 43]

\begin{tabular}{|c|c|c|c|c|c|c|c|c|c|c|}
\hline \multirow[b]{2}{*}{ Study site } & \multicolumn{2}{|c|}{ Volume } & \multicolumn{2}{|c|}{ Duration } & \multicolumn{2}{|c|}{ Delta } & \multicolumn{2}{|c|}{ Number of storms } & \multicolumn{2}{|c|}{ Annual precipitation } \\
\hline & $\begin{array}{l}\text { Average } \\
\text { (inches) }\end{array}$ & $\operatorname{cov}$ & $\begin{array}{c}\text { Average } \\
\text { (hours) }\end{array}$ & $\operatorname{cov}$ & $\begin{array}{c}\text { Average } \\
\text { (hours) }\end{array}$ & $\operatorname{cov}$ & Average & $\operatorname{cov}$ & $\begin{array}{l}\text { Average } \\
\text { (inches) }\end{array}$ & $\mathrm{COV}$ \\
\hline Miller Creek & 0.58 & 1.05 & 11.4 & 0.92 & 131.1 & 1.78 & 65 & 0.21 & 37.4 & 0.26 \\
\hline Unnamed Creek & 0.59 & 1.05 & 11.5 & 0.92 & 130.5 & 1.76 & 65 & 0.19 & 38.4 & 0.25 \\
\hline Tryon Creek at I-5 & 0.59 & 1.05 & 11.3 & 0.91 & 127.2 & 1.76 & 67 & 0.19 & 40.3 & 0.25 \\
\hline Tryon Creek at OR-43 & 0.58 & 1.05 & 11.2 & 0.90 & 125.1 & 1.75 & 68 & 0.19 & 41.0 & 0.24 \\
\hline Murder Creek & 0.63 & 1.08 & 13.3 & 0.93 & 131.9 & 1.80 & 66 & 0.21 & 42.3 & 0.27 \\
\hline Wall Creek & 0.58 & 1.07 & 10.6 & 0.91 & 249.8 & 1.72 & 36 & 0.28 & 21.8 & 0.35 \\
\hline
\end{tabular}


Table 4. Pre-storm streamflow statistics of selected study sites, Oregon.

[Logarithmic statistics are calculated on non-zero flows only. Abbreviations: $\left(\mathrm{ft}^{3} / \mathrm{s}\right) / \mathrm{mi}^{2}$, cubic feet per second per square mile; 7Q10, 7-day 10-year flow; 1B3, 1-day 3-year biological flow; 4B3, 4-day 3-year biological flow; I-5, Interstate 5; OR-43, Oregon Route 43]

\begin{tabular}{|c|c|c|c|c|c|c|c|c|}
\hline \multirow{3}{*}{ Study site } & \multirow{3}{*}{$\begin{array}{c}\text { Proportion } \\
\text { of zero } \\
\text { flows }\end{array}$} & \multicolumn{7}{|c|}{ Arithmetic } \\
\hline & & \multirow{2}{*}{$\begin{array}{c}\text { Mean } \\
{\left[\left(\mathrm{ft}^{3} / \mathbf{s}\right) / \mathrm{mi}^{2}\right]}\end{array}$} & \multirow{2}{*}{$\begin{array}{c}\text { Median } \\
{\left[\left(\mathrm{ft}^{3} / \mathbf{s}\right) / \mathrm{mi}^{2}\right]}\end{array}$} & \multirow{2}{*}{$\begin{array}{l}\text { Standard } \\
\text { deviation } \\
\text { (unitless) }\end{array}$} & \multirow{2}{*}{$\begin{array}{c}\text { Skew } \\
\text { (unitless) }\end{array}$} & \multicolumn{3}{|c|}{$\begin{array}{c}\text { Low-flow statistics } \\
{\left[\left(\mathrm{ft}^{3} / \mathrm{s}\right) / \mathrm{mi}^{2}\right]}\end{array}$} \\
\hline & & & & & & 7010 & $1 B 3$ & 4B3 \\
\hline Miller Creek ${ }^{1}$ & 0.0061 & 2.921 & 1.310 & 4.547 & 4.266 & 0.094 & 0.078 & 0.092 \\
\hline Unnamed Creek $^{1}$ & 0.0061 & 2.921 & 1.310 & 4.547 & 4.266 & 0.094 & 0.078 & 0.092 \\
\hline Tryon Creek at I-5² & 0 & 1.492 & 0.637 & 2.810 & 6.974 & 0.043 & 0.030 & 0.038 \\
\hline Tryon Creek at OR- $43^{2}$ & 0 & 1.492 & 0.637 & 2.810 & 6.974 & 0.043 & 0.030 & 0.038 \\
\hline Murder Creek ${ }^{3}$ & 0 & 2.795 & 0.943 & 4.877 & 4.247 & 0.034 & 0.025 & 0.032 \\
\hline Wall Creek ${ }^{4}$ & 0.091 & 0.639 & 0.171 & 1.325 & 5.320 & 0.000 & 0.000 & 0.000 \\
\hline
\end{tabular}

\begin{tabular}{lcccc}
\hline & \multicolumn{4}{c}{ Logarithm Base 10 (retransformed) } \\
\cline { 2 - 4 } \multicolumn{1}{c}{ Study site } & $\begin{array}{c}\text { Mean } \\
{\left[\left(\mathbf{f t}^{3} / \mathbf{s}\right) / \mathbf{m i}^{2}\right]}\end{array}$ & $\begin{array}{c}\text { Median } \\
{\left[\left(\mathbf{f t}^{3} / \mathbf{s}\right) / \mathbf{m i}^{2}\right]}\end{array}$ & $\begin{array}{c}\text { Standard } \\
\text { deviation } \\
\text { (unitless) }\end{array}$ & $\begin{array}{c}\text { Skew } \\
\text { (unitless) }\end{array}$ \\
\hline Miller Creek $^{1}$ & 1.195 & 1.320 & 4.921 & -0.048 \\
Unnamed Creek $^{1}$ & 1.195 & 1.320 & 4.921 & -0.048 \\
Tryon Creek at I-5 $^{2}$ & 0.637 & 0.637 & 3.626 & 0.206 \\
Tryon Creek at OR-43 $^{2}$ & 0.637 & 0.637 & 3.626 & 0.206 \\
Murder Creek $^{3}$ & 0.853 & 0.943 & 5.290 & 0.030 \\
Wall Creek $^{4}$ & 0.082 & 0.296 & 15.707 & -0.240 \\
\hline
\end{tabular}

${ }^{1}$ Statistics based on average of Willamette Valley ecoregion streamflow gages computed by Stochastic Empirical Loading and Dilution Model (SELDM).

${ }^{2}$ Statistics estimated using MOVE.1 regression of flows measured at USGS gages: 14211315 and 14206900.

${ }^{3}$ Statistics based on USGS Mary's River streamflow gage record (14171000), near Philomath, Oregon computed by SELDM.

${ }^{4}$ Statistics based on USGS Emigrant Creek streamflow gage record (14350000) near Ashland, Oregon computed by SELDM.

Table 5. Surrogate streamflow sites used to select triangular hydrograph recession ratios for the Oregon study site upstream basins.

[The triangular hydrograph recession ratio is the ratio of falling to rising hydrograph limbs. Abbreviations: CA, California; OR, Oregon; MA, Massachusetts; $\mathrm{mi}^{2}$, square miles; ft, foot; ft/mi, foot per mile; MPV, most probable value; I-5, Interstate 5; OR-43, Oregon Route 43]

\begin{tabular}{|c|c|c|c|c|c|c|c|c|c|c|}
\hline \multirow{3}{*}{ Study site } & \multicolumn{10}{|c|}{ Surrogate streamflow site } \\
\hline & \multirow{2}{*}{$\begin{array}{c}\text { USGS } \\
\text { station No. }\end{array}$} & \multirow{2}{*}{ Station name } & \multirow{2}{*}{$\begin{array}{c}\text { Drainage } \\
\text { area } \\
\left(\mathrm{mi}^{2}\right)\end{array}$} & \multirow{2}{*}{$\begin{array}{c}\text { Basin } \\
\text { length } \\
\text { (ft) }\end{array}$} & \multirow{2}{*}{$\begin{array}{c}\text { Mean } \\
\text { basin } \\
\text { slope } \\
\text { (ft/mi) }\end{array}$} & \multirow{2}{*}{$\begin{array}{l}\text { Impervious } \\
\text { fraction }\end{array}$} & \multirow{2}{*}{$\begin{array}{l}\text { Dominant } \\
\text { land use }\end{array}$} & \multicolumn{3}{|c|}{$\begin{array}{l}\text { Triangular hydrograph } \\
\text { recession ratio }\end{array}$} \\
\hline & & & & & & & & $\begin{array}{c}\text { Mini- } \\
\text { mum }\end{array}$ & MPV & $\begin{array}{c}\text { Maxi- } \\
\text { mum }\end{array}$ \\
\hline Miller Creek & 01174600 & Cadwell Creek near Pelham, MA & 0.60 & 10,085 & 129 & 0.004 & Forest & 1.21 & 2.02 & 4.02 \\
\hline Unnamed Creek & 01174600 & Cadwell Creek near Pelham, MA & 0.60 & 10,085 & 129 & 0.004 & Forest & 1.21 & 2.02 & 4.02 \\
\hline $\begin{array}{l}\text { Tryon Creek } \\
\text { at I-5 }\end{array}$ & 11181008 & $\begin{array}{l}\text { Castro Valley Creek at } \\
\text { Hayward, CA }\end{array}$ & 5.51 & 26,928 & 136 & 0.40 & Urban & 1.00 & 3.52 & 11.31 \\
\hline $\begin{array}{l}\text { Tryon Creek at } \\
\text { OR-43 }\end{array}$ & 14211315 & $\begin{array}{l}\text { Tryon Creek near Lake } \\
\text { Oswego, OR }\end{array}$ & 6.21 & 21,120 & 105 & 0.23 & Mixed & 1.29 & 1.29 & 5.84 \\
\hline Murder Creek & 01175670 & $\begin{array}{l}\text { Sevenmile River near } \\
\text { Spencer, MA }\end{array}$ & 8.69 & 41,976 & 39.4 & 0.01 & Forest & 1.59 & 1.67 & 8.60 \\
\hline Wall Creek & 14353000 & $\begin{array}{l}\text { W.F. Ashland Creek near } \\
\text { Ashland, OR }\end{array}$ & 10.6 & 33,528 & 607 & 0.005 & Forest & 1.41 & 1.41 & 6.67 \\
\hline
\end{tabular}




\section{Unnamed Creek at U.S. Route 30, at Portland, Oregon}

South of the Miller Creek highway site, an unnamed creek near the St. Johns Bridge and also located on U.S. Route 30 was selected as a study site (ig. 5). Like Miller Creek, this creek also drains directly into the Willamette River and also is of interest to ODOT because of its proximity to the EPA Willamette River Superfund cleanup effort. Characteristics of the highway catchment and upstream basin for this site are shown in table 2. Determining the highway catchment characteristics was more complicated than for the Miller
Creek site. It was necessary to account for runoff from a steep ramp that extends from the U.S. Route 30 to the St. Johns Bridge. Catchment characteristics were determined from measurements and photographs in a field visit, StreamStats, and Google Earth ${ }^{\mathrm{TM}}$. ODOT also provided highway blueprints of the highway section, which detailed the dimensions and location of the drainage system. Characteristics of the upstream basin, which is almost entirely forested, were measured using StreamStats. Storm-event precipitation, pre-storm streamflow, and triangular hydrograph recession ratio statistics specific to the Unnamed Creek site are shown in tables 3 , $\underline{4}$, and $\underline{5}$.

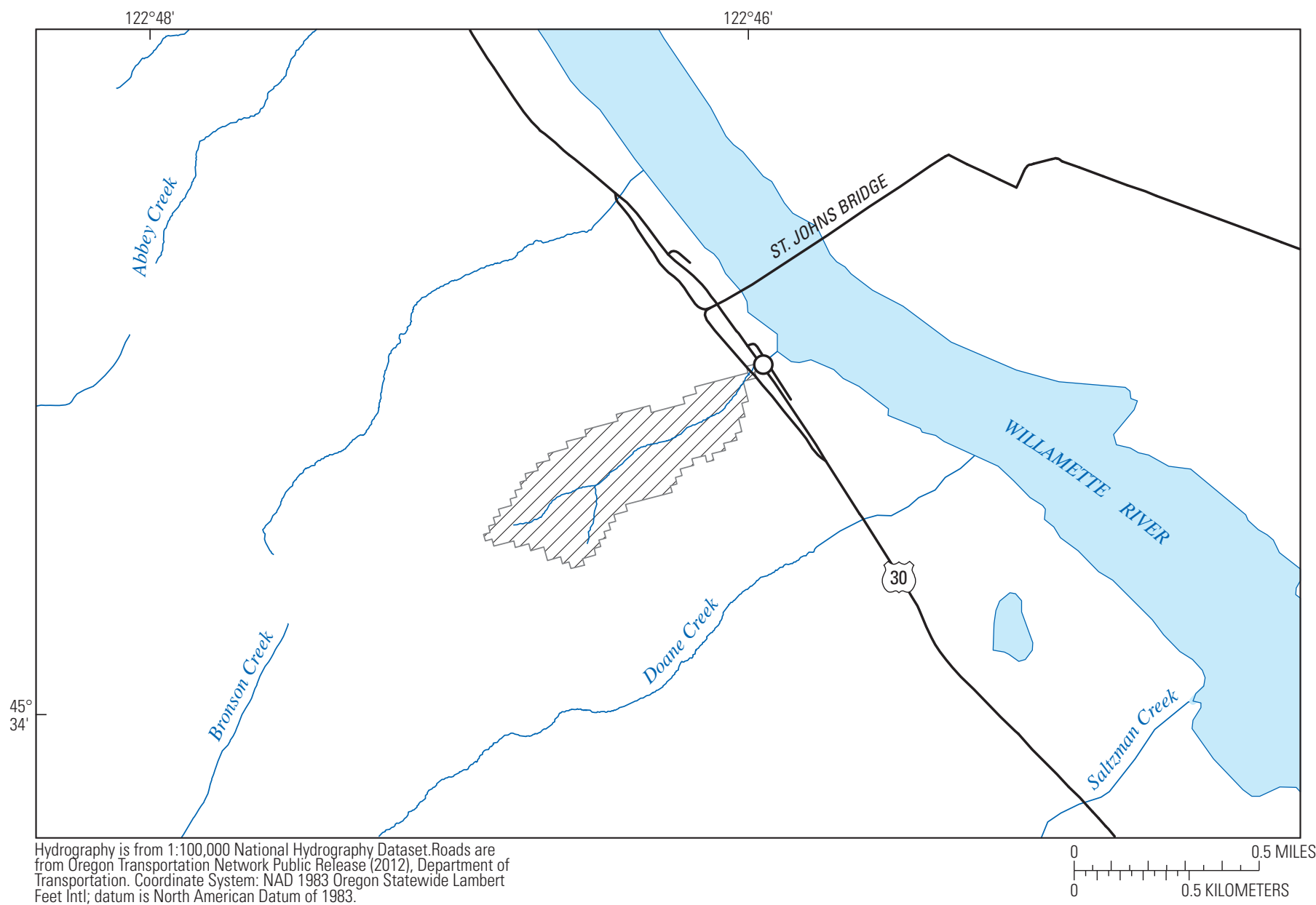

Figure 5. Unnamed Creek at U.S. Route 30 (Lower Columbia River Highway), near St. John's Bridge, at Portland, Oregon. 


\section{Tryon Creek at Interstate 5, at Portland, Oregon}

The Tryon Creek at Interstate 5 study site is located in southwestern Portland (fig. 6). Highway catchment characteristics, determined from measurements and photographs taken during a field visit, StreamStats, and Google Earth ${ }^{\mathrm{TM}}$, are shown in table 2. In addition to Interstate 5, the highway catchment area for this site also includes the Barber Boulevard catchment area, which is closely parallel to Interstate 5 . Both highways cross Tryon Creek at nearly the same location. This highway site and the downstream Tryon Creek site at Oregon Route 43 at Lake Oswego, Oregon, are of interest to ODOT because the combined average daily traffic load of Interstate 5 and Barber
Boulevard (133,100 vehicles per day) is one of the highest for any highway section within Oregon. The $0.63 \mathrm{mi}^{2}$ drainage area upstream of this study site also is the most urbanized and has the highest impervious fraction of all six study sites (table 2).

Upstream of the Tryon Creek at Interstate 5 study site, the USGS operated a field sampling site on Tryon Creek at Dolph Court (14211301) from 1975 to 1977. Although one sample, collected on September 3, 1975, included some trace metals, most of the other 97 samples included turbidity and specific conductance. Storm-event precipitation, pre-storm streamflow, and triangular hydrograph recession ratio statistics specific to the Tryon Creek site at Interstate 5 are shown in tables $3, \underline{4}$, and $\underline{5}$.

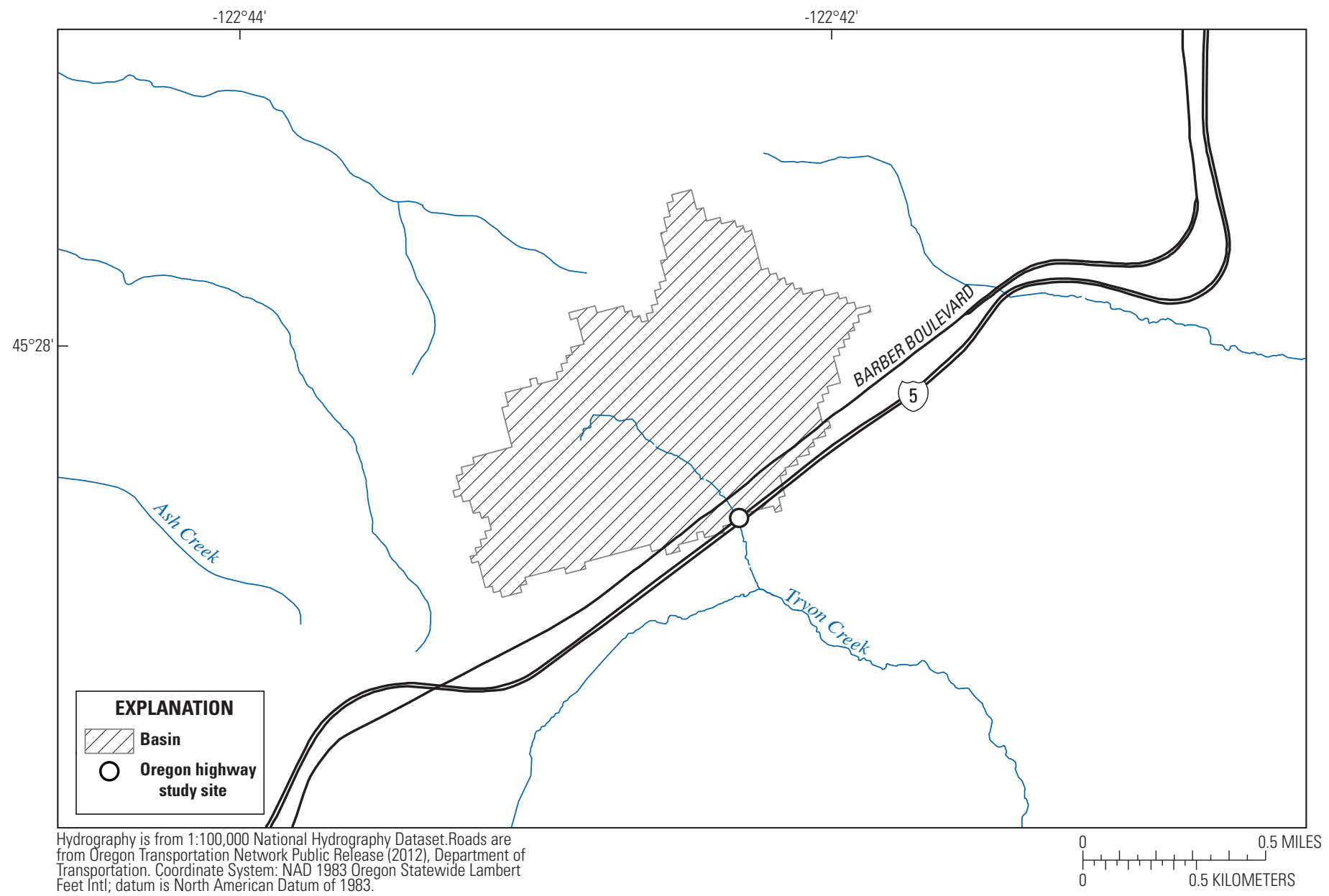

Figure 6. Tryon Creek at Interstate 5 (Pacific Highway), at Portland, Oregon. 


\section{Tryon Creek at Oregon Route 43, at Lake Oswego, Oregon}

The Tryon Creek at Oregon Route 43 study site is located south of Portland and downstream of the Tryon Creek at Interstate 5 study site (fig. 7). Tryon State Park is located almost entirely between both highway study sites. Because the park is heavily forested, the Tyron Creek basin upstream of Oregon Route 43 is less urbanized than the Interstate 5 study site (table 2). Highway catchment characteristics, determined from measurements and photographs taken during a field visit, StreamStats, and Google Earth ${ }^{\mathrm{TM}}$ are shown in table 2. Because Oregon Route 43 crosses Tryon Creek at an intersection with Terwilliger Boulevard, a portion of that street was included in the total highway catchment drainage area.

Since 2001, the USGS has operated a continuous flow streamgage on Tryon Creek near Lake Oswego, Oregon (14211315) located between the two highway study sites. Flow records from this site and the USGS streamgage on Fanno Creek at 56th Avenue at Portland, Oregon (14206900) were used to estimate pre-storm streamflow statistics (average, standard deviation, skew, and median of daily-mean flow, 7Q10, 1B3, and 4B3), which are required input to SELDM. Storm-event precipitation, pre-storm streamflow, and triangular hydrograph recession ratio statistics specific to the Tyron Creek at Oregon Route 43 site are shown in tables 3 , $\underline{4}$, and $\underline{5}$.

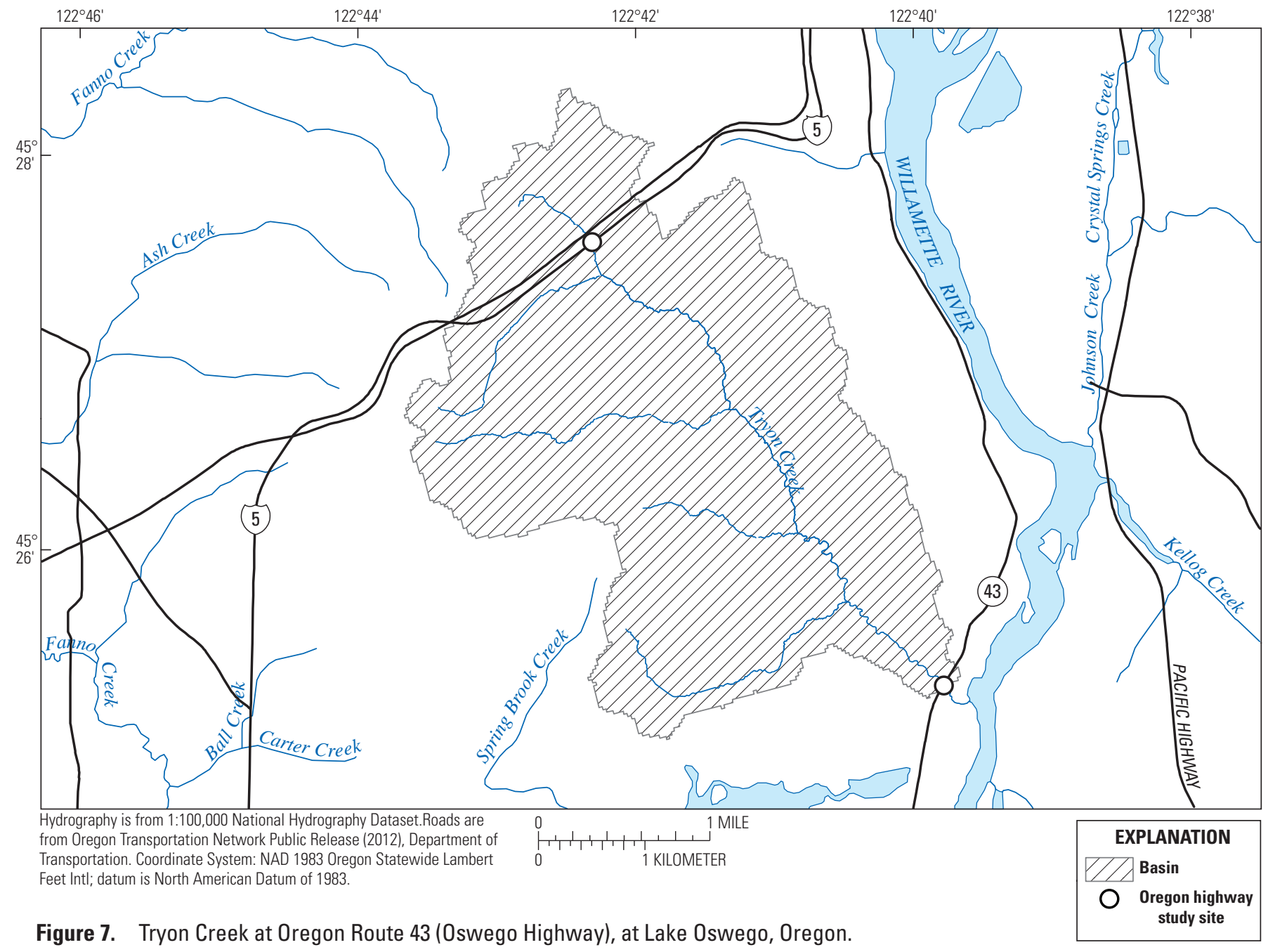




\section{Murder Creek at Interstate 5, near Albany, Oregon}

The Murder Creek highway study site is located on Interstate 5 north of Albany, Oregon (fig. 8). The highway catchment area includes portions of Interstate 5 that are north and south of the creek in addition to portions of adjacent exit ramps (table 2). Murder Creek flows from east to west before it drains into the Willamette River. The upstream basin is extremely low gradient and almost entirely agricultural as both the percent forest cover and urbanization is low (table 2). At the time of this publication (2014), this highway study site was of interest to ODOT because it is located along a section of Interstate 5 (northbound) planned for widening. Assessing the effects of highway and exit ramp modifications on the water quality of the receiving stream is a relevant application of SELDM. Storm-event precipitation, pre-storm streamflow, and triangular hydrograph recession ratio statistics specific to the Murder Creek site are shown in tables $3, \underline{4}$, and $\underline{5}$.

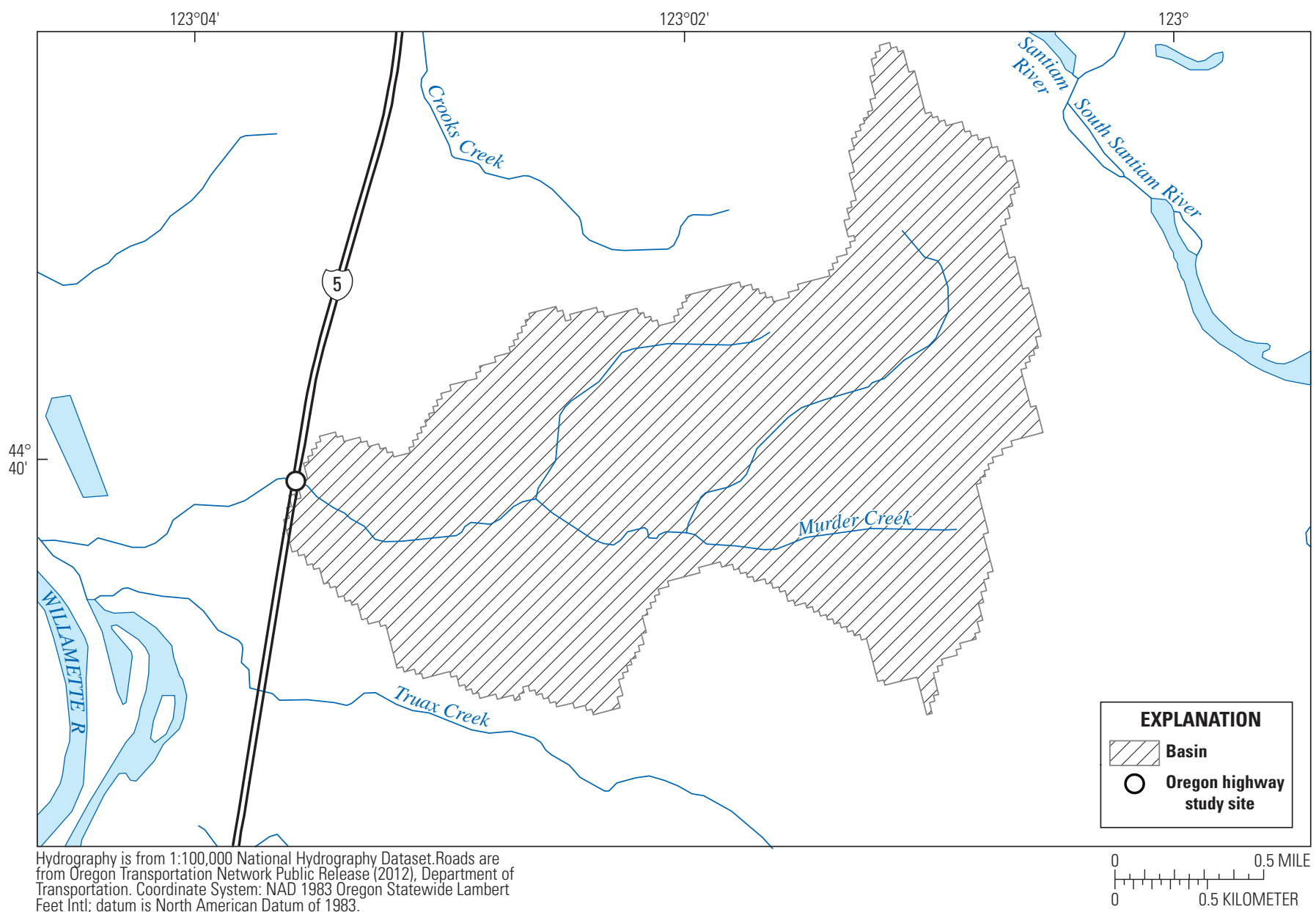

Figure 8. Murder Creek at Interstate 5 (Pacific Highway), near Albany, Oregon. 


\section{Wall Creek at Interstate 5, near Ashland, Oregon}

The Wall Creek highway study site is located on Interstate 5 in the Siskiyou Pass close to the California state line (ig. 9). The study site highway catchment area, which is almost entirely impervious, includes five lanes in addition to paved shoulders and a paved median strip (table 2). The Wall Creek drainage basin upstream of the highway is high gradient and mostly forested (table 2).
This study site was selected because ODOT began a program in late 2012 of winter weather road salt applications on a limited number of mountainous highways including the Siskiyou Pass. SELDM can be used to compare chloride loads draining from highway catchments with background chloride levels in an upstream basin. Storm-event precipitation, pre-storm streamflow, and triangular hydrograph recession ratio statistics specific to the Wall Creek site are shown in $\underline{\text { tables } 3}$, $\underline{4}$, and $\underline{5}$.

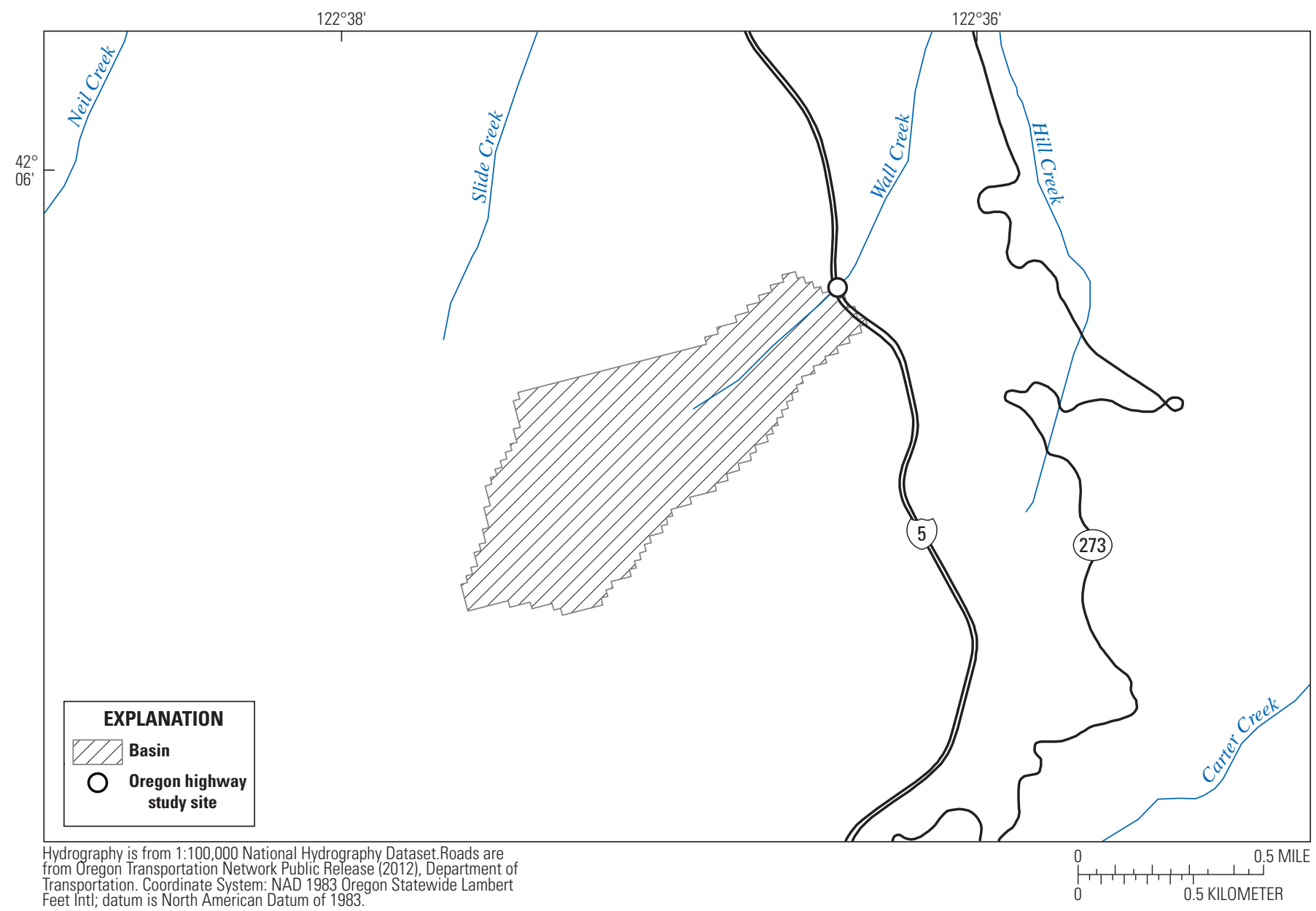

Figure 9. Wall Creek at Interstate 5 (Pacific Highway), near Ashland, Oregon. 


\section{Water-Quality Datasets}

One or more constituents of highway- and upstreamrunoff quality can be defined in SELDM. For this study, all constituents were specified as random and/or as a transport curve (constituents can also be specified as dependent; however, that option was not used). As described in Granato (2013), a random water-quality definition is based on sample statistics from monitoring studies. Users can specify a random water-quality definition by entering the mean, standard deviation, and coefficient of skew of each constituent (or the logarithm of each constituent) as input to SELDM. A transport curve is a relation between streamflow and the concentration of a constituent. The slopes and intercepts of one-segment or multi-segment regression models can be entered into SELDM.

\section{Highway Catchments}

At the time of this study, highway-runoff quality monitoring data in Oregon were insufficient to compute statistical moments or dependent relations required by SELDM. However, with the Highway-Runoff Database (HRDB) (Granato and Cazenas, 2009; Smith and Granato, 2010), it was possible to select highway-runoff-quality datasets from surrogate sites monitored in other States for each of the six study sites and for nine constituents of interest (chloride, cadmium, chromium, copper, iron, lead, nickel, phosphorus, and zinc) (table 6). These other States included California, Massachusetts, Pennsylvania, Florida, and Wisconsin. Although highway-runoff quality has been monitored in western Washington, which has climatic conditions similar to western Oregon, those datasets could not be used because the Washington State Department of Transportation had issued a data advisory indicating that their data did not meet data-quality standards at the time of this study (Richard A. Gersib, Stormwater and Wastersheds Program Manager, Washington State Department of Transportation to the International BMP Database Team, written commun., January 22, 2009).

The selection of surrogate sites was based on similarities between the surrogate and study sites. Characteristics used to evaluate site similarity, in order of importance, included average daily traffic (ADT) load, annual precipitation, surrounding setting (urban or non-urban), number of lanes, highway catchment area size, and impervious fraction of the highway catchment. It is recognized that the frequency and magnitude of highway constituents is dependent on many factors. No single characteristic could be used in the surrogate site selection. For example, the ADT could not be used as a single selection factor because an urban highway typically has more stop and go traffic, than a non-urban highway, potentially causing the urban highway to have a higher runoff contaminant load than a non-urban highway having the same ADT. Additionally, Smith and Granato (2010) determined that concentrations of suspended sediment and sediment-associated constituents increased substantially with the percentage of impervious area within a 1-mile radius of highway-runoff monitoring sites. This indicates that increases in highway runoff concentrations in urban areas may be largely due to contamination from the surrounding area. Therefore, an attempt was made for this study to match all urban (and non-urban) surrogate site datasets with urban (and nonurban) study sites, respectively. Additionally, climate was an important selection factor. Because the Portland area receives more than 40 inches of precipitation per year on average, surrogate highway-runoff-quality sites in arid regions such as southern California were not selected.

Statistics computed from the selected surrogate highwayrunoff-quality datasets for the constituents of interest are shown in table 7. Because statistics for all constituents were skewed, the more normalized common, base 10, logarithm $(\log 10)$ statistics were used as input for the random highwayrunoff-quality definition in SELDM. Some of the surrogate highway-runoff-quality datasets, such as cadmium, chromium, and copper, had concentrations below the detection level. For these datasets, the HRDB computed the statistical moments using the Robust Regression on Order Statistics (ROS) method as described in appendix 1 of Granato and Cazenas (2009). The ROS method is suitable for use when the amount of censoring is less than or equal to 80 percent of the dataset (Helsel, 2005). For the ROS applications used in the datasets for this study, the Cunnane (1978) plotting position option in HRDB was selected.

\section{Upstream Basins}

For the study site upstream basins, it also was necessary to select surrogate water-quality datasets because none of the upstream basins had been monitored. For the five study sites in the Portland and Albany area, which were all located in the Willamette Valley ecoregion, it was necessary to find different sets for urban (Tryon Creek at Interstate 5) and non-urban (Miller Creek at U.S. Route 30, Unnamed Creek at U.S. Route 30, Tyron Creek at Oregon Route 43, and Murder Creek at Interstate 5) study sites (table 8). Separate surrogate water-quality datasets were selected for the Wall Creek at Interstate 5 study site because it is located in the Klamath Mountains ecoregion. The water-quality datasets were collected at USGS streamflow stations. The main criteria used to select the surrogate sites included, in order of importance, the availability of constituent samples, basin drainage area, urbanization, forest cover, and imperviousness. 


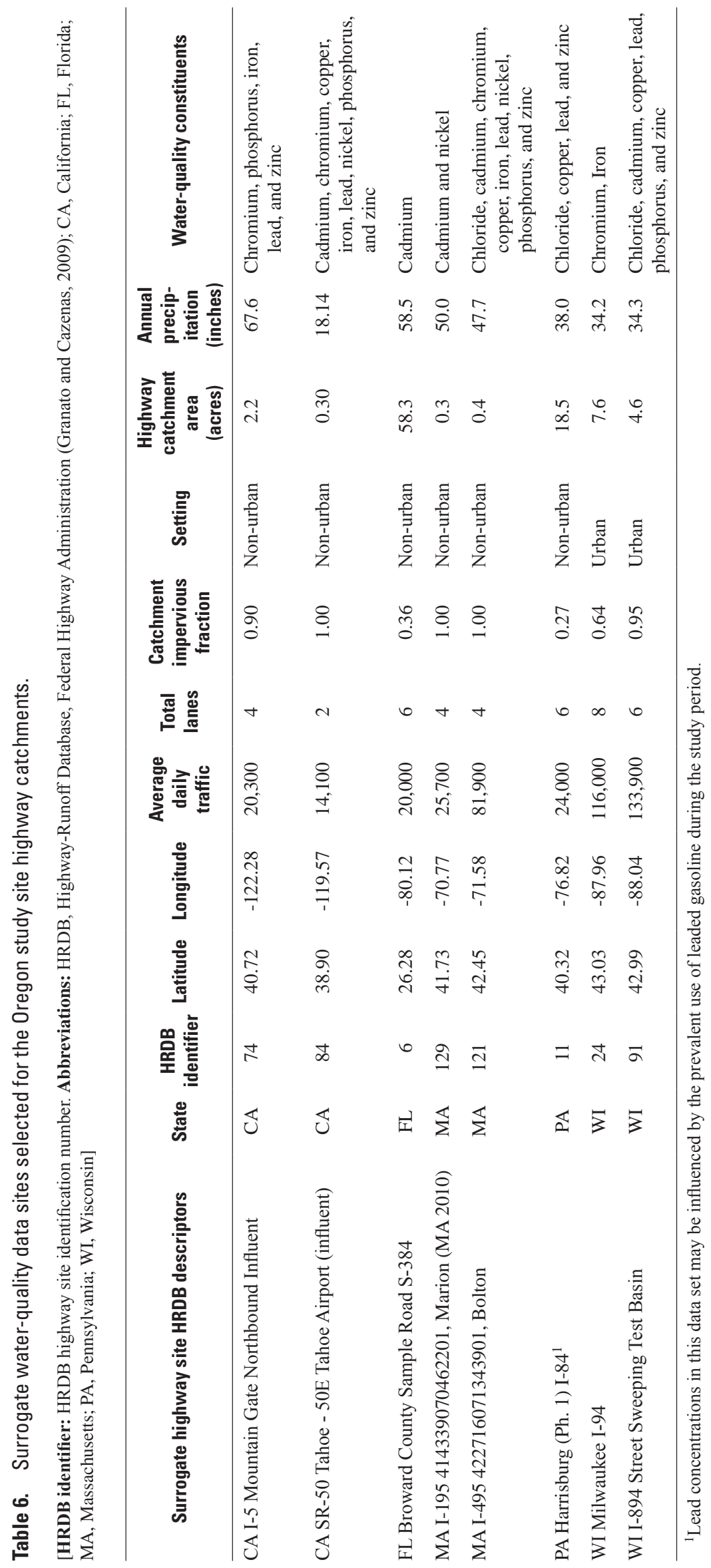




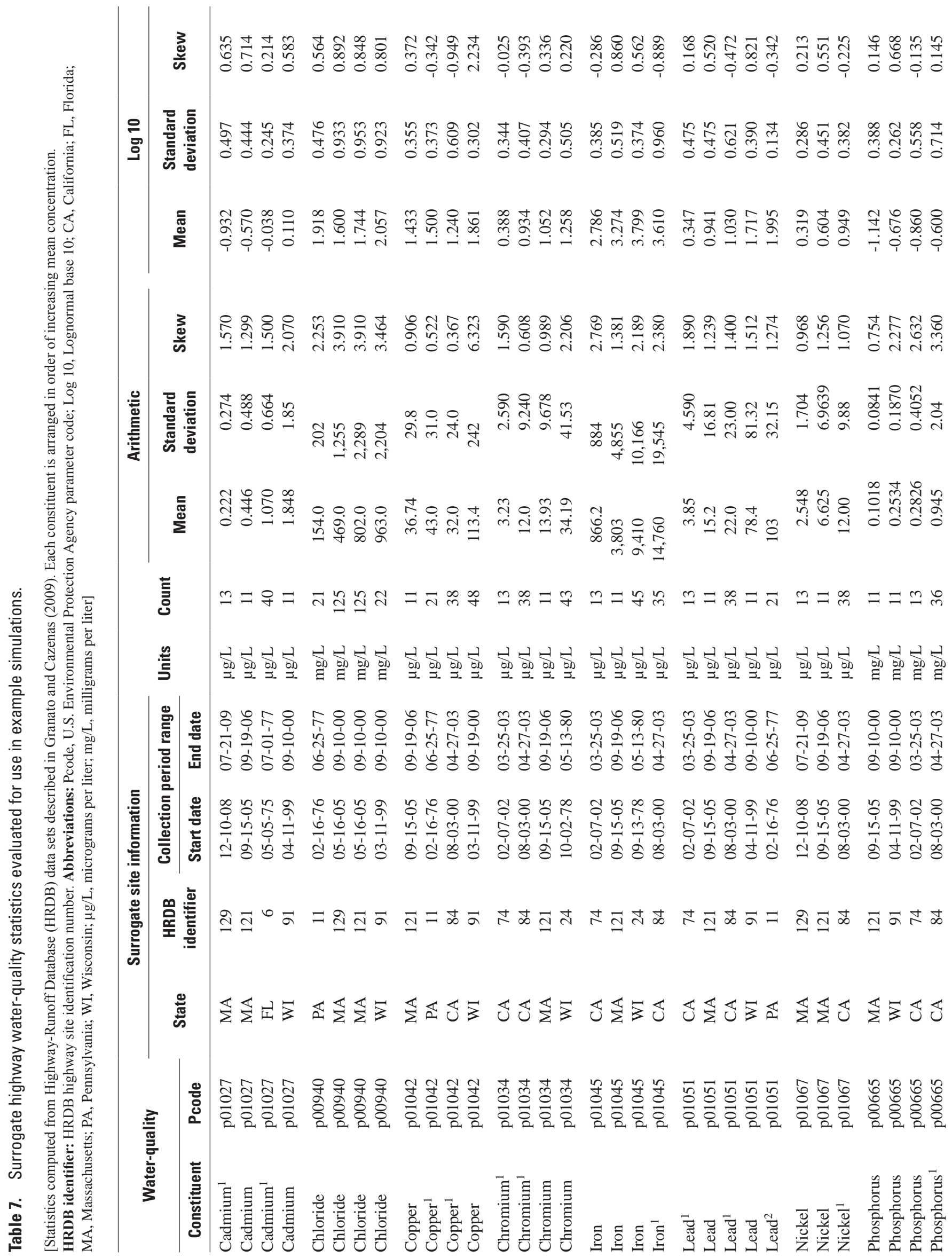




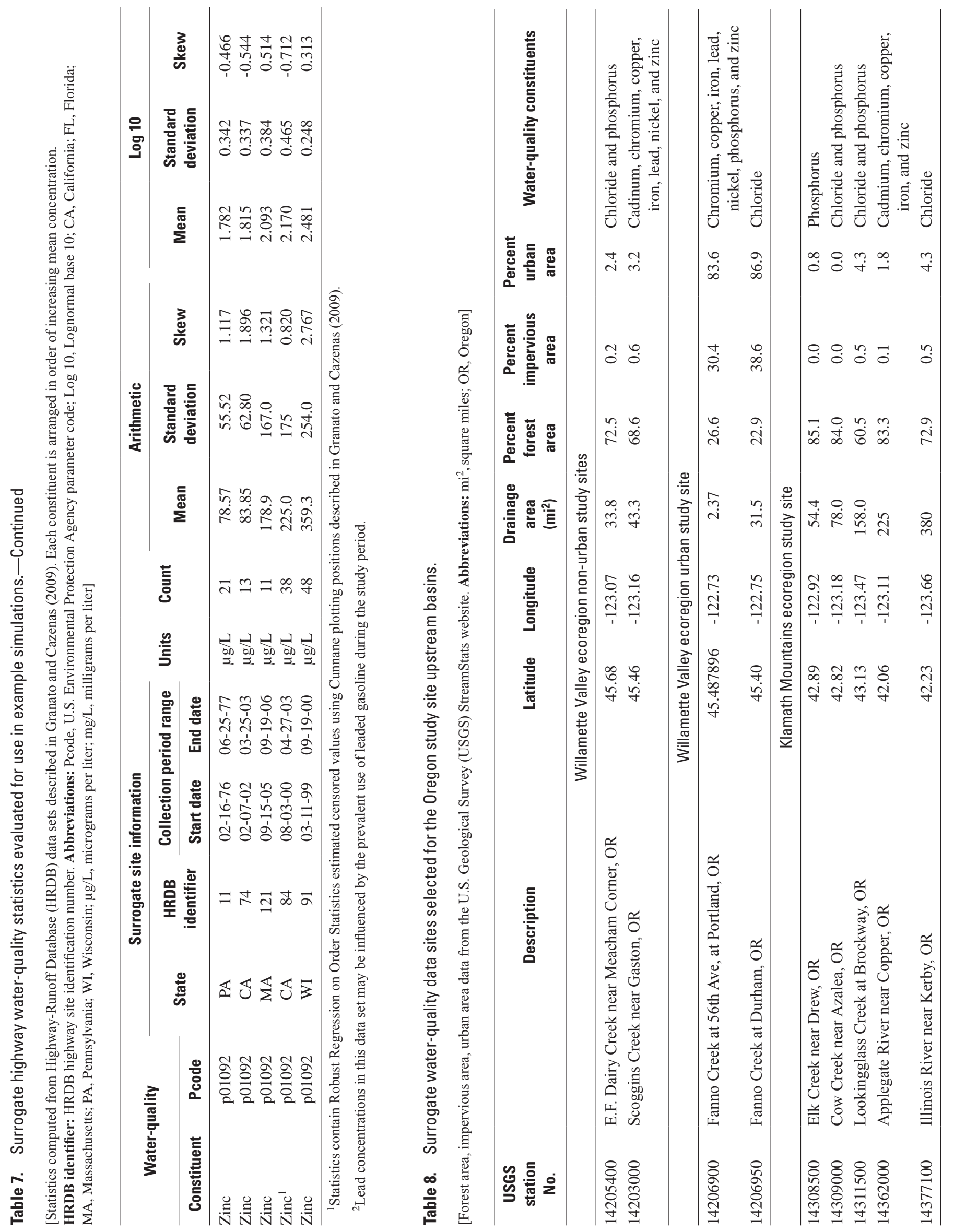




\section{Willamette Valley Ecoregion}

For the Willamette Valley ecoregion (ecoregion 3) non-urban study sites, the USGS streamflow and water-quality sites with the smallest basin drainage areas and having landuse characteristics comparable to the study site upstream basins were East Fork Dairy Creek (14205400) (chloride and phosphorus), and Scoggin Creek (14203000) (chromium, copper, iron, lead, nickel, and zinc). Because all constituent samples at these two sites were collected from separate storm events and were sufficient in number, it was possible to compute their statistical moments and specify them as a random water-quality input to SELDM (table 9). Some of the chromium, lead, and nickel concentrations were below the detection level. For these datasets, statistical moments were computed using the ROS method as described in appendix 1 of Granato and Cazenas (2009) using a Cunnane (1978) plotting position. Although cadmium also was sampled at this site with the other trace metals, it could not be used because more than 80 percent of its concentrations were below the detection level.
Transport curves also were created for chloride, suspendedsediment concentration, and total nitrogen for the Willamette Valley ecoregion non-urban study sites (table 10). The transport curves were created from samples collected at more than one water-quality site. However, all of these sites were located in the Willamette Valley ecoregion, and all sites had non-urban settings.

For the Tryon Creek at Interstate 5 study site, which is almost entirely urbanized, Fanno Creek at 56th Avenue (14206900) (chromium, copper, iron, phosphorus, and zinc) and Fanno Creek at Durham (14206950) (chloride) were selected as surrogate sites. Because many of the samples monitored at these two sites were not from separate storm events, it was not possible to specify them as random water quality input to SELDM. However, by matching these samples to corresponding instantaneous discharges measured at the sites, it was possible to create water-quality transport curves for most of the constituents using the Kendal-Theil Robust Line (KTRLine) program (table 10). Before creating a water-quality transport curve, it is necessary to ensure that the range of instantaneous discharges in the sample set is comparable to the range of discharges in the period of record for the streamgage.

Table 9. Random water-quality statistics used to simulate upstream concentrations at non-urban sites in the Willamette Valley and Klamath Mountains ecoregions, Oregon.

[Abbreviations: mg/L, milligrams per liter; $\mu \mathrm{g} / \mathrm{L}$, micrograms per liter]

\begin{tabular}{|c|c|c|c|c|c|c|c|c|c|c|c|}
\hline \multirow{2}{*}{ Constituent } & \multirow{2}{*}{ Pcode } & \multicolumn{2}{|c|}{ Collection period range } & \multirow{2}{*}{ Units } & \multirow{2}{*}{ Count } & \multicolumn{3}{|c|}{ Arithmetic } & \multicolumn{3}{|c|}{$\log 10$} \\
\hline & & Start date & End date & & & Mean & $\begin{array}{l}\text { Standard } \\
\text { deviation }\end{array}$ & Skew & Mean & $\begin{array}{l}\text { Standard } \\
\text { deviation }\end{array}$ & Skew \\
\hline \multicolumn{12}{|c|}{ Willamette Valley ecoregion } \\
\hline Chloride & p00940 & $12-06-01$ & $09-22-10$ & $\mathrm{mg} / \mathrm{L}$ & 53 & 2.20 & 0.218 & 0.372 & 0.340 & 0.043 & -0.127 \\
\hline Chromium $^{1}$ & p01034 & 02-21-91 & $12-06-11$ & $\mu \mathrm{g} / \mathrm{L}$ & 34 & 2.30 & 4.180 & 2.870 & -0.022 & 0.527 & 0.785 \\
\hline Iron & p01045 & 02-21-91 & $12-06-11$ & $\mu \mathrm{g} / \mathrm{L}$ & 62 & 1,470 & 2,545 & 4.786 & 2.962 & 0.345 & 1.512 \\
\hline Lead $^{1}$ & p01051 & 02-21-91 & $12-06-11$ & $\mu \mathrm{g} / \mathrm{L}$ & 62 & 0.17 & 0.090 & 1.540 & -0.818 & 0.208 & 0.244 \\
\hline Nickel $^{1}$ & p01067 & 02-21-91 & $12-06-11$ & $\mu \mathrm{g} / \mathrm{L}$ & 62 & 1.00 & 1.420 & 6.310 & -0.103 & 0.218 & 3.270 \\
\hline Phosphorus & p00665 & $12-06-01$ & $07-22-10$ & $\mathrm{mg} / \mathrm{L}$ & 51 & 0.04 & 0.009 & 0.617 & -1.449 & 0.101 & -0.008 \\
\hline Zinc & p01092 & 02-21-91 & $12-06-11$ & $\mu \mathrm{g} / \mathrm{L}$ & 62 & 7.46 & 8.216 & 3.275 & 0.7234 & 0.3365 & 0.6462 \\
\hline Iron & p01045 & 09-17-80 & $08-28-87$ & $\mu \mathrm{g} / \mathrm{L}$ & 13 & 152.3 & 97.74 & 1.360 & 2.098 & 0.2980 & -0.5199 \\
\hline Phosphorus & p00665 & 09-04-90 & 09-01-92 & $\mathrm{mg} / \mathrm{L}$ & 14 & 0.023 & 0.0073 & 0.2769 & -1.660 & 0.1476 & -0.6440 \\
\hline Zinc $^{1}$ & p01092 & 09-17-80 & $08-28-87$ & $\mu \mathrm{g} / \mathrm{L}$ & 13 & 31.00 & 24.00 & 1.280 & 1.360 & 0.3690 & -0.2380 \\
\hline
\end{tabular}

\footnotetext{
${ }^{1}$ Statistics contain Robust Regression on Order Statistics estimated censored values using Cunnane plotting positions described in Granato and Cazenas (2009).
} 


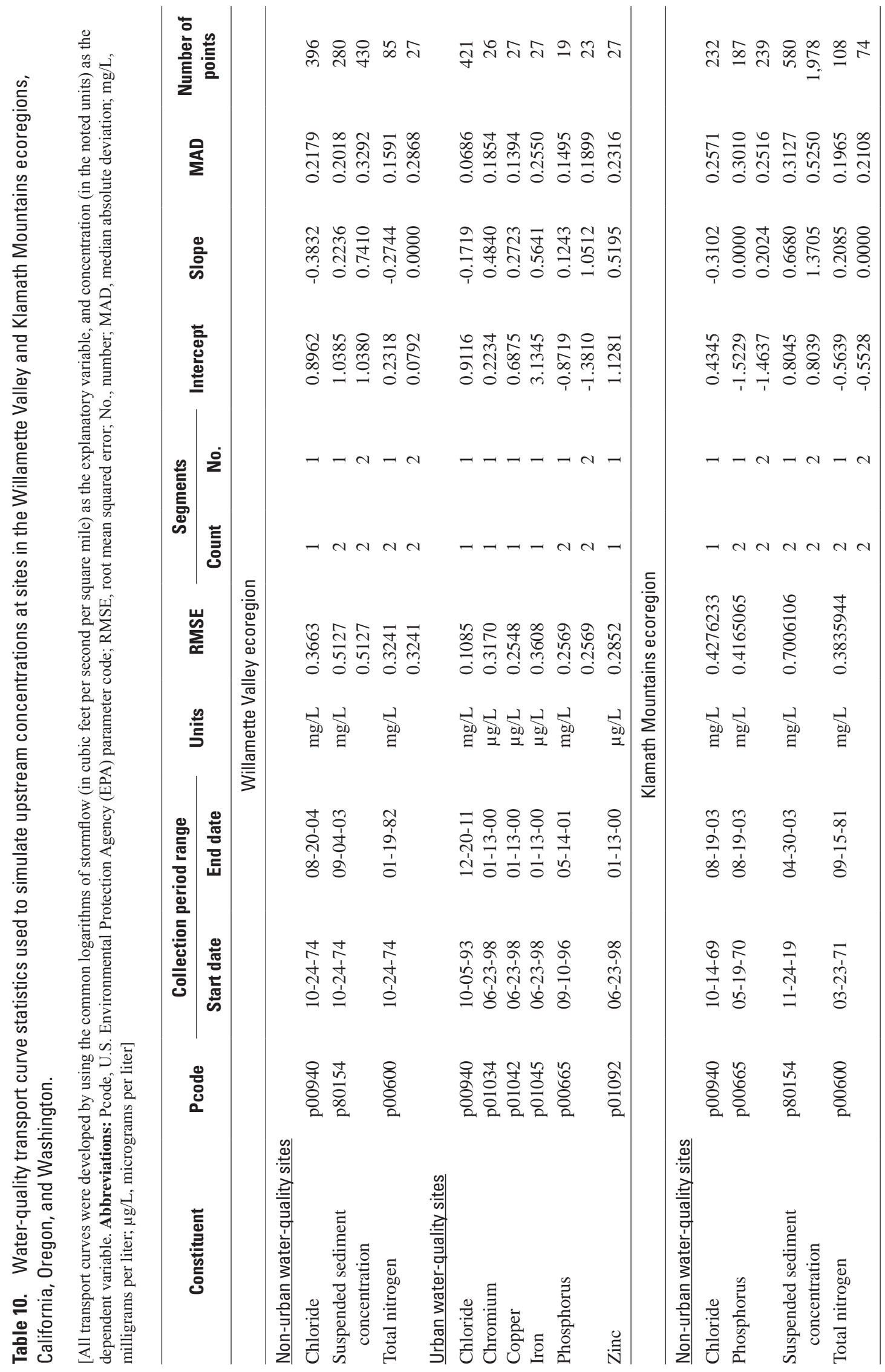


For chloride, monitored at Fanno Creek at Durham (14206950), which had 421 samples, the minimum and maximum instantaneous flows were 0.35 and $898 \mathrm{ft}^{3} / \mathrm{s}$, respectively. For the period of record from water years (WY) 1994 to 2012, these flows were less than and greater than the 1st and 99th flow percentiles, respectively.

The other constituents (chromium, copper, iron, phosphorus, and zinc), which were monitored at Fanno Creek at 56th Avenue, ranged from 26 to 42 in number of samples. The distribution of instantaneous flows for these sets of samples was comparable to the Fanno Creek at 56th Avenue (14206900) streamgage period of record (WY 1990-2012). The constituent dataset with the highest minimum instantaneous flow was less than the 13th flow percentile; and the constituent dataset with the lowest maximum instantaneous flow was greater than the 99th flow percentile. Transport curves could not be created for cadmium, lead, and nickel because they had too many concentrations below the detection level causing too many concentration values (Y axis) to fall into a flat horizontal line relationship with discharge ( $\mathrm{X}$ axis).

\section{Klamath Mountains Ecoregion}

Surrogate water-quality datasets selected for the Wall Creek at Interstate 5 study site, located in the Klamath Mountains ecoregion (ecoregion 78), were monitored from several basins in that region (table 8). Because the availability of water-quality data for this region is more limited than other regions of Oregon, potential datasets monitored at sites with small drainages and closer in size to the Wall Creek at Interstate 5 study site upstream basin $\left(0.88 \mathrm{mi}^{2}\right)$ were nonexistent. For chloride and phosphorus, it was necessary to combine samples from several sites. However, aside from drainage area size, the land-use characteristics (forest cover, imperviousness, and urbanization) of the selected surrogate sites were comparable to the Wall Creek at Interstate 5 study site upstream basin. Because all constituent samples at these sites were collected from separate storm events, it was possible to compute their statistical moments and specify them as random water-quality input to SELDM (table 9). Some of the chromium and zinc samples were below the detection level. For these datasets, statistical moments were computed using the ROS method as described in appendix 1 of Granato and Cazenas (2009) using a Cunnane (1978) plotting position. Statistics could not be computed for cadmium, lead, and nickel because the number of available samples was insufficient to compute statistics or too many of the concentrations were below the detection level, or both.

In addition to the random water-quality defined inputs to SELDM, it also was possible to create water-quality transport curves for chloride, phosphorus, suspended-sediment concentrations, and total nitrogen for the Klamath Mountains ecoregion (table 10).

\section{Stochastic Analysis Concepts}

SELDM can be used as a planning tool and an analysis tool. As a planning tool, SELDM can be used to run hypothetical scenarios to explore the effects of flows, concentrations, and loads on water quality downstream of a stormwater outfall. It also may be used to explore the potential effectiveness of various BMPs for achieving water-quality goals. As an analysis tool, SELDM can be used to simulate the quality and quantity of stormflows at a site of interest. It can be used to identify problem areas, simulate application of mitigation measures, and calculate loads necessary for analyzing TMDLs. Additional functionality of the SELDM approach is described in this section to illustrate the kinds of insight that are available using this approach. An analysis of dilution factors was done to demonstrate use of dilution factors for comparing relative risk among sites. An analysis of hardness-dependent, waterquality criteria was done to illustrate the effects of variations in hardness and flow on the application and interpretation of such criteria. An analysis of uncertainties in input and output values was done to demonstrate that properly selected robust datasets are needed to represent conditions at a site of interest. An analysis of BMP modeling methods was done to demonstrate use of the model for estimating treatment requirements for meeting water-quality objectives.

\section{Dilution Factors}

SELDM has a dilution-factor analysis module to facilitate rapid analysis of the relative risks for water-quality exceedances among sites with similar highway and upstream concentrations, based on the proportion of highway stormflow in the downstream flow. The model uses the stochastically generated stormflows to calculate dilution factors for each storm. The dilution factor is the ratio of stormflow from the highway site to the concurrent downstream stormflow. The dilution factor can vary from 0 to 1 as the highway stormflow increases in proportion to the concurrent upstream stormflow. A dilution factor near 0 indicates that highway stormflow is a negligible portion of the downstream stormflow and a dilution factor of 1 indicates that the downstream stormflow is all highway stormflow. The dilution factor increases as dilution of highway stormflow into the downstream stormflow decreases; Driscoll and others (1990a) defined the dilution factor in this way to prevent division by 0 errors in the 1990 FHWA runoff model.

SELDM calculates dilution factors for highway stormflow with and without BMP modification. A BMP that extends highway stormflows will decrease the dilution factor (increasing dilution) by incorporating a larger portion of the total upstream stormflow as concurrent stormflow. A BMP that reduces the volume of highway runoff also will decrease the dilution factor (increasing dilution). The highway and BMP dilution-factor outputs will be equal if there is no BMP flow modification. 
The dilution-factor output provides a quick initial assessment of the risks for water-quality exceedances with and without BMP treatment. For example, examination of the dilution-factor file for each of several highway-stream crossings can be used to identify the streams with the highest potential for exceedances. Similarly, if a highway with many outfalls is parallel to a stream, information about the cumulative upstream drainage and pavement areas at each outfall can be used to run SELDM. The dilution-factor file for each outfall can be used to identify the point along the stream with the highest potential for exceedances. In either case, this information can be used to allocate resources for a detailed analysis of flows, loads, and concentrations at the most critical site(s).

The two highway-runoff sites along Tryon Creek, Interstate 5 at Portland, Oregon (I-5) and Oregon Route 43 at Lake Oswego, Oregon (OR-43), were used to examine the type of information that could be obtained by using dilution-factor analyses. These two sites will be considered independent sites with equivalent flow statistics for this analysis. At the I-5 crossing, there are 11.83 acres of highway and $0.63 \mathrm{mi}^{2}$ of upstream basin (about 2.9 percent of the upstream area). At the OR-43 crossing, there is 3.96 acres of highway and $6.56 \mathrm{mi}^{2}$ of upstream basin (about 0.094 percent of the upstream area). These sites were selected because streamflow in Tryon Creek has been measured at USGS streamgage Tryon Creek near Lake Oswego, Oregon (14211315), from August 2001 through September 2012. This record was extended to the period October 1990 through September 2012 with data from USGS streamgage Fanno Creek at 56th Ave, at Portland, Oregon (14206900), by using the Streamflow Record Extension Facilitator (SREF) (Granato, 2009). The flow statistics used by SELDM were calculated by using Streamflow (Q) Statistics (QSTATS) (Granato, 2009), and the 7Q10 was calculated by using DFLOW (Rossman, 1990). The long-term average flow was $1.49\left(\mathrm{ft}^{3} / \mathrm{s}\right) / \mathrm{mi}^{2}$, monthly average streamflows ranged from 0.26 to $3.39\left(\mathrm{ft}^{3} / \mathrm{s}\right) / \mathrm{mi}^{2}$, and the $7 \mathrm{Q} 10$ was $0.037\left(\mathrm{ft}^{3} / \mathrm{s}\right) / \mathrm{mi}^{2}$. The retransformed and normalized geometric mean is $0.637\left(\mathrm{ft}^{3} / \mathrm{s}\right) / \mathrm{mi}^{2}$, the retransformed standard deviation is 3.626 , and the skew of the logarithms of streamflow is 0.206 .

These example dilution-factor analyses indicate the importance of the stochastic approach and demonstrate how BMPs can increase dilution (reduce the dilution factor) by extending the duration of the runoff hydrograph and reducing the volume of the highway discharge. SELDM was used to simulate seven scenarios for each site (fig. 10). In the first scenario, highway runoff was simulated as if there was a full storm-sewer drainage system without any BMP treatment. At the I-5 site, dilution factors for this system ranged from 0.0015 to 0.586 with a median of 0.0817 . At the OR- 43 site, dilution factors for this system ranged from 0.000026 to 0.102 with a median of 0.0039 . The largest dilution factors occur for short, high-intensity precipitation events with small prestorm streamflows because the highway drains well before the peak of the upstream stormflow hydrograph. The next three scenarios are used to examine potential effects of highway runoff with hydrograph extension, flow reduction, and both, by use of a grassy swale. Analysis of data in the International BMP Database (http://www.bmpdatabase.org/) indicates that flow extensions may range from about 0.1 to 3 hours and the ratios of outflow to inflow may range from 0.07 to 1.21 . If flow extension is used without flow reduction, this reduces dilution factors to range from 0.0014 to 0.575 with a median of 0.0791 at the I-5 site and from 0.000024 to 0.076 with a median of 0.0035 at the OR-43 site. If flow reduction is used without flow extension, this reduces dilution factors to range from 0.0008 to 0.429 with a median of 0.0441 at the I-5 site and to range from 0.000003 to 0.085 with a median of 0.002 at the OR-43 site. If both flow extension and flow reduction are used, dilution factors are reduced to range from 0.00077 to 0.418 with a median of 0.0422 at the I-5 site and from 0.000003 to 0.046 with a median of 0.0018 at the OR- 43 site. These dilution-factor scenarios indicate that highway runoff and BMP discharge are greater than 10 percent of the downstream flows (a dilution factor greater than 0.1 ) while the highway is discharging to the stream during fewer than 30 percent of storms at the I- 5 site and 0.03 percent of storms at the OR- 43 site (fig. 10). Therefore, depending on the concentration of concern and the sensitivity of the receiving stream, this dilution factor analysis indicates that the I-5 site is at much greater risk for adverse effects from highway runoff. If a project covers many stream crossings, the dilution factors can provide a rapid risk-based method for assessing relative risks among sites and the need for further analysis at selected sites.

The last three scenarios were run for each site to evaluate potential effects of more deterministic analyses on the dilution factors and therefore the perceived risk of water-quality exceedances (fig. 10). In each case, the dilution factor is calculated by using the same deterministic streamflow value and the stochastic highway-runoff duration and volume for each storm. If the mean annual upstream flow rate was used to simulate instream flows rather than stochastic stormflows, this would result in an upward bias. On average, these dilution factors for the I-5 and OR-43 sites are 4.13 and 4.33 times the fully stochastic highway-runoff simulation. If mean monthly upstream flow rates were used, the dilution factors would be biased by 4.8 and 7.8 times the fully stochastic highway-runoff simulation, on average, for the I-5 and OR-43 sites. Results of these scenarios indicate substantial bias over the range of dilution factors, which occurs because flow averages are heavily weighted by long periods of baseflow that comprise more than 86 percent of the 29-year simulation period. 


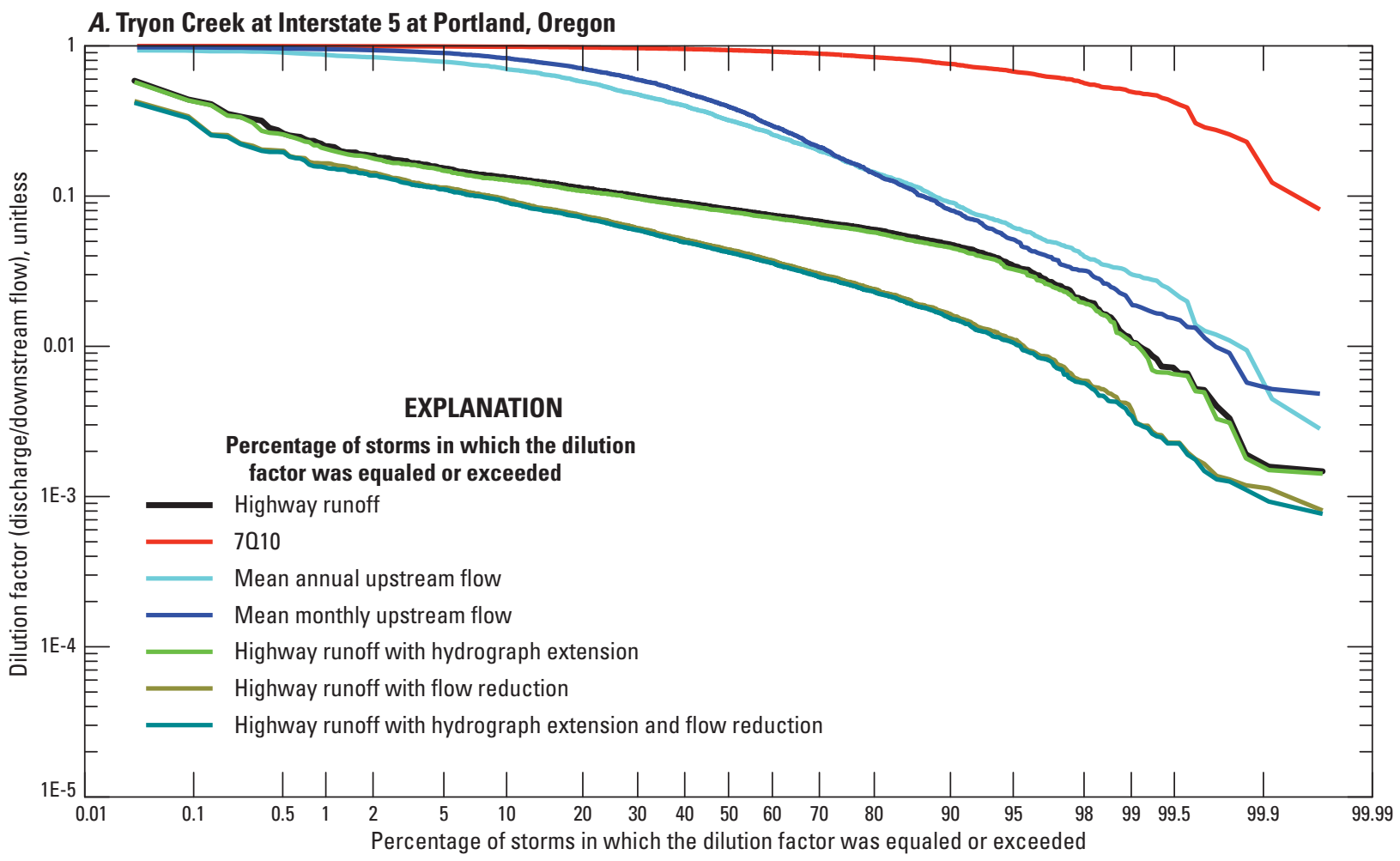

B. Tryon Creek at State Highway 43 at Lake Oswego, Oregon

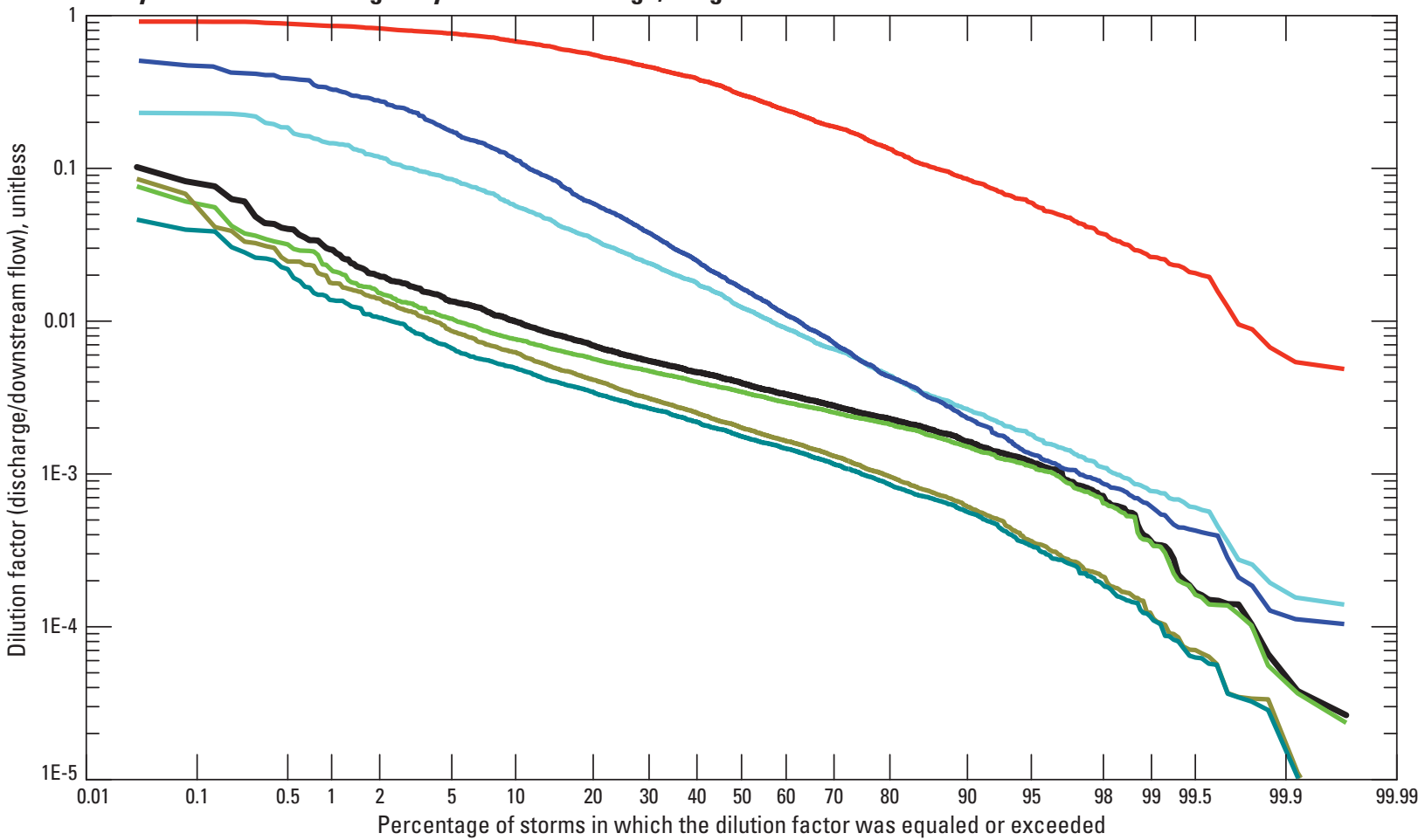

Figure 10. Stochastic populations of dilution factors for highway runoff or best management practices (BMP) discharge showing the effect of BMP treatments and upstream flow assumptions on the simulated dilution factors for $(A)$ Tryon Creek at Interstate 5, at Portland, Oregon, and $(B)$ Tryon Creek at Oregon Route 43, at Lake Oswego, Oregon. 
The last scenario was to use a constant value of upstream flow equal to the $7 \mathrm{Q} 10$ during every storm event because wastewater rules commonly are applied to stormwater discharges. In this scenario, the 7Q10-based dilution factors are, on average, 10 and 64 times the fully stochastic highway-runoff simulation for the I-5 and OR-43 sites. Bias in the dilution factors may prompt the user to do a more thorough post-run analysis at many sites that could otherwise be safely triaged. Furthermore, if highway runoff (or BMP effluent) concentrations are higher than instream concentrations, then use of these constant flow rates may indicate that mitigation measures are required at sites where they are not needed.

\section{Hardness Dependent Water-Quality Criteria}

ODEQ has adopted a series of hardness-dependent water-quality criteria for trace metals in receiving waters (Oregon Department of Environmental Quality, 2013). Total recoverable (whole water) criteria are established for cadmium and copper. Dissolved (filtered water) criteria are established for lead, nickel, and zinc, but these criteria represent adjustments to earlier total recoverable (whole water) criteria. The EPA dissolved criteria (and by definition, the ODEQ criteria) are based on the original total recoverable criteria dataset with correction factors that were based on EPA estimates of the percentage of dissolved metals in the original laboratory tests. The total recoverable criteria for all metals were used for comparison in this report because more robust datasets are available for whole-water concentrations than dissolved (filtered) concentrations in highway runoff and receiving waters. Many dissolved-metal datasets are less robust than available whole-water datasets because the requirements for collecting meaningful dissolved metal samples are much more stringent than for collecting whole-water samples (Breault and Granato, 2003). Furthermore, the ODEQ memorandum for initial analysis of trace-metal discharges indicates that the whole-water criteria should be used for initial (Tier 1) screening-level analyses (Bohaboy and others, 2013). A more detailed analysis with the dissolved criteria can be conducted by doing a concentration-of-concern analysis with SELDM (Granato, 2013), but the effort to develop the adverse-effect ratio statistics for receiving waters in Oregon is beyond the scope of this study. Therefore, this stochastic analysis of hardness dependent water-quality criteria will be focused on the whole-water concentrations. The hardness-dependent criteria are calculated using logarithmic regression equations between the total hardness concentration in the receiving water and the criterion value (Oregon Department of Environmental Quality, 2013). The ODEQ provides a table of metal criteria values calculated by using a hardness concentration of $100 \mathrm{mg} / \mathrm{L}$, but this hardness concentration is not representative of water quality in many areas of Oregon.
SELDM can be used to calculate total hardness values by using site-specific data or by using ecoregion-transport curves developed by Granato and others (2009). For this study, the regional transport curves for the Willamette Valley and Klamath Mountains ecoregions were used to evaluate water quality at the sites of interest in each ecoregion. The transport curve equations shown in figure 11 provide the general relation between the stochastically generated stormflows and total hardness concentrations. SELDM also recreates the scatter of concentrations around the transport curve by stochastically generating normal-random variates that are multiplied by the scatter of residuals. The result is a pattern of total hardness values that mimics the relation between hardness in flow that would occur at a site of interest over a long period of time. The average hardness concentrations in these simulated datasets for the Willamette Valley and Klamath Mountains ecoregions are about 24 and $41 \mathrm{mg} / \mathrm{L}$, respectively.

For this example, the Unnamed Creek at U.S. Route 30 in Willamette Valley ecoregion was selected because this site has the largest drainage-area ratio of highway to upstream basin and the Wall Creek site was selected because it is the only study site in the Klamath Mountains ecoregion. Random values were generated for the highway-runoff contribution to downstream total hardness concentrations at both sites. Total hardness concentrations from Washington State were selected for simulating highway runoff in the Willamette Valley ecoregion. The values for the average, standard deviation, and skew of the logarithms of total hardness from these data were $1.42,0.36$, and -0.0974 , respectively. Total hardness concentrations from northwestern California were selected for simulating highway runoff in the Klamath Mountains ecoregion. The values for the average, standard deviation, and skew of the logarithms of total hardness from these data were $1.23,0.381$, and 0.818 , respectively. The results of this analysis indicate that the total hardness in stormflows generated with the Washington statistics have a higher median and mean, and are much more variable, than the upstream statistics calculated with the transport curve (fig. 12). Although the ratio of highway to upstream area (about 5 percent) at this site is the highest among example sites, the highway runoff does not have a substantial effect on the downstream total-hardness values. In comparison, the total hardness in stormflows generated with the northwestern California statistics are substantially lower than the receiving-water statistics (fig. 12), but downstream hardness concentrations are not substantially different than upstream concentrations because the highway contribution to downstream stormflow is relatively small at this site. Therefore, in these examples, the distribution of upstream hardness values can be used to estimate the potential distribution of hardness-dependent criteria at these sites. 


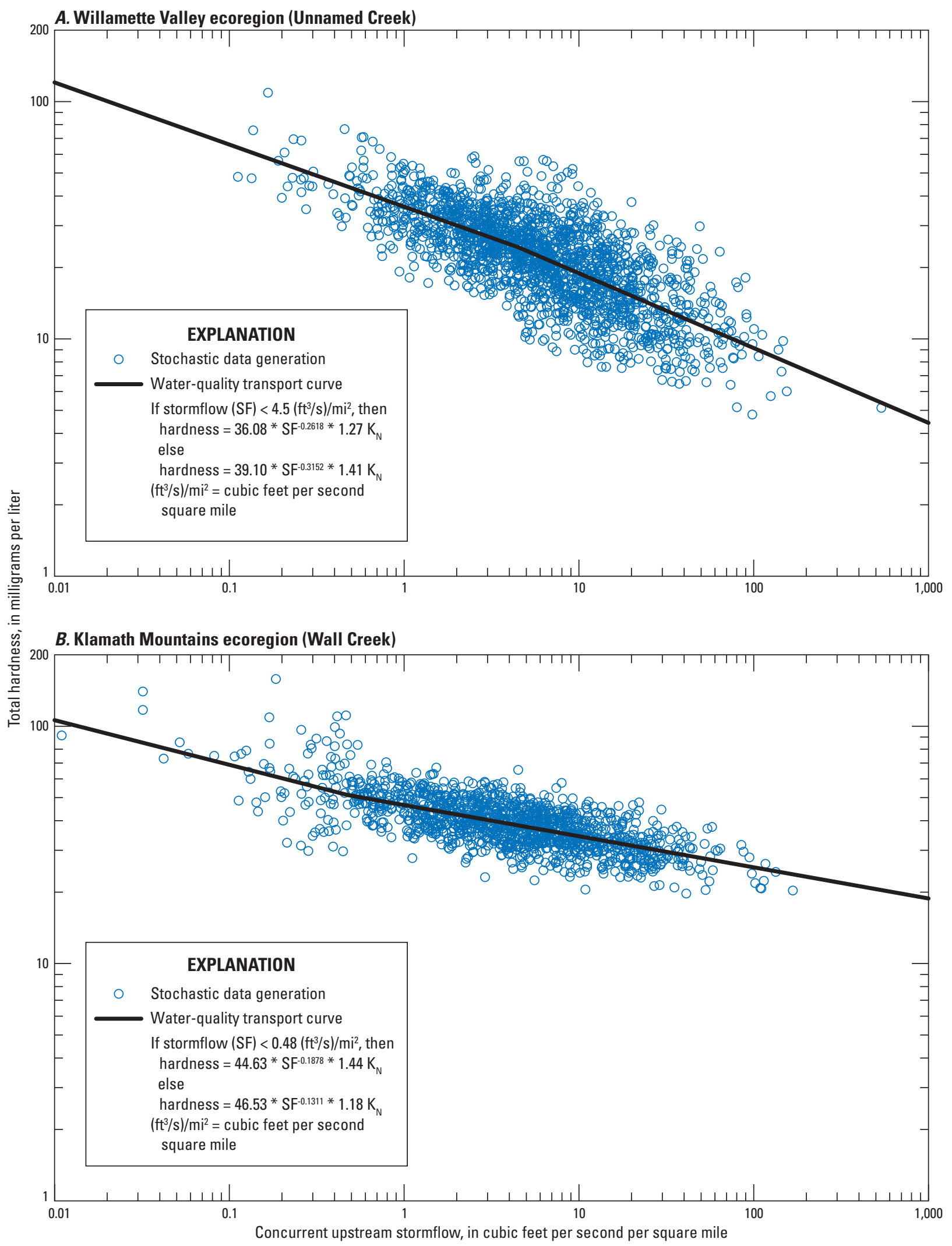

Figure 11. Water-quality transport curves and stochastically generated data for (A) Willamette Valley ecoregion and (B) Klamath Mountains ecoregion generated by using concurrent upstream stormflows in Unnamed Creek at U.S. Route 30, Portland, Oregon, and Wall Creek at Interstate 5, near Ashland, Oregon, respectively. $\mathrm{K}_{\mathrm{N}}$ is the normal-random variate generated by the Stochastic Empirical Loading and Dilution Model, which provides the scatter of harness concentrations above and below the transport curve. 


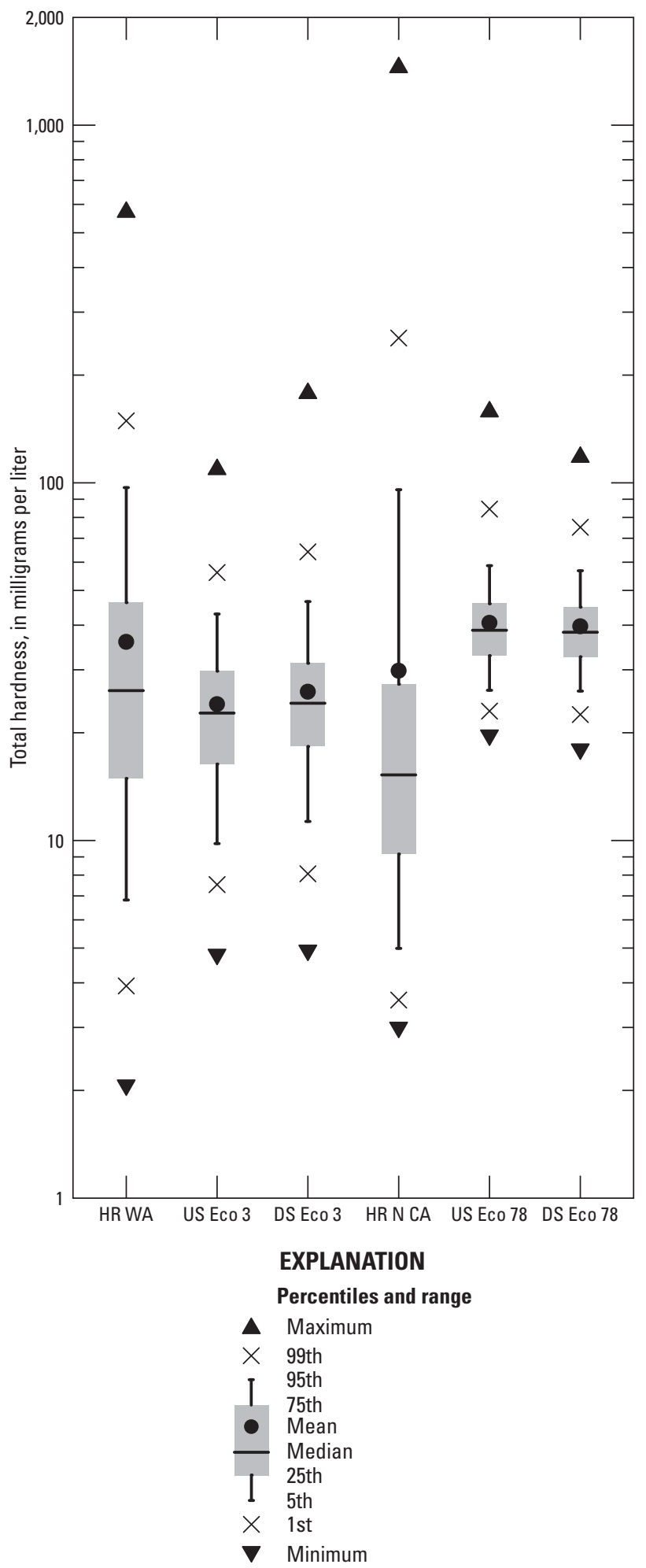

Figure 12. Total hardness concentrations in highway runoff, upstream stormflows, and downstream stormflows. (HR WA is Washington state highway runoff; US Eco 3 is upstream Willamette Valley ecoregion; DS Eco 3 is downstream Willamette Valley ecoregion; HR N CA is northwestern California highway runoff; US Eco 78 is upstream Klamath Mountains ecoregion; DS Eco 78 is downstream Klamath Mountains ecoregion.)
The range of water-quality criteria for the trace metals cadmium, chromium, copper, lead, nickel and zinc vary substantially from storm to storm as a function of stormflow and the resultant variation in hardness concentrations. These criteria range by a factor of 14-53 for the stochastically generated dataset from the Willamette Valley ecoregion (fig. 13). In comparison, the upstream stormflow rate for this site in the Willamette Valley ecoregion varied by a factor of about 4,800. Similarly, these total-metal criteria range by a factor of 5.8-14 for the stochastically generated dataset from the Klamath Mountains ecoregion (fig. 13). In comparison, the upstream stormflow rate for this site in the Klamath Mountains ecoregion varied by a factor of about 20,000. Although increased dilution tends to decrease the hardnessbased criteria, the magnitude of the change in dilution is much greater than the magnitude of the change in the criteria. If the upstream basin is not a substantial source of the solute in question, then the added dilution from higher flows may reduce the risks for an exceedance even if the criteria is lower at higher flows. However, because the relation between flow and total hardness is not deterministic, there can be wide variation in hardness concentration (and therefore in the criteria) for any given streamflow (fig. 13). A stochastic model may be needed to properly represent the complex interplay of flows, hardness, constituent concentrations, and water-quality criteria from storm to storm that may result in water-quality exceedances at a site of interest.

The method used to simulate and apply hardness concentrations may have a substantial effect on the simulated risks for water-quality exceedances. If trace element concentrations are high with respect to the criterion and hardness is simulated as a random variable, then the choice between the stochastic hardness approach and average hardness approach to calculate criteria may not have a large effect on the number of exceedances. However, if trace element concentrations are low with respect to the criterion and hardness is simulated as a random variable, then the random combinations of trace element concentrations and stochastic criterion values may produce more exceedances. For example, if the hardness-based lead criterion were to be applied to highway runoff concentrations from different sites (table 7), then the number of exceedances would be a function of the geometric mean concentration and the hardness values used. Highway runoff was used for this example because the range in geometric-mean lead concentrations was high and hardness is a random variable. The geometric mean concentration of lead at the HRDB site 11 on Interstate 84 in Pennsylvania (PA I-84) is about $99 \mathrm{mg} / \mathrm{L}$ even though it is a non-urban site because the data were collected in the late 1970s when use of leaded gasoline was still prevalent. The geometric mean concentration of lead at the HRDB site 91 on Interstate 894 site in Milwaukee, Wisconsin (WI I-894) is about $52 \mathrm{mg} / \mathrm{L}$ because this site is in an ultra-urban area with a long history of industrial production of metal products. 


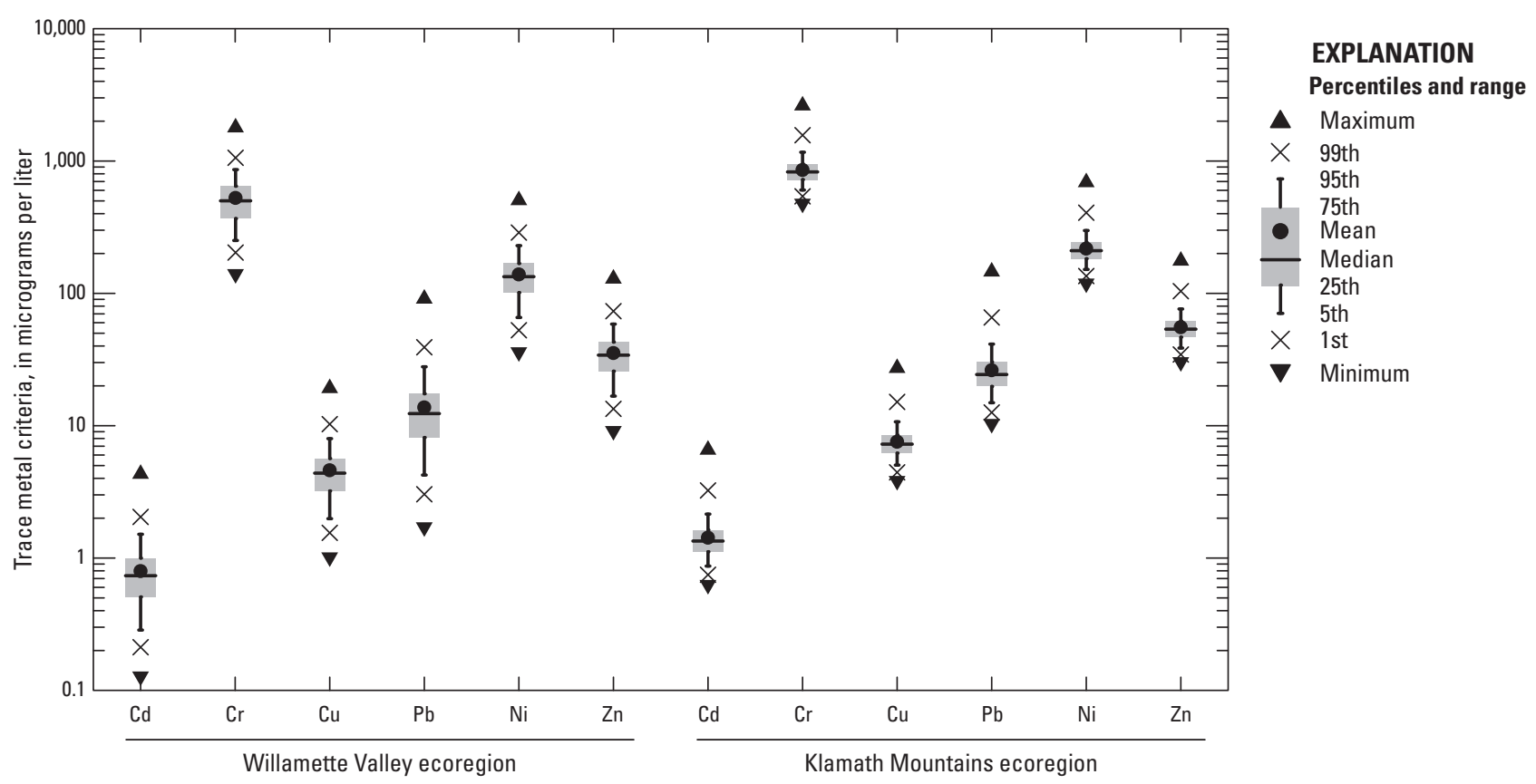

Figure 13. Hardness-based total recoverable aquatic-life criteria for cadmium (Cd), chromium (Cr), copper $(\mathrm{Cu})$, lead (Pb), Nickel (Ni), and Zinc (Zn) based on simulated stormflows and associated concentrations of total hardness in the Unnamed Creek study site in the Willamette Valley ecoregion and in Wall Creek study site in the Klamath Mountains ecoregion, Oregon. Aquatic-life criteria are from the Oregon Department of Environmental Quality (2013).

The geometric mean concentrations of lead at HRDB site 121 on Interstate 495 in Massachusetts (MA I-495), HRDB site 74 on Interstate 5 in California (CA I-5), and HRDB site 84 on U.S. Route 50 in California (US-50) are much lower (10.7, 8.73, and $2.22 \mathrm{mg} / \mathrm{L}$, respectively) because these are from recent data collection efforts in non-urban areas. Figure 14 shows the relation between highway runoff as a function of the stochastic and average hardness criteria for total recoverable lead and the choice between the Washington State hardness statistics and the northern California hardness statistics for these sites. As the graph indicates, the number of exceedances is highly correlated with the geometric mean value. In this example, random hardness modeling produces more exceedances than using the average hardness concentration if the geometric mean lead concentrations are less than about $50 \mu \mathrm{g} / \mathrm{L}$ (fig. 11). The lower hardness concentrations in the California highway-runoff dataset reduce the lead criterion and therefore increase the number of exceedances in comparison to the hardness concentrations in the Washington State highway-runoff dataset.

If a transport curve is used with the upstream flow (fig. 11) to represent reductions in hardness and therefore reductions in the water-quality criteria with increasing flows, this will affect the pattern of water-quality exceedances. If a transport curve is used, then lower hardness-based criterion values generally will be associated with higher dilution from upstream flows (with some random variation at any given flow). If this is the case, the difference between use of the stochastic values and average hardness value may be less pronounced than if hardness is simulated as a random variable. For example, simulated total recoverable lead exceedances in the Unnamed Creek at U.S. Route 30 are shown in figure 15. The upstream lead concentrations are calculated by using data from Scoggins Creek, a largely forested basin near Gaston, Oregon (table 8). This site has a geometric mean lead concentration of $0.152 \mu \mathrm{g} / \mathrm{L}$. The highway lead statistics were simulated using the previously defined lead statistics from the CA I-5, PA I-84, MA I-495, WI I-894, and US-50 datasets. Basin properties from the Unnamed Creek site of interest were selected for this example because this site has the highest ratio of highway catchment size to upstream basin size (approximately 5 percent) and, therefore, the downstream exceedances would show a range of values. Although the percent exceedances still are higher for the stochastic criteria with the transport-curve approach, the differences are much less than criteria based on the average hardness concentration. As with the randomhardness approach, the results from the two approaches converge as the total number of exceedances increases (fig. 15). 


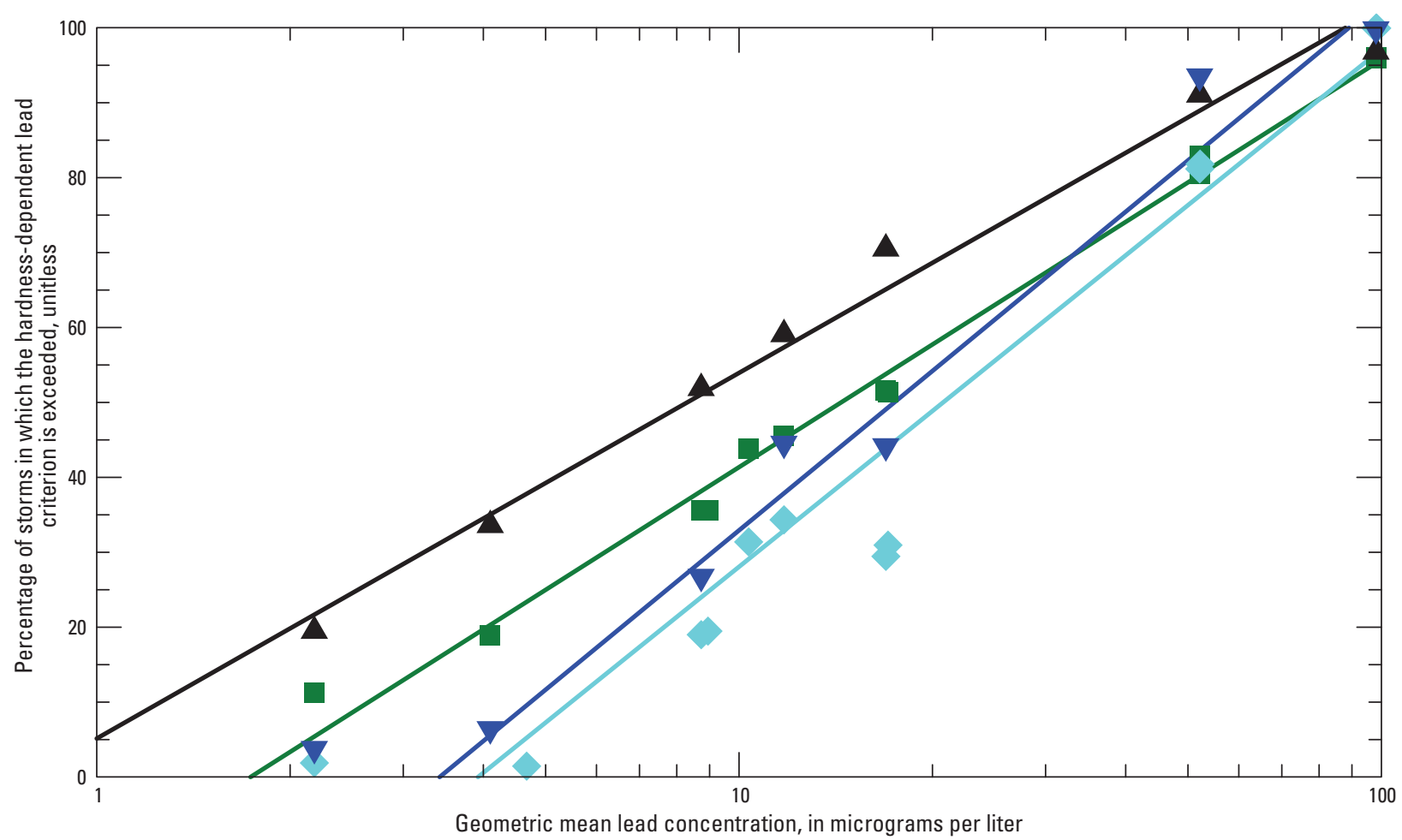

Figure 14. Example of total recoverable lead exceedances in highway runoff in comparison with the Oregon Department of Environmental Quality hardness-based aquatic-life criteria as a function of the geometric mean lead concentration and the modeling method used. Regression relations are shown only to indicate patterns in the data and are not valid for geometric-mean lead concentrations that produce percent-exceedance values that are less than zero or greater than 100 percent.

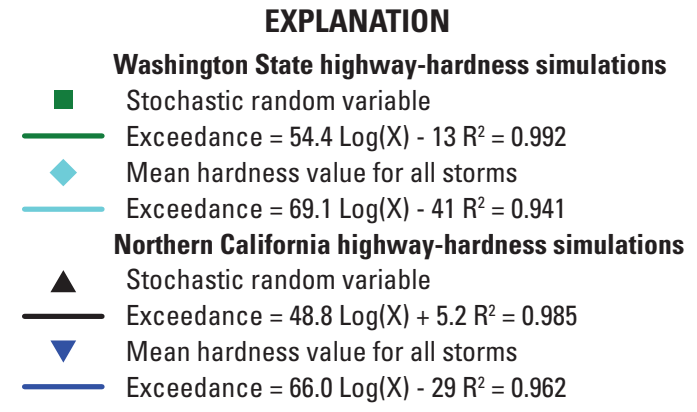

Water-quality exceedances commonly have a recurrence interval. For example, the Oregon Department of Environmental Quality (2013) aquatic-life criteria indicate that the criteria should not be exceeded more than once every 3 years. The annual average number of storms in these stochastic analyses was about 66 storms per year. Therefore, a monthly exceedance would have an 18.2 percent risk; a quarterly exceedance would have a 6.1 percent risk; an annual exceedance would have a 1.52 percent risk; and a 3-year exceedance would have a 0.51 percent risk. The equations in figures 14 and $\underline{15}$ were developed with the line of organic correlation (Helsel and Hirsch, 2002) and so can be used to calculate the geometric mean from the risk of exceedance. In the highway-runoff example (ig. 14) with the Washington State hardness values and the stochastic criteria, the 3-year recurrence risk for total-recoverable lead in the effluent may be satisfied if the geometric mean concentration is less than about $1.77 \mu \mathrm{g} / \mathrm{L}$. In the downstream example, with the Washington State hardness values and the stochastic criteria, the 3-year recurrence risk for total-recoverable lead in the receiving stream may be satisfied if the geometric mean concentration is less than about $1.29 \mu \mathrm{g} / \mathrm{L}$. The instream threshold value is less than the effluent threshold value because the hardness in the stream is generally lower than the hardness in runoff (fig. 12). These values are just general rules of thumb based on available statistics from different monitoring sites rather than a systematic sensitivity analysis. The standard deviation and skew of the logarithms of the lead concentrations (or other constituent of interest) also would affect the relation between input concentrations and exceedances. Differences in these statistics influence whether the stochastic dataset plots above or below the regression lines. The risk for exceedances shown in these examples are based on whole water concentrations instead of dissolved concentrations and do not reflect the potential effectiveness of structural BMPs or other mitigation measures for meeting these criteria. 


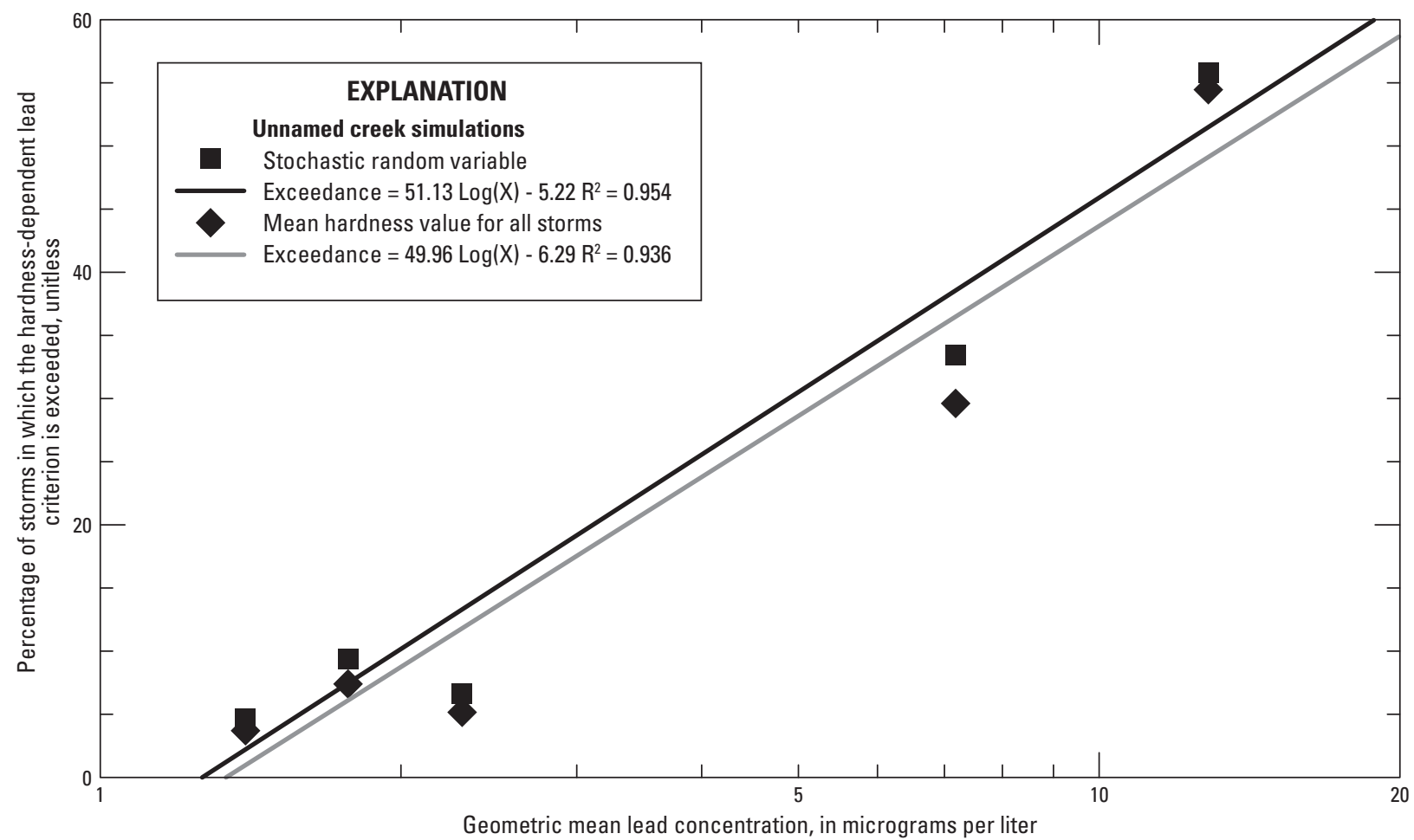

Figure 15. Example of total recoverable lead exceedances in the Unnamed Creek at U.S. Route 30, at Portland, Oregon, in comparison the Oregon Department of Environmental Quality hardness-based aquatic-life criteria as a function of the geometric mean lead concentration and the modeling method used. Regression relations are shown only to indicate patterns in the data and are not valid for geometric-mean lead concentrations that produce percent-exceedance values that are less than zero or greater than 100 percent. The Willamette Valley ecoregion transport curve was used to calculate upstream hardness values.

\section{Uncertainty in Input and Output Values}

The ability of SELDM to generate flows, concentrations, and loads from user input statistics provides many methods for evaluating water-resource management decisions that are based on limited data. The benefit of the Monte Carlo analysis is not to decrease uncertainty in the input statistics, but to represent the different combinations of the values of variables that determine potential risks for water-quality exceedances from the applicable criterion. Simpler methods may provide estimates of mean values, but it is commonly the extreme events that are of most interest to scientists, engineers, and decision makers for evaluating the potential for exceedances. Uncertainty in input values may be caused by limitations in the data used to calculate the statistics that are used and the uncertainty in the selection of data from sites that represent conditions at the site of interest. Uncertainty in the outputs depends on the proper selection of input values. Sensitivity analyses, which are done by varying input values and noting the effects on the output values, can be done to assess the importance of different selections on the results of analysis.
SELDM can be used to evaluate uncertainties in actual data used to make management decisions by evaluating potential outcomes that may occur based on available data. A case study based on randomly generated highway-runoff concentrations was selected to simplify the example to examine only one environmental variable. Total phosphorus concentration statistics from 13 storm-event samples collected at Interstate 5 at Mountain Gate Northbound in California (HRDB site 74; table 6) were selected for this example because total phosphorus is a constituent of concern, and it is a major ion that may be subject to less sampling artifacts than trace metals, which also are of concern. In this example, the same concentration statistics were used to run the model with 22 different stochastic realizations. Each stochastic realization is generated from a different random number stream. Conceptually, this approach indicates what would happen if 21 teams were monitoring highway runoff at the same site in different storms (or in parallel universes). This analysis demonstrates how random variation from storm to storm may affect the perceived risk of exceedance and need for mitigation measures at a site of interest. Figure 16 shows the moving 
average values from the 22 stochastic samples generated with the California statistics as each additional storm is accumulated. The sample average value (from 13 storms) was $0.283 \mathrm{mg} / \mathrm{L}$. If 22 teams were instructed to collect a single EMC sample at this hypothetical site, then the correct answers for the site average would range by a factor of 165 from 0.013 to $2.14 \mathrm{mg} / \mathrm{L}$ (fig. 16). The variability among "answers" could be much greater if grab samples were used because the EMC statistics do not represent within-storm variability. As the storm event sample size increases, the cumulative runningaverage values converge toward the actual site average value. At a sample size of 13 storms, the site average would range by a factor of 16 from 0.06 to $0.96 \mathrm{mg} / \mathrm{L}$ among the 21 different simulations. Thus, based on the statistics from the available samples, the actual site average may actually be substantially higher or lower than the measured average at that site. The datasets begin to converge for sample sizes greater than 15 samples. At this point, the site average ranges by a factor of 7.6 from 0.11 to $0.85 \mathrm{mg} / \mathrm{L}$. After more than 1,870 simulated storms, the averages range from 0.28 to $0.32 \mathrm{mg} / \mathrm{L}$. Average values tend to stabilize more rapidly with each additional sample than the standard deviation or skew because these statistics are calculated using the sum of squared differences between each value and the average and the sum of cubed differences between each value and the average, respectively. Although most values of the mean in figure 16 converge fairly well by seven samples, more samples are required to produce robust estimates of the standard deviation and skew. For a simple example like this, the theoretical confidence intervals of the statistics for the lognormal distribution would be sufficient for estimating such values, even though the logarithms of sample data are slightly skewed. However, this type of parametric approach would be difficult once different variables are combined.

The perceived risk for water-quality exceedances may drive decisions for implementation of mitigation measures. Knowledge of the potential implications of sample size on such risks and potential mitigation costs may help inform resource allocation decisions for monitoring and mitigation. Individual EMC values from the 22 stochastic realizations in the previous example were used to estimate the risk for highway-runoff discharge values to exceed a commonly used wastewater discharge criterion of $0.5 \mathrm{mg} / \mathrm{L}$ of total phosphorus (Litke, 1999). The risk of exceeding this criterion among the 13 actual samples collected along I-5 in California was about 14 percent, and the average risk of exceedance from 1,870 simulated storms for each of the 22 stochastic realizations is about 16 percent. If only one EMC sample is collected, the calculated risk will either be 0 or approximately 100 percent (fig. 17). In this case, only 2 of the 22 realizations indicated an exceedance. Because each trial is binary (there is an exceedance or not), risks may increase or decrease in the saw-tooth pattern between discrete risk levels as additional exceedances and non-exceedances are detected (ig. 17).
The perceived risk of exceedance with 13 samples ranges from 0 to 23 percent based on the values generated among the 22 stochastic realizations. It is possible, but unlikely, that the first 13 samples could exceed the criterion even though the statistical risk is closer to 16 percent. These exceedances were generated with the statistics from CA I-5. If statistics from one of the stochastic realizations shown in figure 16 are more representative of long-term values at CA I-5, then there may be many more or far fewer exceedances at this site. Analytical methods also could be used to assess these risks based on input statistics, but assessing the risks for downstream exceedances would be more complex because of the interplay of values from the quantity and quality of highway runoff and upstream flows.

The example analyses shown in figures 14 and $\underline{15}$ demonstrate the concept of input dataset selection uncertainty. In both cases, total lead statistics from five highway-runoff monitoring sites shown in table 7 (CA I-5, PA I-84, MA I-495, WI I-894, and US-50) were used to examine the potential for water-quality exceedances in highway runoff and in a small receiving stream (the Unnamed Creek at U.S. Route 30 in Portland, Oregon). In these cases, the percentage of exceedances in highway runoff ranged from 1.45 to 99.95 percent depending largely on the highway dataset that was selected (fig. 14). Similarly, the percentage of exceedances in the receiving water downstream of the highway ranged from 0.16 to 55.8 percent depending largely on the highway dataset that was selected. As indicated, the highest values were associated with data collected at a semi-rural Pennsylvania site (PA I-84) when use of leaded gasoline was still prevalent and with recent data collected in an urbanized site (WI I-894) in an industrial city, Milwaukee, Wisconsin. If these sites are removed from consideration, the maximum risk for waterquality exceedances downstream of the highway outfall are reduced to about 9.4 percent if the whole water lead statistics from the California US-50 site are used.

\section{Generating Extreme Values}

SELDM and other Monte Carlo models may generate extreme values from input statistics, which may or may not be feasible based on physicochemical or hydrological limits. For example, the extreme concentrations of chloride in highwayrunoff generated as part of the Wall Creek study site analysis highlight the need for the model user to carefully examine and evaluate the results of analysis (fig. 18). In this case, several stochastic realizations made using the chloride-concentrations statistics from Site 121 (MA I-495, table 7) produce values that greatly exceed the maximum chloride concentration of a saturated brine solution at near freezing temperatures (about 220,000 mg/L); even though these statistics are calculated with measurements from about 130 events and these statistics are similar to chloride statistics measured at eight other monitoring sites in Massachusetts (Smith and Granato, 2010). 


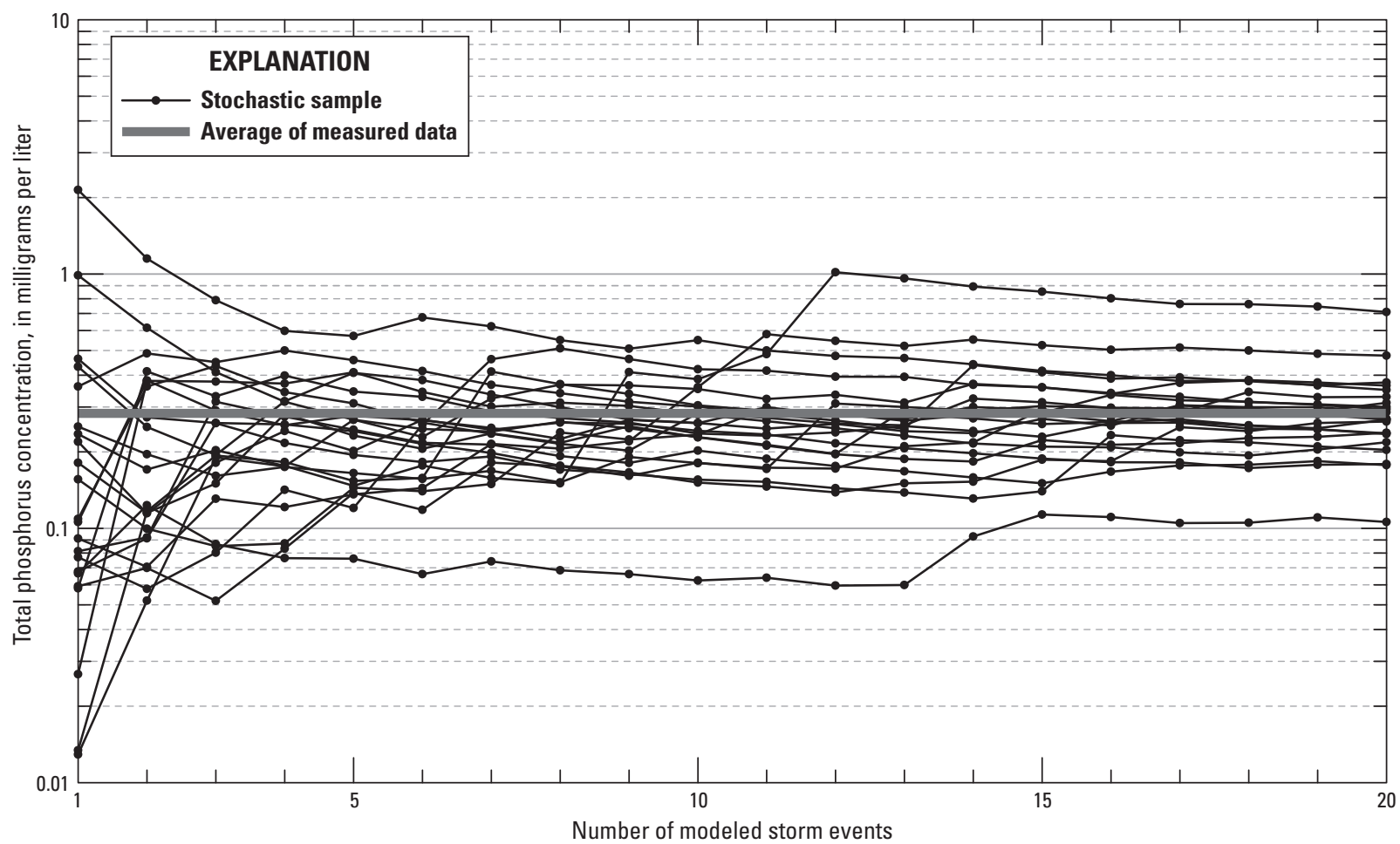

Figure 16. Moving average values of total phosphorus concentrations for 22 stochastic samples generated with statistics from Interstate 5 at Mountain Gate Northbound, California. The mean, standard deviation, and skew of the logarithms are equal to -0.8603 , 0.5581 , and -0.1349 , respectively. The original sample was comprised of 13 storms with an average of 0.283 milligrams per liter.

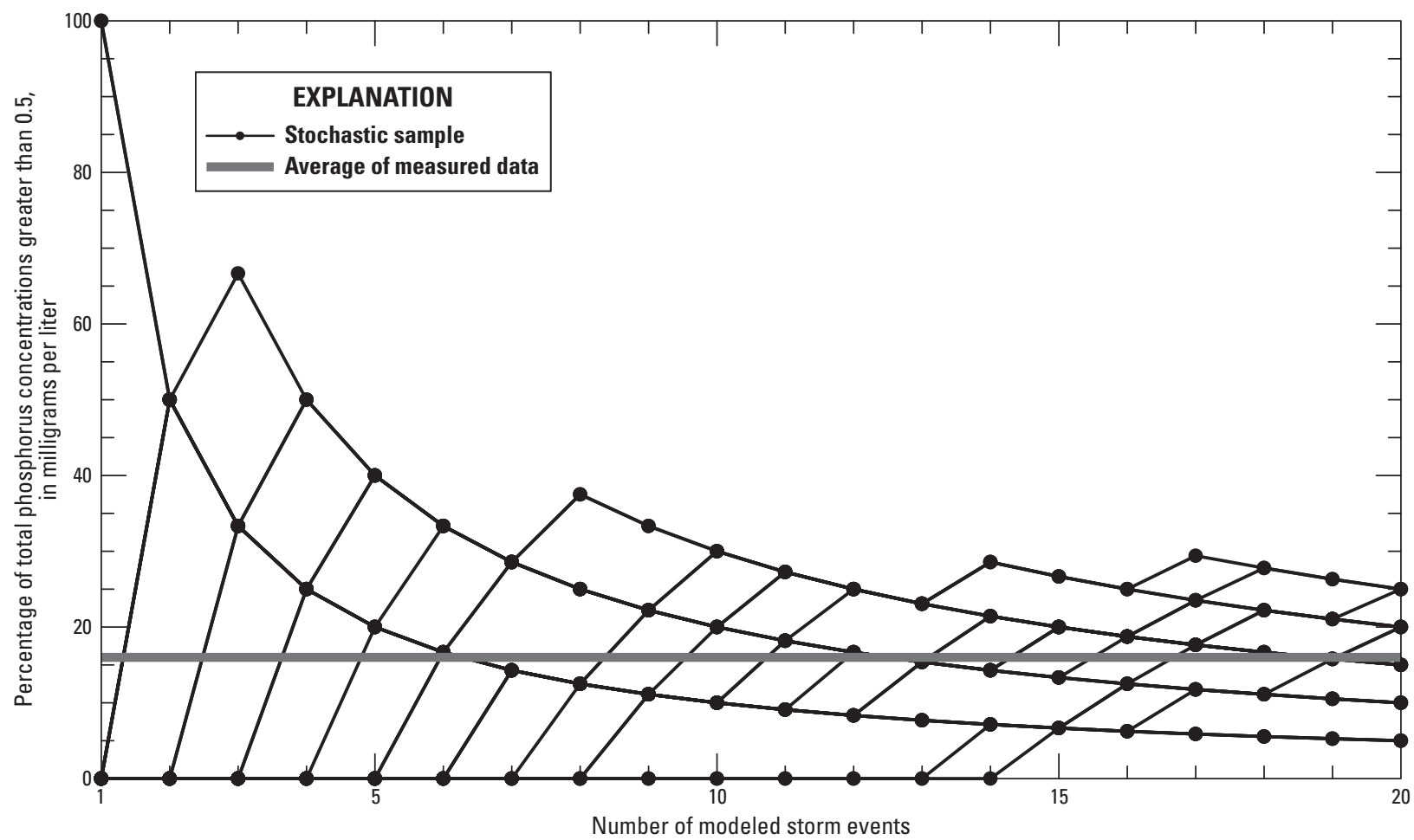

Figure 17. Cumulative total phosphorus concentration-exceedances greater than 0.5 milligrams per liter in percent for 22 stochastic samples generated with statistics from Interstate 5 at Mountain Gate Northbound, California. The original sample was comprised of 13 storms with exceedance rate of about 14 percent; the stochastic population has an exceedance rate of 16 percent. 


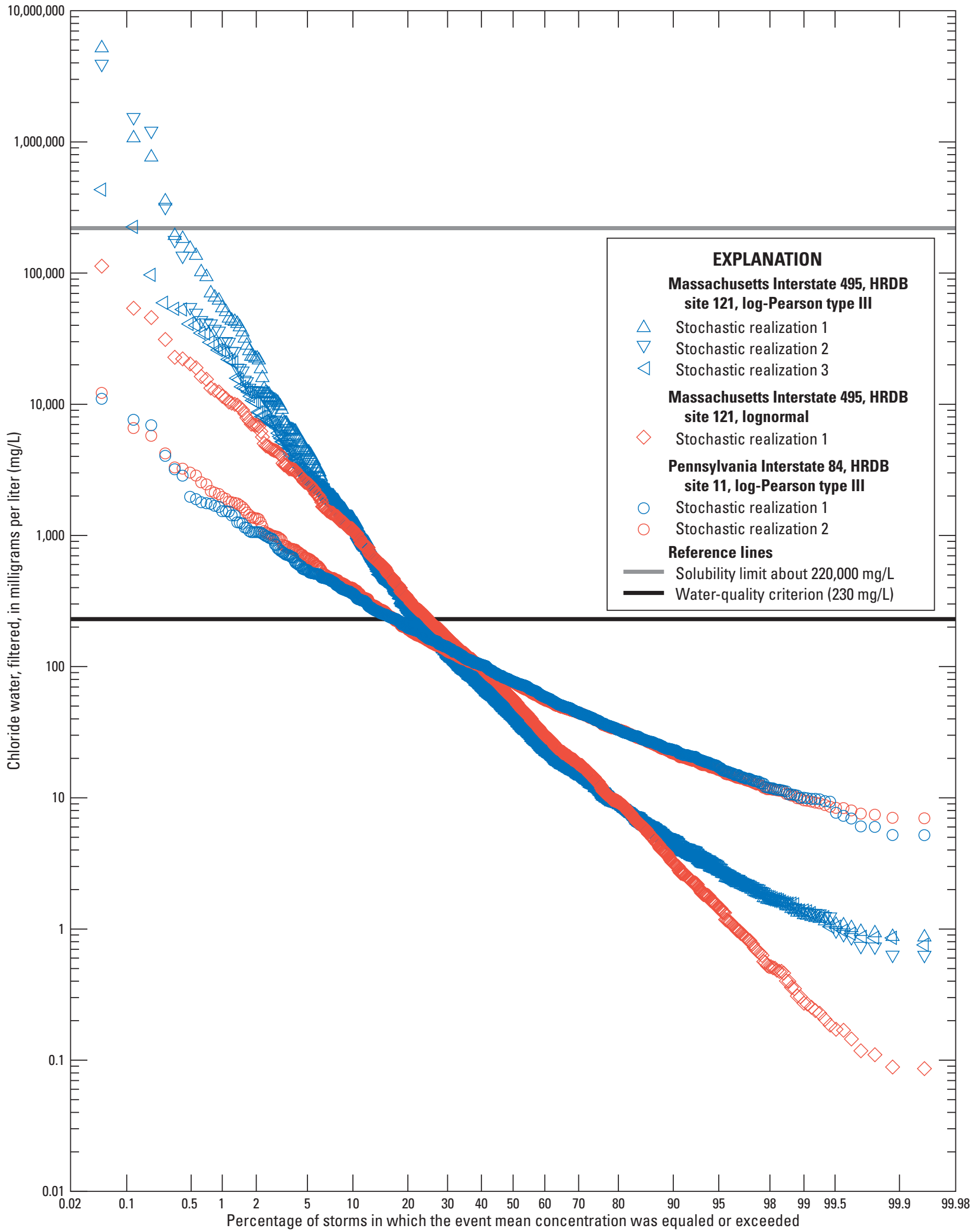

Figure 18. Example analyses of the concentrations of chloride in highway runoff generated by using a logPearson type III distribution or a lognormal distribution. For each set of statistics, the stochastic realizations use a different series of random-number inputs. HRDB is Highway-Runoff Database. 
Because data are limited, with many datasets containing a few (commonly less than 20 storms) to a few hundred storms, generating a large record set requires extrapolation beyond the percentiles of the original data. SELDM generates concentration and flow values by using the logPearson type III frequency factor method as a function of the average, standard deviation, and skew of the logarithms of monitoring data (Granato, 2013). If data are simulated as lognormal, the skew is set equal to zero, which linearizes the distribution of generated data with respect to the logarithmic and probability axes. In comparison, datasets with positive skews are concave up, which results in higher values at both ends of the distribution. Large positive skew values, when coupled with large standard deviation values may produce unrealistic concentrations, flows, and loads if an extreme random number is generated. The first number generated by SELDM in a stochastic scenario could be a far outlier; trimming the number of storms will not correct such a problem. The skew value is more uncertain than the mean or standard deviation (Haan, 1977; Interagency Advisory Committee on Water Data, 1982; Helsel and Hirsch, 2002) and so adjustments to this value are appropriate if extreme outliers are generated.

The frequency factor equation may be used to calculate a skew value that will reduce the chance that such extreme values will be generated. To do this, take the logarithm of the upper bound, in log space, subtract the mean from the upper bound then divide by the standard deviation used in the analysis. In this example, the logarithm of $220,000 \mathrm{mg} / \mathrm{L}$ is about 5.34; subtracting the mean (1.74) and dividing by the standard deviation (0.953) of the logarithms yields a frequency factor value of about 3.78. Tables of log-Pearson type III frequency factors can be used to calculate the risk of exceeding this physical limit (Kirby, 1972; Interagency Advisory Committee on Water Data, 1982; Natural Resources Conservation Service, 1998; Granato, 2010). Given a skew value of about 0.9 and the frequency factor of 3.78, the risk of exceeding the solubility limit is about 3 storms per 1,000 on average. Simulating these data as a lognormal distribution (with a log-space skew of zero) reduces the risk of exceeding the solubility limit to about 1 storm per 10,000 on average. In this case, with the extreme-random number produced by stochastic realization 1 , the maximum generated value was 113,000 , which is still an extreme outlier, but is about one-half the solubility limit rather than 23 times the solubility limit (fig. 18). As noted, SELDM may yet produce such an extreme outlier, but the chance is much less with the reduced skew. To understand why very extreme outliers may not have very extreme percentiles, it is important to understand that the plotting positions written to the output files by SELDM are the sample statistics, calculated from the ranks of the output values rather than the population statistics, which are the percentiles based on the random number that is generated.
The difference between the realizations with the positive skew and the lognormal realization are evident in figure 18. In this case, the percentage of water-quality criterion exceedances for the log-Pearson type III realizations, which range from about 21.7 to 23.4 percent, are less than for the lognormal distribution, which is about 24.8 percent. Large negative skews may produce extremely low concentrations, but such concentrations (with the exception of constituents such as $\mathrm{pH}$, dissolved oxygen with lower-limit criteria) will not affect the number of water-quality exceedances and will not have such a drastic effect on storm or annual loads.

The probability for generating an extreme value also is affected by the standard deviation of the data (or logarithms of data). The standard deviation, which is calculated by using the mean and the square root of the number of samples minus one, also converges to the correct value more slowly than the mean with increasing sample size (Haan, 1977). Therefore, there also may be a substantial amount of uncertainty in the input standard deviation if small sample sizes are used to calculate this statistic. Lumping statistics from different sites may inflate the standard deviation if the selected sites represent different conditions; however, taking the median of standard deviations from different sites may provide a more robust estimate than for a single site. The standard deviation of the logarithms is the slope of a lognormal distribution on a graph with a logarithmic concentration axis and a probability scale axis. Comparison between the stochastic realizations with the Pennsylvania and Massachusetts statistics highlight the importance of the standard deviation for generating extreme values. The mean of the logarithms of the Pennsylvania data are higher than the Massachusetts values (about 1.92 versus 1.6), and the Pennsylvania data have a strong positive skew of 0.564 (table 7), which results in a maximum value of $11,000 \mathrm{mg} / \mathrm{L}$ (fig. 18) for the Pennsylvania data. Despite these factors, the maximum value of the Massachusetts data is about an order of magnitude higher than the Pennsylvania data because the standard deviation of the logarithms of the Pennsylvania data is about one-half the Massachusetts value. The maximum values generated with the Pennsylvania statistics are about an order of magnitude less than the maximum lognormal value generated with the mean and standard deviation of the Massachusetts values.

Chloride has a physicochemical solubility control because it is a dissolved constituent, but it may be more difficult to recognize upper limits for whole-water constituents because the solid phase of whole-water samples may contain high-concentration particulates. For example, Smith (2002) notes that large metal debris including bottle caps were found in an oil-grit separator which received runoff from a catch basin. He also found pieces of wire and pieces of lead-alloy wheel-weights in debris that had been transported by highway runoff through a catch basin to an oil-grit separator (Kirk Smith, U.S. Geological Survey, oral commun., 2013). 
Although potentially rare, a small particle of metal in a runoff sample could substantially increase the whole water concentration. For example, a piece of wire $1 \mathrm{~mm}$ long with a $0.4 \mathrm{~mm}$ diameter would add about $5,000 \mu \mathrm{g} / \mathrm{L}$ of copper to a runoff sample. A $1 \mathrm{~mm}$ piece of lead-alloy wheel weight would add $11,000 \mu \mathrm{g} / \mathrm{L}$ of lead to a runoff sample. Bleiwas (2006) estimates that about 3 percent of lead wheel weights (about 2,000 tons) are lost on United States roadways each year. Furthermore, extremely high concentrations of some whole-water constituents have been measured in receiving waters (Granato and others, 2009). For example, hyper-concentrations of suspended sediment greater than $400,000 \mathrm{mg} / \mathrm{L}$ may commonly occur in some arid areas, and the maximum concentration of 1,770,000 $\mathrm{mg} / \mathrm{L}$ in the USGS NWIS web database represents sediment transport from the Mount St. Helens explosion in 1980. Hyper-concentrated sediment concentrations may occur in highway and urban runoff if high flows scour out previously settled contents of BMP structures.

If an extremely high concentration or load is generated in a SELDM run, the analyst can copy an analysis several times and generate new master random seeds (on the Analysis options tab of the analysis form) (Granato, 2013). If the maximum values among runs vary substantially, then the analyst may need to examine the input statistics more carefully. For example, in this Wall Creek example, the maximum values generated in stochastic realizations 1 and 2 are more than 3 million $\mathrm{mg} / \mathrm{L}$ higher than the physicochemically unrealistic concentration of 432,000 mg/L of dissolved chloride in stochastic realization 3 (fig. 18).

In any case, the stochastic results shown in figure 18 highlight the need for careful selection of input statistics to represent conditions at the site of interest. Multiple sets of statistics were used in many of the analyses in this report to highlight differences in concentrations and the number of exceedances, which may occur given different sets of input statistics. Given the uncertainties in applying data from one site to another, it may be prudent to evaluate statistics from a number of sites and to use the median of the statistics from multiple representative sites.

\section{BMP Modeling}

If runoff mitigation measures are needed to achieve water-quality objectives, then SELDM can be used to simulate flow reduction, hydrograph extension, and concentration reduction by BMPs. The USGS is currently (2014) analyzing data from the international stormwater BMP database (http:// www.bmpdatabase.org/) to estimate performance statistics for different types of structural BMPs. When that study is complete, SELDM users will be able to select values for different types of BMPs based on statistics calculated from many available monitoring studies. However, SELDM can be used with or without those statistics to assess performance criteria needed to achieve water-quality goals. BMP design engineers can use such modeling results to assess the feasibility of meeting treatment objectives and if the treatment objectives are feasible for designing the BMPs that will meet such objectives.

In this example, the Unnamed Creek scenario with the total lead concentration statistics from the California US-50 highway site (table 6) was used to assess the potential effect of deterministic flow reductions on water-quality exceedances. In SELDM, BMP performance statistics are defined by a lower value, a lower bound of the most probable value, an upper bound of the most probable value, and a maximum value (Granato, 2013). The minimum value must be less than the maximum value. To simplify the analyses, the minimum value was 0.001 less than the nominal value, the most probable values were set equal to the nominal value, and the maximum was set equal to 0.001 more than the nominal value. Figure 19 shows the percentage of storms in which the hardness-dependent lead criterion is exceeded, when the criterion is calculated as a function of the stochastic random hardness concentration. The points on the graph represent the percentage of exceedances in relation to the geometric-mean, instream lead concentration. The upstream values and the downstream values are shown with no BMP and 10, 20, 50, $80,85,89,90$, and 99 percent flow reductions. As indicated on the graph, the BMP selected would have to achieve volume reductions that equal or exceed about 89 percent of the highway runoff volumes to meet this whole-water lead criterion. If these values are infeasible, then a combination of flow reduction, hydrograph extension, and concentration reduction may provide a solution. In some cases, BMPs may not be able to achieve water-quality targets and alternative mitigation strategies may be pursued. Alternatively, the highway-runoff or upstream stormflow concentration statistics that were selected may result in the number of exceedances shown in this example. In this case, selection of more representative values may indicate that BMP treatment will provide a feasible solution to the risk for exceedances. Such an approach may require on-site data collection to support use of lower values at high-risk sites. In such cases, decision makers may consider the cost of high-quality sampling efforts in relation to the long-term cost of installing and maintaining advanced BMP treatment technologies at this site and similar sites throughout the state. 


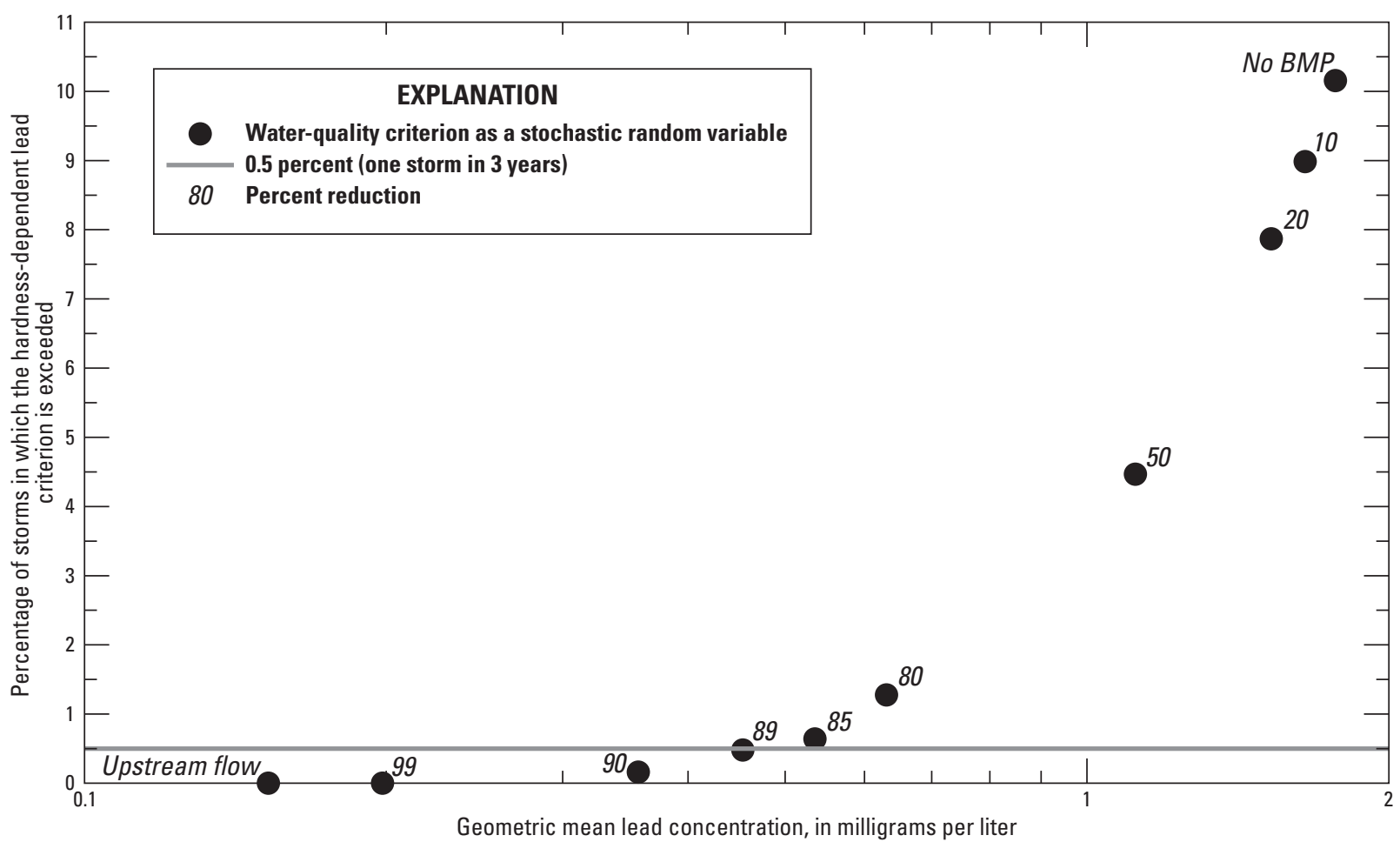

Figure 19. Example of total recoverable lead exceedances in relation to the geometric mean flow upstream and downstream of the highway discharge with various deterministic flow-reduction ratios indicating the potential effectiveness of infiltration without concentration reduction or flow extension for meeting the total lead criterion, not to exceed 1 event mean concentration during each 3 -year period. This is a 0.5 percent risk based on the average number of runoff generating events per year during the full simulation period.

\section{Non-Stochastic Background Concentrations}

ODOT requested information about the model and modeling methods that are being used by Washington Department of Transportation (WSDOT) to evaluate potential effects of their methods on potential exceedances on water quality (William Fletcher, Oregon Department of Transportation, oral commun., March 2, 2012). The WSDOT model, known as HI-RUN, uses an annual average flow or average monthly flows to represent streamflow and a single non-stochastic background concentration to represent the quality of receiving waters upstream of the highway-runoff outfall (Herrera Environmental Consultants, Inc., 2009, 2011a). The discussion in section "Dilution Factors" demonstrates that use of average annual flows, average monthly flows, or a low-flow statistic would not properly represent receiving-water flow rates during periods when highways are discharging to receiving waters. The literature establishes the need for stochastic modeling methods for upstream flow and concentrations in runoffquality risk assessment studies (Di Toro, 1984; Driscoll and others 1989; Schwartz and Naiman, 1999; Novotny, 2004;
Elshorbagy and others, 2007; Kuzin and Adams, 2010), but none of these studies were done explicitly with data from the northwestern United States. Additionally, the suitability of grab samples for simulating event-mean concentrations is in question. WSDOT commonly uses a single grab sample or a few grab samples collected during a storm event to derive the value input to HI-RUN as the background concentration (Alex Nguyen, Washington State Department of Transportation, oral commun., July 23, 2013). Grab samples, commonly are bottle-dip samples, which are not collected by using time-weighted averaging, flow-weighted averaging, depth or width integrated sampling, or isokinetic methods. Use of grab samples is not limited to WSDOT (Julie Wood, Charles River Watershed Association, and Mark Mattson, Massachusetts Department of Environmental Protection, oral commun., September 19, 2013) and is allowed in EPA NPDES sampling documents (for example, U.S. Environmental Protection Agency, 2009). An example analysis was done to demonstrate the uncertainty in use of grab samples and to evaluate use of a static background water-quality concentration for analysis of the risks for water-quality analyses. 
Although water-quality data for sites in the Northwest are ubiquitous, a long series of discrete paired concentration and flow values that could be used to evaluate differences between instantaneous grab samples and event-mean concentrations was not available. Therefore, samples from USGS streamgage (14138900) North Fork Bull Run River near Multnomah Falls, Oregon, were selected because a large dataset of 411 paired suspended-sediment and streamflow measurement data are available. A long record of instantaneous streamflow measurements also is available for this site. The North Fork Bull Run River upstream of the streamgage has a drainage area of $8.32 \mathrm{mi}^{2}$ and is completely undeveloped, so it should be representative of background water quality from small basins. The paired streamflow and suspended-sediment data were used to develop a two-segment water-quality transport curve (fig. 20). The data indicate that sediment concentrations vary randomly at low flow [less than about $\left.9.59\left(\mathrm{ft}^{3} / \mathrm{s}\right) / \mathrm{mi}^{2}\right)$ ] and increase substantially with increasing runoff flows. The unit-value streamflow measurements recorded on a one-half hour interval at the station during WY 2011 (October 1, 2010 to September 30,2011) were used to identify 46 runoff events during the water year. These streamflows were used with the water-quality transport curve, the standard deviation of the residuals, and a set of random normal variates to generate 3,280 simulated discrete samples that can be used to estimate the value of any individual grab sample collected during the year (fig. 20).

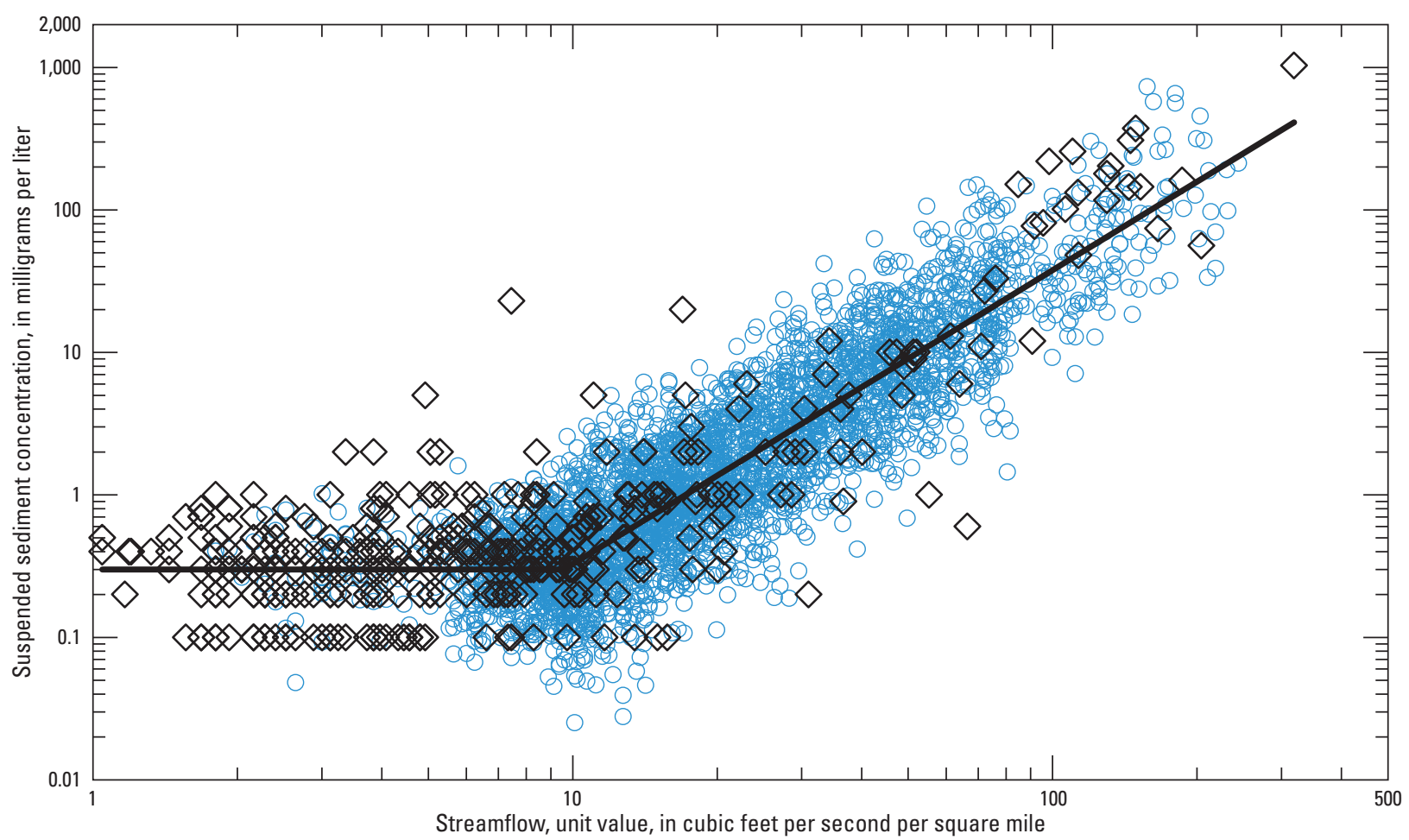

EXPLANATION

Measured suspended sediment concentrations
Two-segment water-quality transport curve
If $0<9.59$, then $C=10^{\left(-0.523+0.264 \times \mathrm{K}_{\mathrm{N}}\right)}$
else $\mathrm{C}=10^{\left(-2.547+2.062 \times \log (0)+0.357 \times \mathrm{K}_{\mathrm{N}}\right)}$
Stochastic concentration values (C)
generated from measured stormflow (0)

Figure 20. Measured suspended-sediment concentration, streamflow, two-segment water-quality transport curve, and stochastically generated suspended-sediment data calculated for each measured stormflow data point during water year October 1, 2010 to September 30, 2011. $Q$ is the measured streamflow, $C$ is the calculated suspended-sediment concentration, and $\mathrm{K}_{\mathrm{N}}$ is a normal random variate. 
These discrete sample concentrations were multiplied by the instantaneous flow, and the time between measurements to calculate flow-weighted EMCs for each of the 46 identified runoff events in WY 2011. The distributions of grab-sample concentrations and EMCs for suspended sediment are shown in figure 21A. Sediment concentrations in the simulated grab samples range from about 0.025 to $732 \mathrm{mg} / \mathrm{L}$ with an average of 8.72, a standard deviation of 33.4, and a geometric mean of $1.55 \mathrm{mg} / \mathrm{L}$. Sediment concentrations in the simulated EMC samples range from about 0.34 to $120 \mathrm{mg} / \mathrm{L}$ with an average of 7.32, a standard deviation of 19.1 and a geometric mean of $1.86 \mathrm{mg} / \mathrm{L}$. If only one grab or EMC sample is collected, the chance that this value would be within the 95-percent confidence limit of the geometric mean EMC (1.19-2.91 mg/L) is only 17.4 percent for the EMC and 16.9 percent for the grab samples. Although the percentages of samples within the 95- percent confidence limit are similar, there is a much higher risk for selecting a non-representative grab sample. The root mean square error (RMSE) for the grab samples is $33.5 \mathrm{mg} / \mathrm{L}$, whereas the RMSE for the EMC samples is only $18.9 \mathrm{mg} / \mathrm{L}$. Therefore, this analysis shows that collection of one or a few grab sample(s) is not likely to produce background concentrations that represent mean values, and that the potential error in estimates made using such data may be large. Furthermore, in a model like HI-RUN, use of a single deterministic input value may facilitate selection and use of a single favorable sample result.

Estimates of total copper concentrations were made by using both the discrete and EMC sediment concentrations and the average of copper concentrations in fine streambed sediment from sites in the Willamette Basin with impervious areas less than 10 percent (Rice, 1999). The geometric mean sediment concentration from 22 of these streambed sediment samples was 0.05195 micrograms of copper per milligram of sediment with values ranging from 0.023 to 0.12 micrograms of copper per milligram of sediment. Copper values in these sediment samples were not correlated to the impervious fraction of the basin upstream of the sampling point. Total copper concentrations in the simulated grab samples range from about 0.0013 to $38 \mu \mathrm{g} / \mathrm{L}$ with an average of 0.45 , a standard deviation of 1.74 , and a geometric mean of $0.081 \mu \mathrm{g} / \mathrm{L}$ (fig. 21B). Total copper concentrations in the simulated EMC samples ranged from about 0.018 to $6.25 \mu \mathrm{g} / \mathrm{L}$ with an average of 0.38 , a standard deviation of 0.994 , and a geometric mean of $0.097 \mu \mathrm{g} / \mathrm{L}$. As with the sediment samples, there is a low probability (about 17 percent) that any one measured concentration will fall within the 95-percent confidence interval for the geometric mean EMC value and the RMSE for the grab samples is about twice that for the EMC values. This analysis of copper concentrations, which is based on the sediment values, also indicates that collection of one or a few grab sample(s) is not likely to produce background concentrations that represent mean values and that the potential error in estimates made using such data may be large.
Copper concentrations were estimated to compare the results of analyses made by using the WSDOT HI-RUN method (use of stochastic highway-runoff concentrations with a single background concentration) with the results of an analysis made by using the SELDM method (use of stochastic highway-runoff and background water-quality concentrations). These simulations were made to assess the effect of inputs on the simulated risk for water-quality exceedances in the receiving stream. These simulations were done by using the fully stochastic stormflow values defined for the Miller Creek scenarios used throughout this report (tables 2, $\underline{3}$ and $\underline{4}$ ). These input parameters resulted in a stochastic dataset with 1,863 simulated runoff events over 28 annual-load accounting years. Highway-runoff concentrations were simulated by using statistics from the HRDB site 121, (MA I-495) in Massachusetts (table 7). About 95 percent of the highwayrunoff concentrations exceed the hardness-dependent criterion for total copper. SELDM was run in stochastic mode by using 14 selected values within the range of EMCs as the average of logarithms while holding constant the standard deviation and skew of the sample of 46 EMCs. SELDM was run in deterministic mode by using 20 selected values within the range of grab samples as the average of logarithms while holding the standard deviation and skew equal to zero to prevent any random variation in upstream copper concentrations. This was done to simulate calculations done by HI-RUN, which uses a constant upstream concentration. The results of each analysis were compared to copper criteria calculated by using stochastic hardness values and to a copper criterion calculated by using the average hardness value for the upstream or downstream receiving water. The results of these analyses are shown in figure 22.

Comparison of deterministic and stochastic results for the upstream water-quality values demonstrates the type of artifacts that can be introduced by using a single upstream value (fig. 22A). If the deterministic upstream concentration is used with the average hardness criterion, there will be no upstream exceedances unless the upstream value is greater than the criterion, then every storm will exceed the criteria. If the upstream hardness value (and therefore the copper criterion) is stochastic, there will be more variation in upstream exceedances for the deterministic copper scenarios, because the exceedance percentages will go from zero (when the upstream value is below the smallest stochastic hardness criteria) to 100 percent (when the upstream value is above the largest stochastic hardness criteria). If the upstream copper concentrations are simulated as a stochastic variable, the percentages of exceedances change more gradually with increasing average concentration. In comparison to the deterministic approach, stochastic copper results have a higher rate of exceedances with small average values because of the occurrence of larger random values. Similarly, stochastic copper results with large average values have a lower rate of exceedances than the deterministic approach because of the occurrence of smaller random values. 


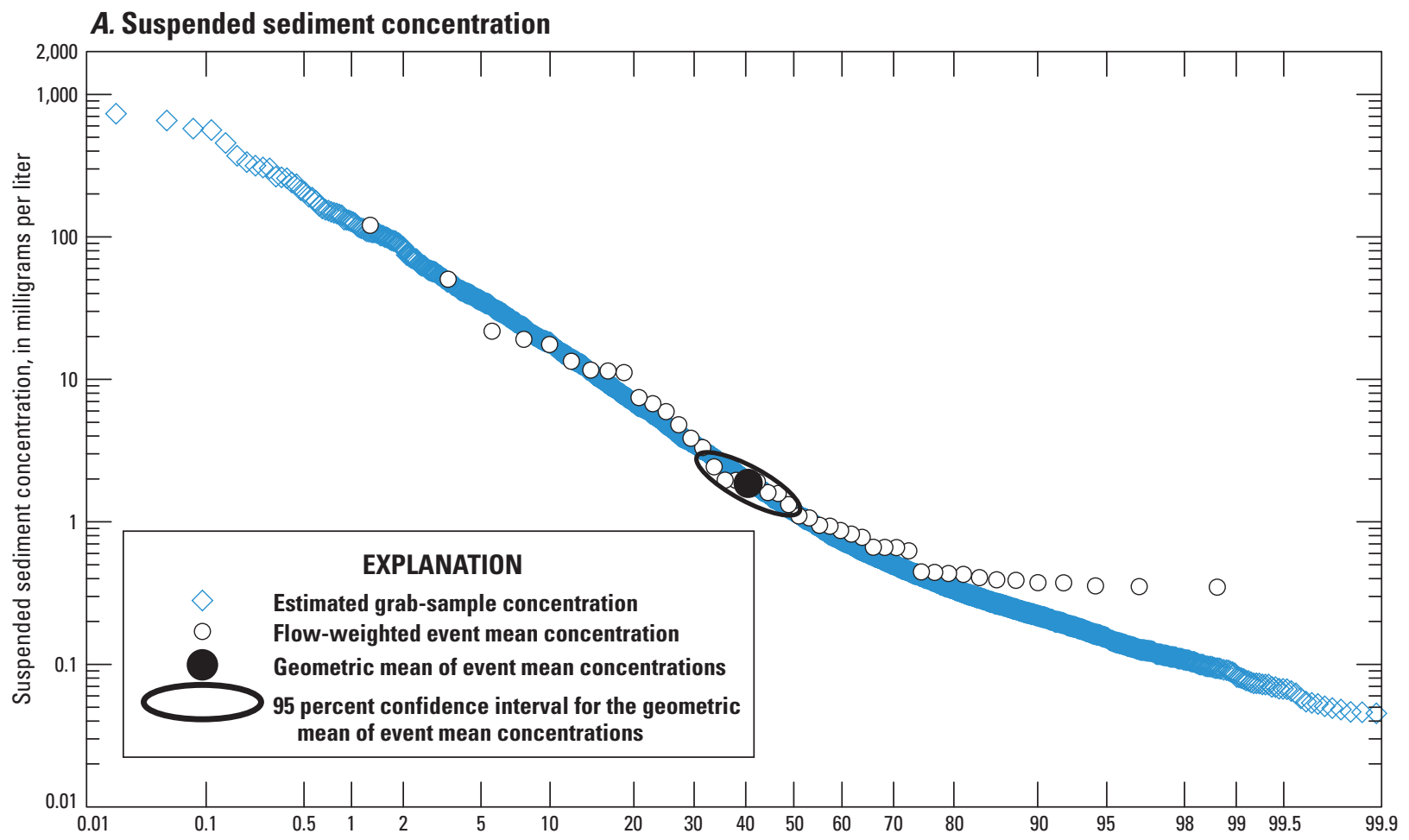

B. Total copper concentration

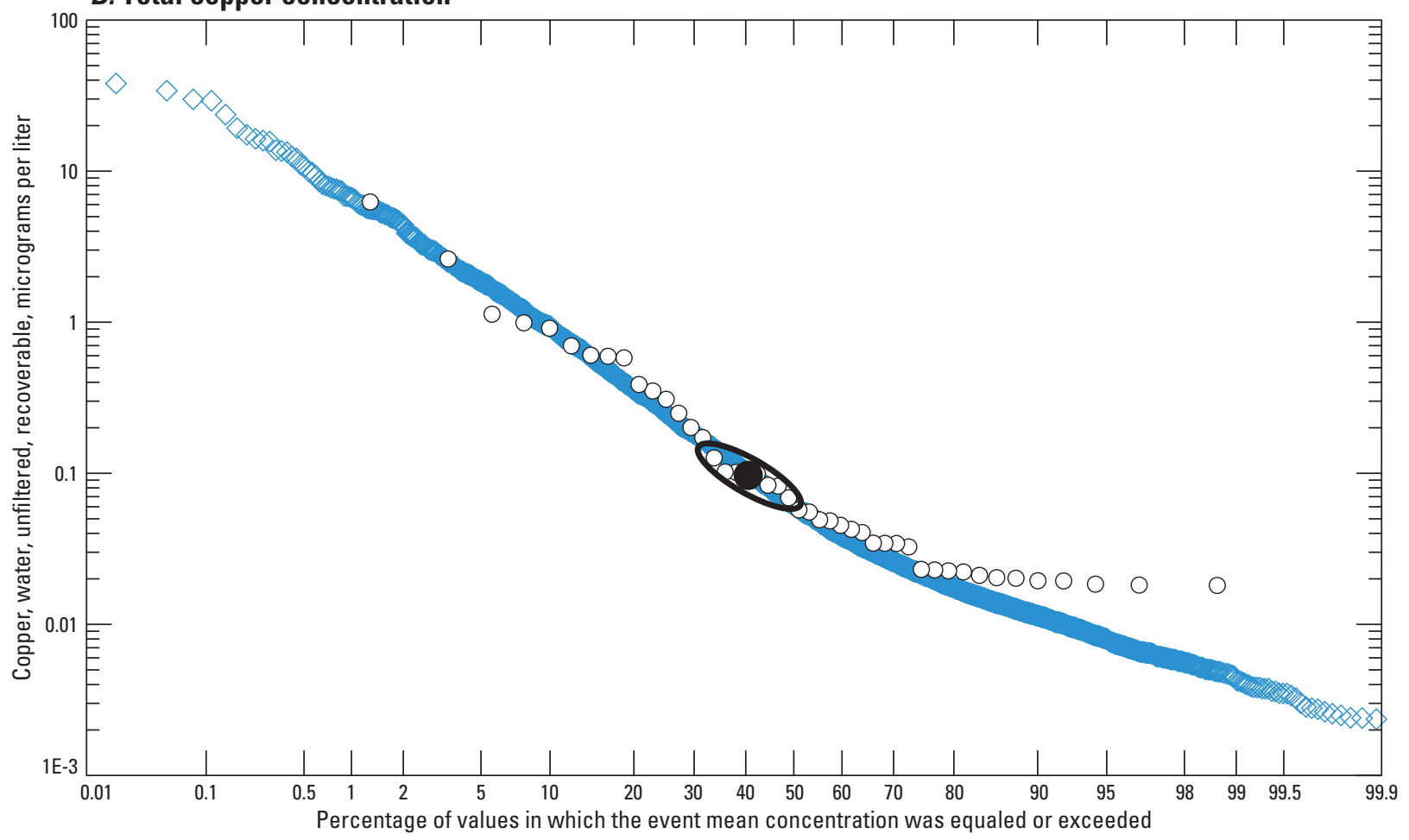

Figure 21. Suspended-sediment $(A)$ and total copper $(B)$ concentrations estimated by using the transportcurve sediment concentrations and the geometric mean concentration of copper (52 micrograms per gram) in fine streambed sediment from sites in Willamette Basin, Oregon, with impervious areas less than 10 percent (Rice, 1999). 

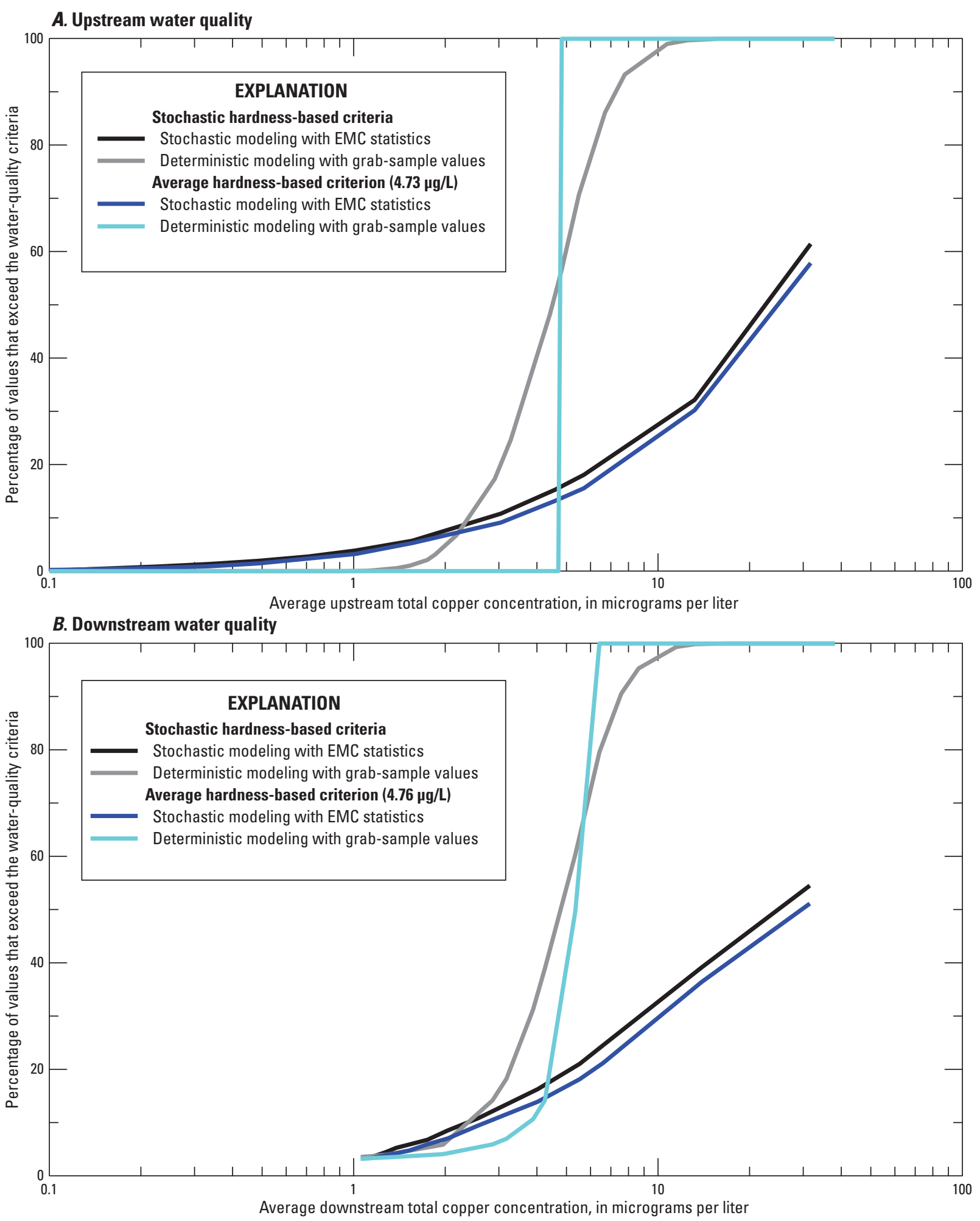

Figure 22. Percentage of water-quality exceedances as a function of the average concentration, modeling method, and type of criteria applied for $(A)$ the upstream and $(B)$ the downstream water quality. EMC is event mean concentration. 
Comparison of deterministic and stochastic results for the downstream water-quality values shows that the deterministic methods still do not produce representative results even though these effects are somewhat obscured by the random highway inputs (fig. 22B). In each set of downstream scenarios, the rate of exceedances starts at a little higher than 1 percent, which reflects the dilution of highway runoff. As with the upstream case, the deterministic upstream copper concentrations and the average hardness criterion do not produce a marked increase in exceedances until the upstream copper value approaches the criterion. Use of the stochastic criteria with the deterministic copper concentrations improves the results, but does not mimic the pattern that would occur with natural upstream variation. The scenarios, which use the stochastic upstream concentrations also increase with increasing concentration, but do so at a slower rate because of the variations greater than and less than the mean value. As with the upstream scenarios, use of the average-hardness criterion rather than a stochastic-hardness criterion results in a small downward bias in the percentage of exceedances; this bias is probably within the uncertainty of the input copper statistics.

\section{Example Analyses}

Example analyses were done for six study sites to illustrate the risk-based information that SELDM will provide. Stochastic populations of flow volumes, concentrations, and loads of selected constituents were simulated for each basin. Although the simulated flow output is based on measured precipitation and streamflow data from the region or vicinity of the study sites, the simulated chemical output is hypothetical because surrogate highway and upstream water-quality datasets were used for all study sites.

The potential effect of highway runoff on the quality of downstream stormflows is a function of the ratio of highway area to upstream area. The drainage areas of the selected sites, which range from 0.16 to $6.56 \mathrm{mi}^{2}$ (table 2) are relatively small in relation to many stream crossings in Oregon. For example, among the 348 streamgages included in appendix B, the minimum drainage area is $5.4 \mathrm{mi}^{2}$ and about 98 percent of these streamgages have drainage areas greater than $10 \mathrm{mi}^{2}$. Similarly, among the 353 Oregon streamgages in the USGS ecological-streamflow database (Falcone and others, 2010), the minimum basin size is $0.66 \mathrm{mi}^{2}$, about 99.4 percent are greater than $1 \mathrm{mi}^{2}$, and about 92.6 percent are greater than $10 \mathrm{mi}^{2}$. Among the 243 USGS water-quality monitoring sites in Oregon documented in the Surface Water Quality Data Miner (SWQDM) database (Granato and others, 2009), the minimum basin size is $0.27 \mathrm{mi}^{2}$, about 97.5 percent are greater than $1 \mathrm{mi}^{2}$, and about 81 percent are greater than $10 \mathrm{mi}^{2}$. Many of the monitoring sites in all three of these datasets are located at or near road crossings. The results of these analyses may represent conditions that may therefore occur in small basins in each ecoregion that are likely to be affected by runoff, but these results should not be extrapolated to many highway crossings throughout the State.

\section{Miller Creek at U.S. Route 30, near Linnton, Oregon}

In comparison to most of the other sites selected for analysis in this study, Miller Creek (table 2) has a low ratio of highway drainage area to upstream drainage area (about 0.5 percent) and the impervious fraction is 0.0219 (table 2). As a result, simulated highway flow volumes were minimal in comparison to upstream flow volumes (fig. 23). The average highway-runoff volume was $5,110 \mathrm{ft}^{3}$ and the average concurrent upstream runoff, upstream stormflow, and downstream stormflow volumes were about 179,000, 361,000, and $366,000 \mathrm{ft}^{3}$, respectively. On average, the upstream runoff comprised about 62 percent of the upstream stormflow during the period concurrent to the highway runoff. This ratio ranged from about 0.25 to 100 percent among the 1,863 simulated storm events. On average, the highway runoff comprised about 2.6 percent of the downstream stormflow during the period concurrent to the highway runoff; this ratio ranged from about 0.004 to 71 percent. The concurrent period is presented because this period represents the time in which the highway is affecting downstream concentrations near the point of discharge (Granato, 2013). Because a highway catchment commonly is smaller, shorter, and more impervious than the upstream basin, the highway runoff period commonly is shorter than the upstream storm runoff period for any given event. Therefore, the concurrent period is used to calculate downstream concentrations and loads for the mass-balance analysis at the Miller Creek site and all other sites (fig. 1).

Concentrations of total recoverable lead were simulated for the Miller Creek site to provide comparison to the Unnamed Creek scenarios used to demonstrate the hardness-dependent criteria and BMP analysis examples. As indicated in those examples, the total lead concentrations from the Pennsylvania and Wisconsin datasets are not representative of current (2014) conditions in relatively undeveloped basins in Oregon. Total lead data statistics from California HRDB sites 74 (CA I-5) and 84 (US-50) were used as surrogate highway water-quality statistics for the Miller Creek site (table 7). The Willamette Valley ecoregion non-urban water-quality statistics (table 9) were used to simulate upstream concentrations. If statistics from California sites CA I-5 and US-50 are used to simulate highway runoff quality discharging from U.S. Route 30 to Miller Creek, then the geometric mean lead concentrations downstream of the outfall for the two sites would be 0.22 and $0.45 \mu \mathrm{g} / \mathrm{L}$ (fig. 24), respectively. If an average total hardness value of $24.6 \mathrm{mg} / \mathrm{L}$ 


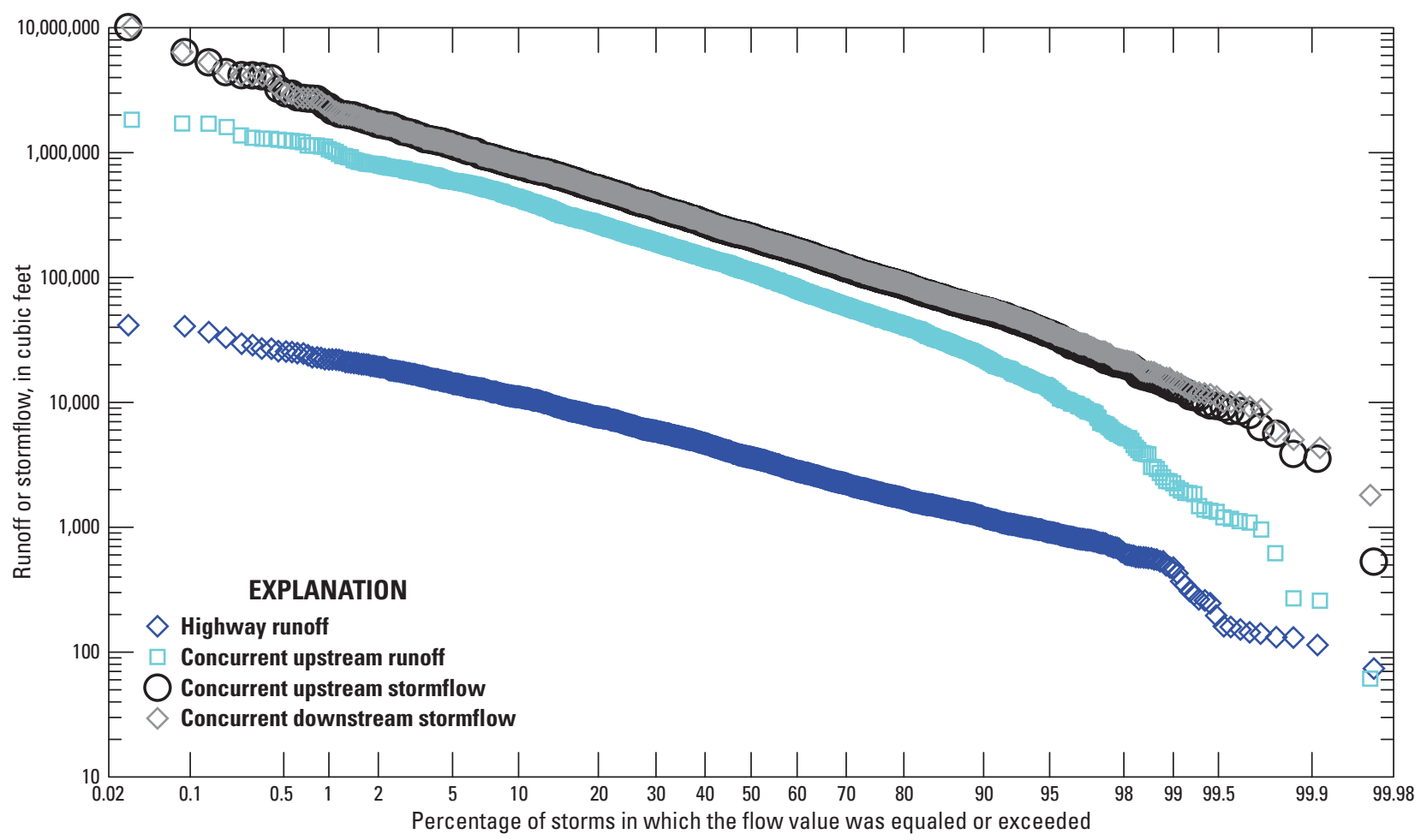

Figure 23. Example analyses of stormflows including highway-runoff volumes and the concurrent upstream runoff, upstream stormflow, and downstream stormflow volumes in Miller Creek, at U.S. Route 30, near Linnton, Oregon.

is used to calculate a total recoverable criterion for lead then the value would be $13.7 \mu \mathrm{g} / \mathrm{L}$ (fig. 13) and the percentage of downstream exceedances for CA I-5 and US-50 would be 0 and 0.11 percent, respectively (fig. 24). If the stochastic total recoverable criteria for lead (shown as the "stochastic hardness dependent standard" in fig. 24) are used, then the percentage of downstream exceedances for CA I-5 and US-50 would be 0 and 0.27 percent, respectively. Although it does not appear that any of the downstream EMCs exceed the stochastic criteria in figure 24, each set of concentrations is ranked independently. As a result, some of the high lead concentrations are paired with some of the low criteria values. (This is illustrated in fig. 34 in Granato [2013]). On average, runoff with EMCs calculated with statistics from the SR-50 site, using stochastic hardnessdependent criteria, is expected to exceed the criterion in one storm every 5.6 years, which is almost twice the allowable recurrence interval in the ODEQ standards (Oregon Department of Environmental Quality, 2013). In this case, the percentage of exceedances for the SR-50 data calculated by using the average total hardness value of about $24.6 \mathrm{mg} / \mathrm{L}$ would be about 0.11 percent (or about one storm every 14 years).
Storm loads, which are the product of concentration and flow, vary by about 5 orders of magnitude in this scenario (fig. 25). Almost all upstream stormflow loads are greater than the highway runoff loads simulated using the CA I-5 data. However, about 70 percent of the US-50 simulated highway runoff loads exceed the upstream stormflow loads. As with the concentrations, however, the percentile values in figure 25 are not paired with the upstream or downstream stormflow loads for any given storm. For example, a high percentile highway runoff load may be paired with a low percentile upstream stormflow load, which may result in a mid-percentile downstream stormflow load.

SELDM also calculates total annual flows and loads for each highway-runoff constituent. Total annual loads with the CA I-5 statistics ranged from 0.051 to $0.295 \mathrm{lb}$ with an average value of $0.098 \mathrm{lbs}$ of lead during the simulated 28 -year period. Total annual loads with the US-50 statistics ranged from 0.303 to $1.35 \mathrm{lb}$ with an average value of $0.55 \mathrm{lb}$ of lead. 


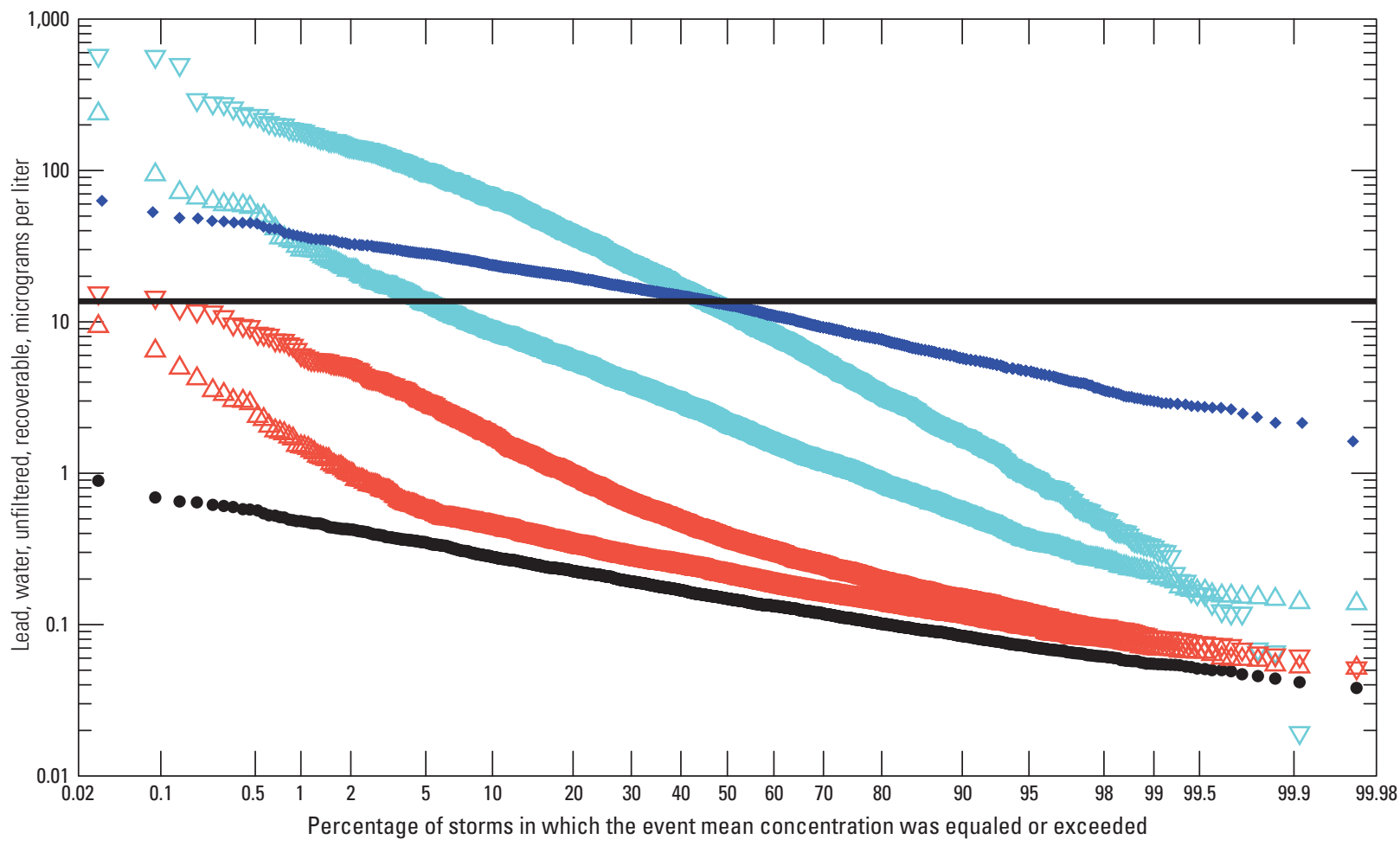

\section{EXPLANATION}

Highway runoff, HRDB site 74, California Interstate 5

Highway runoff, HRDB site 84, California U.S. Route 50

- Upstream stormflow, Willamette Valley ecoregion non-urban

$\triangle$ Downstream stormflow by using HRDB site 74, California Interstate 5

$\nabla \quad$ Downstream stormflow by using HRDB site 84, California U.S. Route 50

Average hardness dependent standard, hardness $=24.59 \mathrm{mg} / \mathrm{L}$

- Stochastic hardness dependent standard

Figure 24. Example analyses of the concentrations of total recoverable lead in highway runoff, upstream stormflows, and downstream stormflows concurrent to the period of highway runoff in Miller Creek at U.S. Route 30, near Linnton, Oregon. Concentrations are ranked independently. In most cases, the percentiles for a storm do not match. Stochastic exceedances occur if the concentration for a given storm exceeds the stochastic standard generated for that storm by using the total-hardness transport curve. HRDB is Highway-Runoff Database. 


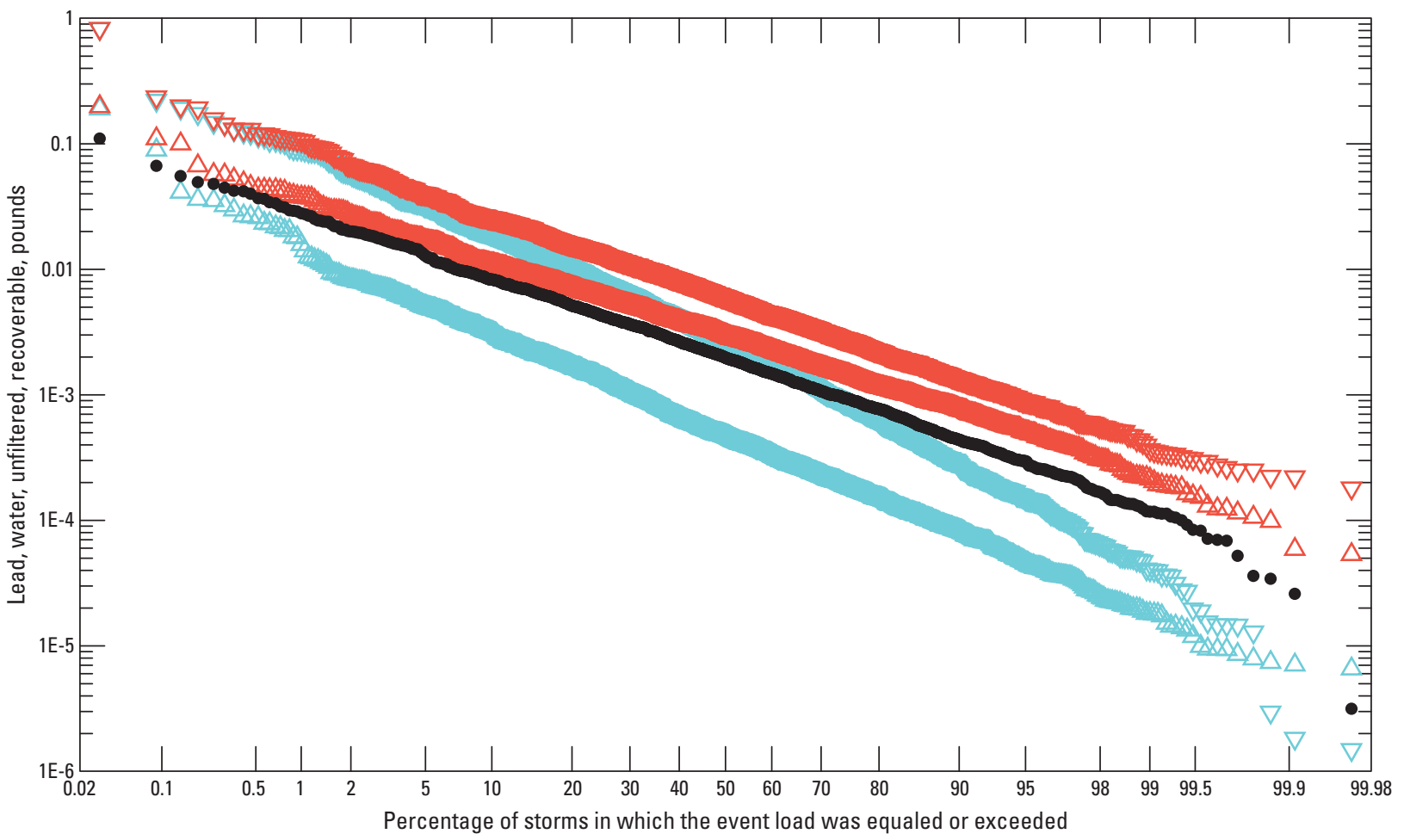

\section{EXPLANATION}

$\triangle$ Highway runoff, HRDB site 74, California Interstate 5

$\nabla$ Highway runoff, HRDB site 84, California U.S. Route 50

- Upstream stormflow, Willamette Valley ecoregion non-urban

$\triangle$ Downstream stormflow by using HRDB site 74, California Interstate 5

$\nabla$ Downstream stormflow by using HRDB site 84, California U.S. Route 50

Figure 25. Example analyses of the loads of total recoverable lead in highway runoff, upstream stormflows, and downstream stormflows concurrent to the period of highway runoff in Miller Creek at U.S. Route 30, near Linnton, Oregon. HRDB is Highway-Runoff Database. 


\section{Unnamed Creek at U.S. Route 30, at Portland, Oregon}

Among all sites selected for analysis in this study, Unnamed Creek (table 2) has the highest ratio of highway drainage area to upstream drainage area (about 5 percent) and the impervious fraction is 0.008 (table 2). As a result, simulated highway flow volumes were a substantial portion of downstream stormflow volumes (fig. 26). The average highway runoff volume was about $8,310 \mathrm{ft}^{3}$ and the average concurrent upstream runoff volume, upstream stormflow, and downstream stormflow volumes were about 25,500, 57,800 , and $66,100 \mathrm{ft}^{3}$, respectively. On average, the upstream stormflow comprised about 79 percent of the downstream stormflow during the period concurrent to the highway runoff; this ratio ranged from 2 to 99.9 percent among the 1,880 simulated storm events. On average, the highway runoff comprised about 21 percent of the downstream stormflow during the period concurrent to the highway runoff; this ratio ranged from about 0.0006 to 98 percent.

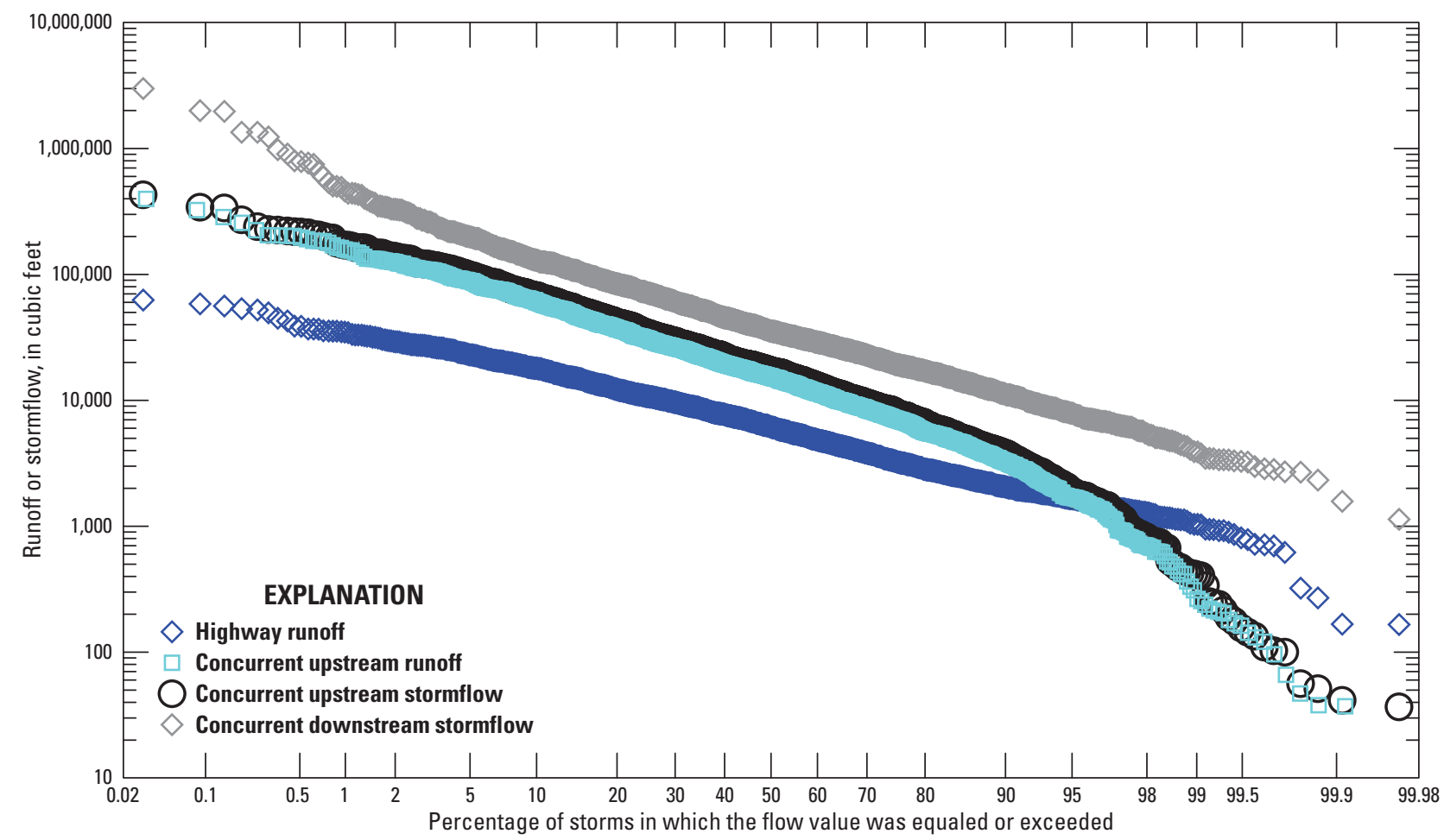

Figure 26. Example analyses of stormflows including highway runoff volumes and the concurrent upstream runoff, upstream stormflow, and downstream stormflow volumes in Unnamed Creek at U.S. Route 30, at Portland, Oregon. 
Concentrations of total recoverable nickel were simulated for the Unnamed Creek site. Total nickel statistics from California HRDB site 84 (US-50) and Massachusetts HRDB site 129 (MA I-195) were used in this analysis (table 7). The Willamette Valley ecoregion non-urban water-quality statistics (table 9) were used to simulate upstream concentrations. If statistics from US-50 and MI-195 are used to simulate highway runoff quality discharging to Unnamed Creek, then the geometric mean nickel concentrations downstream of the outfall would be about 2.46 and $1.12 \mu \mathrm{g} / \mathrm{L}$, respectively. If an average total hardness value of $26.2 \mathrm{mg} / \mathrm{L}$ is used to calculate a total recoverable criterion for nickel, then the criterion would be about $151 \mu \mathrm{g} / \mathrm{L}$ and the percentage of downstream exceedances would be 0 percent for both sites (fig. 27). If the stochastic total recoverable criteria for nickel (shown as the "stochastic hardness dependent standard" in figure 27) are used, then the percentage of downstream exceedances also would be 0 percent for both sites.

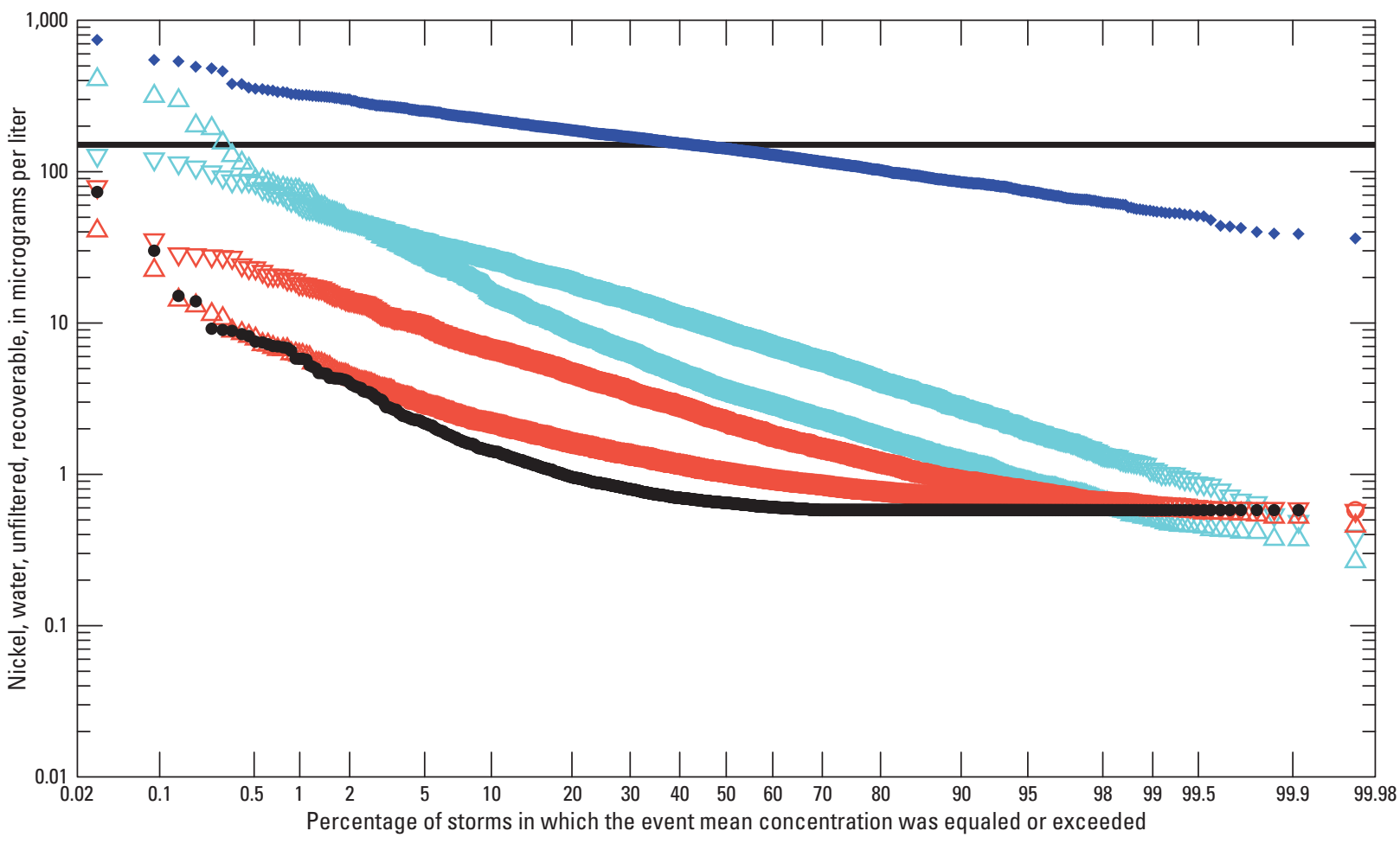

\section{EXPLANATION}

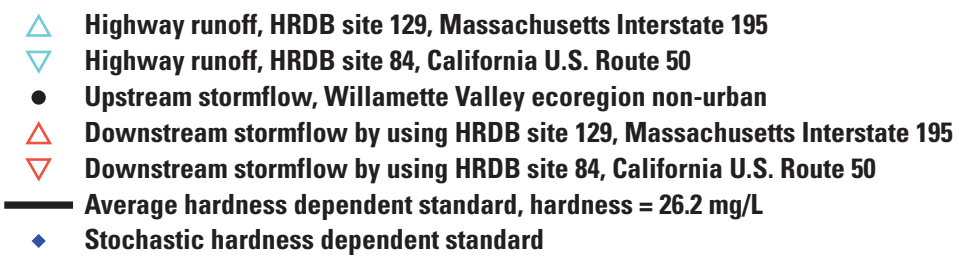

Figure 27. Example analyses of the concentrations of total recoverable nickel in highway runoff, upstream stormflows, and downstream stormflows concurrent to the period of highway runoff in Unnamed Creek at U.S. Route 30, at Portland, Oregon. Concentrations are ranked independently. In most cases, the percentiles for a storm do not match. Stochastic exceedances occur if the concentration for a given storm exceeds the stochastic standard generated for that storm by using the total-hardness transport curve. HRDB is Highway-Runoff Database. 
Storm loads vary by about 3 orders of magnitude in this scenario (fig. 28). About 75 percent of the simulated US-50 storm loads (ig. 28, Highway runoff HRDB site 84, US-50) exceed the simulated upstream storm load values. About 33 percent of the simulated MA I-195 storm loads (fig. 28, Highway runoff HRDB site 129, MA I-195) exceed the simulated upstream storm loads (fig. 28, Upstream stormflow, Willamette Valley ecoregion non-urban). As with the concentrations, however, the percentile values in figure 28 are not paired with the upstream or downstream loads for any given storm.

Total annual nickel loads with the US-50 statistics ranged from 0.287 to $0.694 \mathrm{lb}$ with an average value of $0.439 \mathrm{lb}$ of nickel during the simulated 28-year period. Total annual loads with the MA I-195 statistics ranged from 0.066 to $0.129 \mathrm{lb}$ with an average value of $0.093 \mathrm{lb}$ of nickel.

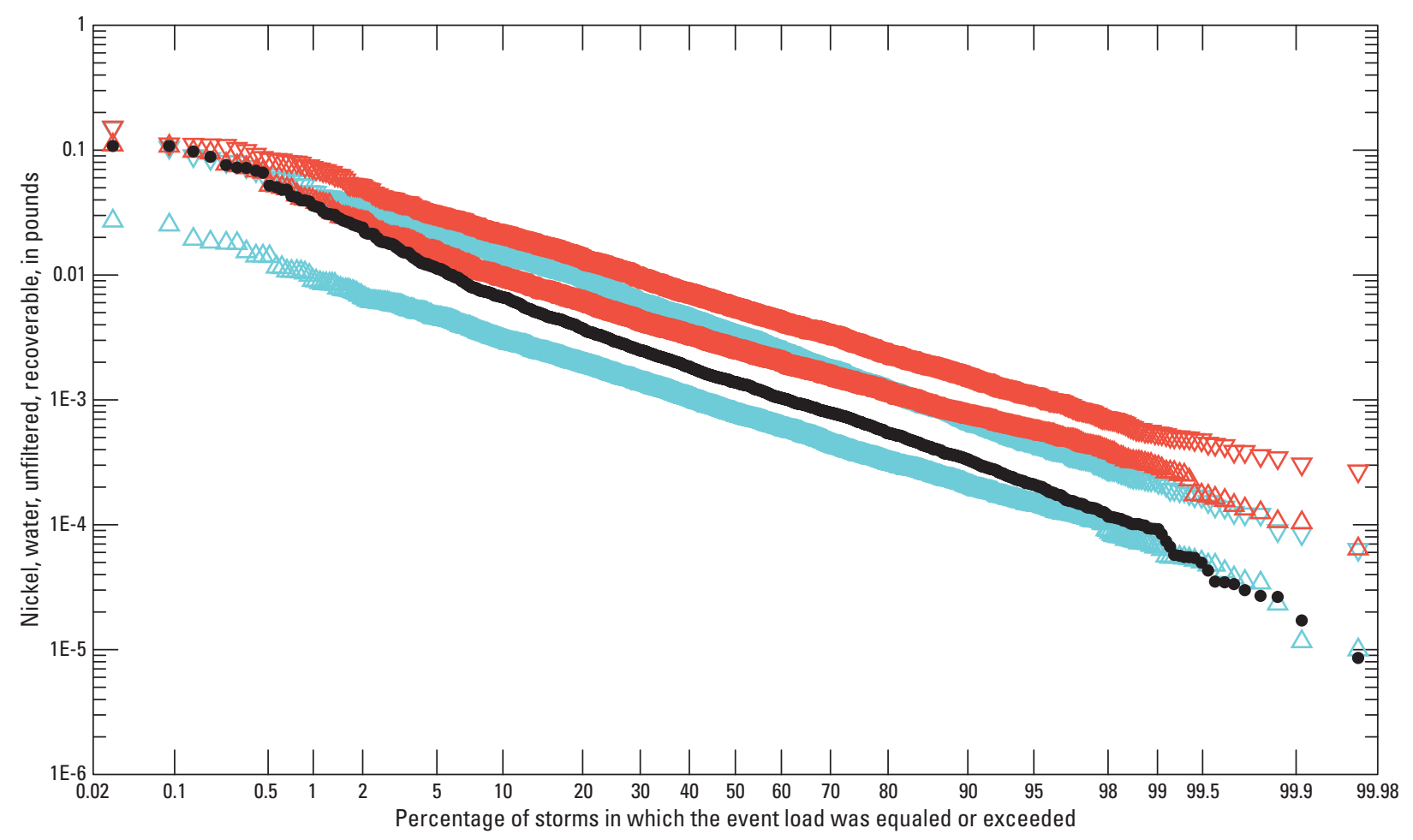

EXPLANATION

$\triangle$ Highway runoff, HRDB site 129, Massachusetts Interstate 195

$\nabla$ Highway runoff, HRDB site 84, California U.S. Route 50

- Upstream stormflow, Willamette Valley ecoregion non-urban

$\triangle$ Downstream stormflow by using HRDB site 129, Massachusetts Interstate 195

$\nabla$ Downstream stormflow by using HRDB site 84, California U.S. Route 50

Figure 28. Example analyses of the loads of total recoverable nickel in highway runoff, upstream stormflows, and downstream stormflows concurrent to the period of highway runoff in Unnamed Creek at U.S. Route 30, at Portland, Oregon. HRDB is Highway-Runoff Database. 


\section{Tryon Creek at Interstate 5, at Portland, Oregon}

The Tryon Creek at Interstate 5 study site also has a high ratio of highway catchment size to upstream basin size (almost 3 percent) in comparison to the other study sites (table 2). However, because the upstream basin is urbanized with a total impervious surface area of approximately 45 percent, the upstream basin storm runoff duration was shorter than less urbanized upstream basins, which reduced the highway runoff proportion of the downstream flow (fig. 29). The average highway runoff volume was about $19,350 \mathrm{ft}^{3}$ and the average concurrent upstream runoff volume, upstream stormflow, and downstream stormflow volumes were about 185,000, 227,000, and $247,000 \mathrm{ft}^{3}$, respectively. On average, the upstream runoff comprised about 83 percent of the upstream stormflow during the period concurrent to the highway runoff; this ratio ranged from 3 to 99.9 percent among the 1,909 simulated storm events. On average, the highway runoff comprised about 8.7 percent of the downstream stormflow during the period concurrent to the highway runoff; this ratio ranged from about 0.25 to 40 percent.

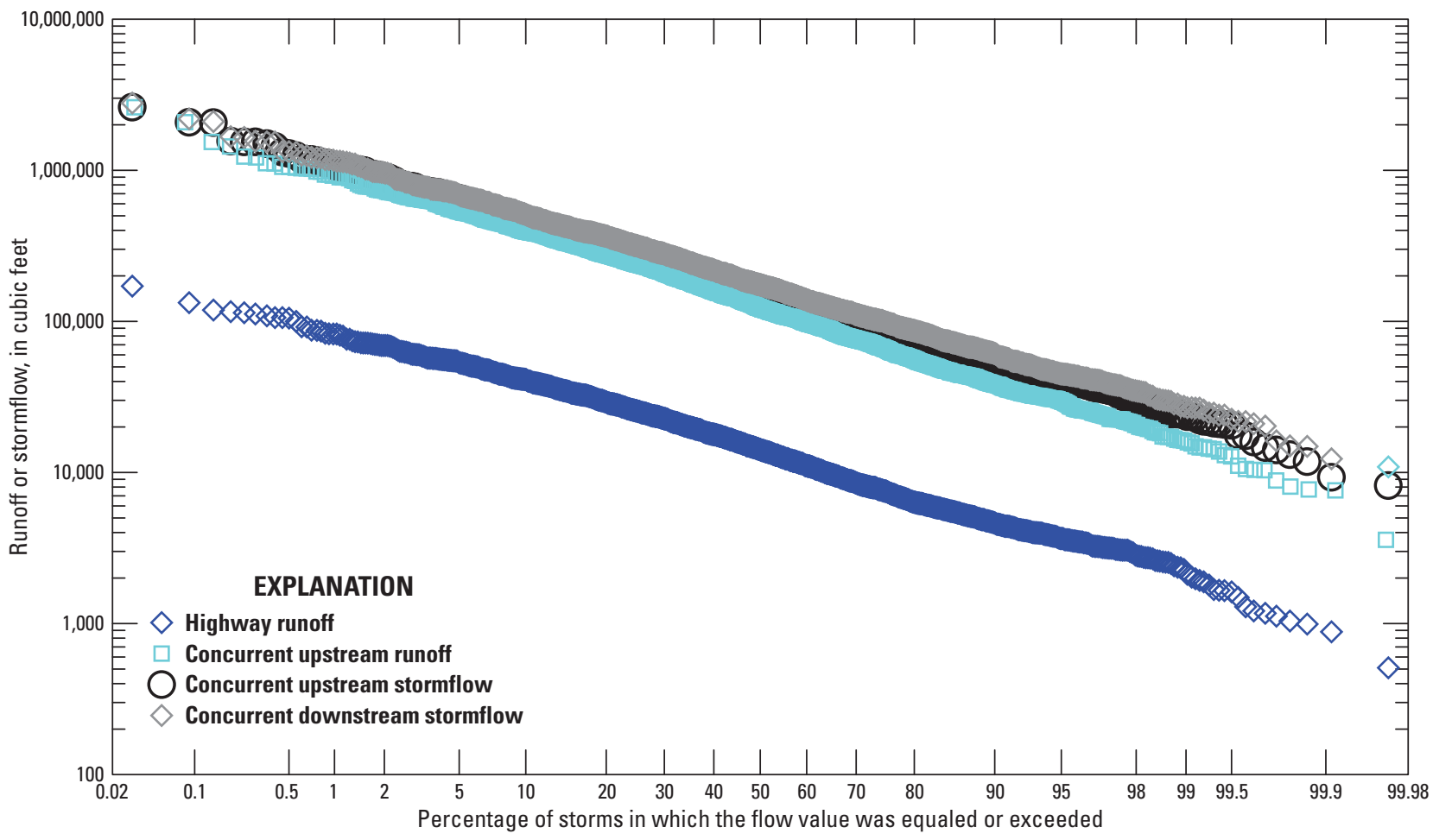

Figure 29. Example analyses of stormflows including highway runoff volumes and the concurrent upstream runoff, upstream stormflow, and downstream stormflow volumes in Tryon Creek at Interstate 5, at Portland, Oregon. 
To simulate upstream basin copper concentrations and loads for this study site, it was possible to create a transport curve using copper data monitored at a nearby USGS streamgage on Fanno Creek at Portland, Oregon (14206900) (tables 8 and $\underline{10}$ ). Like Tryon Creek at Interstate 5, Fanno Creek is also heavily urbanized. If an average upstream total hardness value of $22 \mathrm{mg} / \mathrm{L}$ is used to calculate a total recoverable criterion for copper then the criterion value would be about $4.25 \mu \mathrm{g} / \mathrm{L}$ and the percentage of upstream exceedances would be about 95 percent. If the stochastic total recoverable criteria for copper based on the Willamette Valley ecoregion transport curve for total hardness (fig. 30, Stochastic hardness dependent standard) are used, then the percentage of upstream exceedances would be about 86 percent. If the Pennsylvania HRDB site 11 (PA I-84) or Wisconsin
HRDB site 91 (WI I-894) total copper statistics (table 7) are used, then the percentage of highway runoff exceedances, using an average-hardness criterion, would be about 96.6 and 99.9 percent, respectively (fig. 30). The percentage of the associated downstream exceedances with the PA I-84 copper statistics would be about 94.1 percent if the stochastic criteria are used and about 98.8 percent if the average-hardness criterion is used. The percentage of the associated downstream exceedances with the WI I-894 copper statistics would be about 98.2 percent if the stochastic criteria are used and about 99.9 percent if the average-hardness criterion is used. Because the upstream concentrations and percentages of exceedances are so high, use of a structural BMP to reduce copper concentrations in runoff from the highway at this site would be ineffective for achieving the 3-year criteria downstream of the highway.

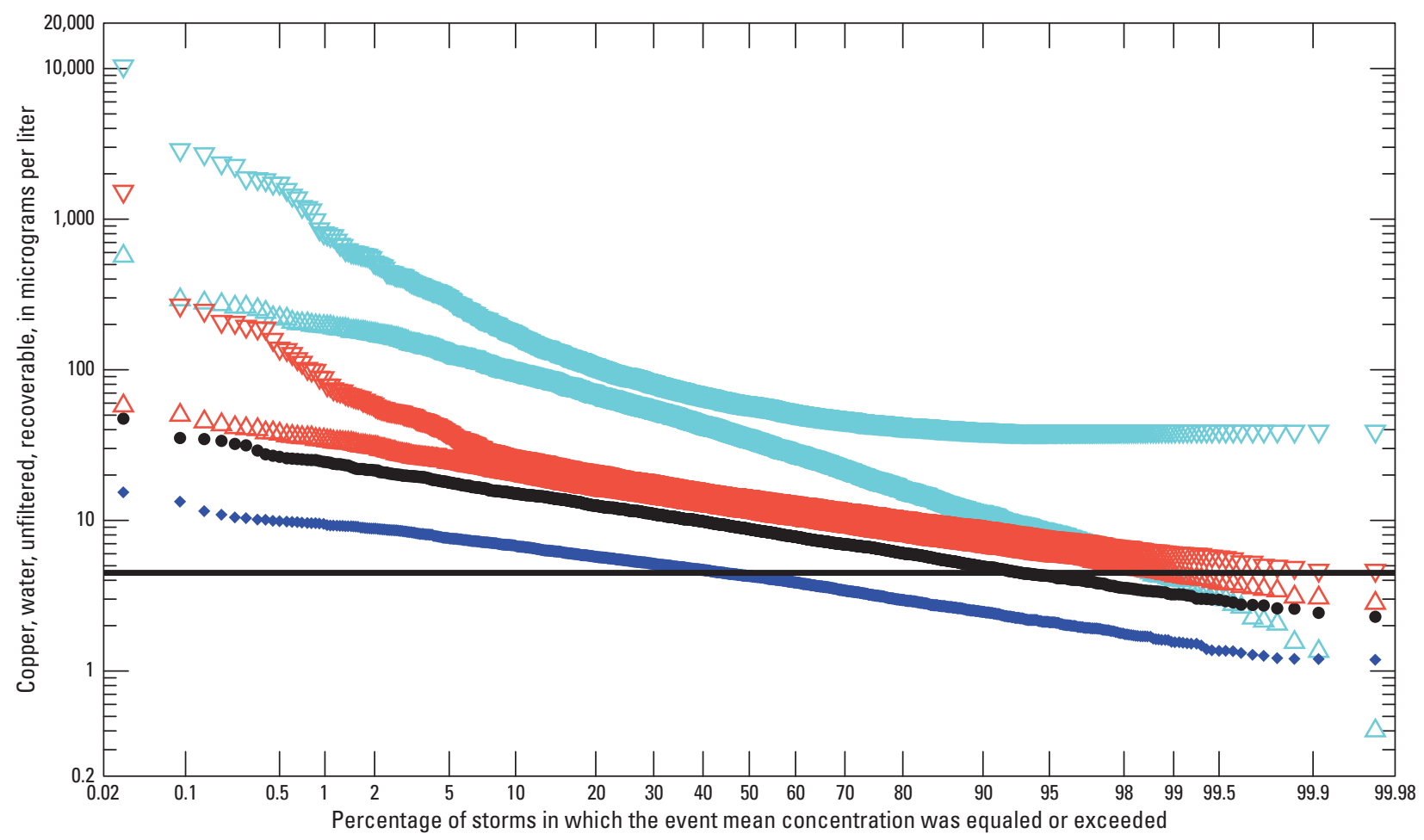

EXPLANATION

Highway runoff, HRDB site 11, Pennsylvania Interstate 84 Highway runoff, HRDB site 91, Wisconsin Interstate 894

- Upstream stormflow, transport-curve concentrations, USGS streamgage (14206900) on Fanno Creek at Portland, Oregon

$\triangle$ Downstream stormflow by using HRDB site 11, Pennsylvania Interstate 84

$\nabla \quad$ Downstream stormflow by using s HRDB site 91, Wisconsin Interstate 894

Average hardness dependent standard, hardness $=23.14 \mathrm{mg} / \mathrm{L}$

- Stochastic hardness dependent standard

Figure 30. Example analyses of the concentrations of total recoverable copper in highway runoff, upstream stormflows, and downstream stormflows concurrent to the period of highway runoff in Tryon Creek at Interstate 5, at Portland, Oregon. Concentrations are ranked independently. In most cases, the percentiles for a storm do not match. Stochastic exceedances occur if the concentration for a given storm exceeds the stochastic standard generated for that storm by using the totalhardness transport curve. HRDB is Highway-Runoff Database. 
The highway concentration values in figure 30 highlight the effect of skew on the results. Although the mean of the PA I-84 values is double the mean of the WI I-894 values and the standard deviations are similar, the skew of the PA I-84 data are weakly negative, while the skew of the WI I-894 data is strongly positive (table 7). Because of the difference in skew, the probability plot of the PA I-84 data is concave down, which limits the generation of high outliers. The positive skew of the probability plot of the WI I-894 data is concave up, which results in large concentrations for a long simulation period (fig. 30). The statistics for both datasets are based on more than 20 EMC samples (table 7) so they should be fairly robust.
Storm loads vary by about 3 orders of magnitude in this scenario (fig. 31). In this scenario, the urban-upstream copper concentrations and quick-flow runoff from the impervious basin result in large upstream loads. About 85 and 68 percent upstream loads exceed the PA I-84 and WI I-894 highway loads, respectively.

Total annual copper loads with the PA I-84 statistics ranged from 2.67 to $5.65 \mathrm{lb}$ with an average value of $3.72 \mathrm{lb}$ during the simulated 28-year period. For the same simulated period, total annual loads with the WI I-894 statistics ranged from about 4.87 to $15.4 \mathrm{lb}$ with an average value of $8.84 \mathrm{lb}$ of copper.

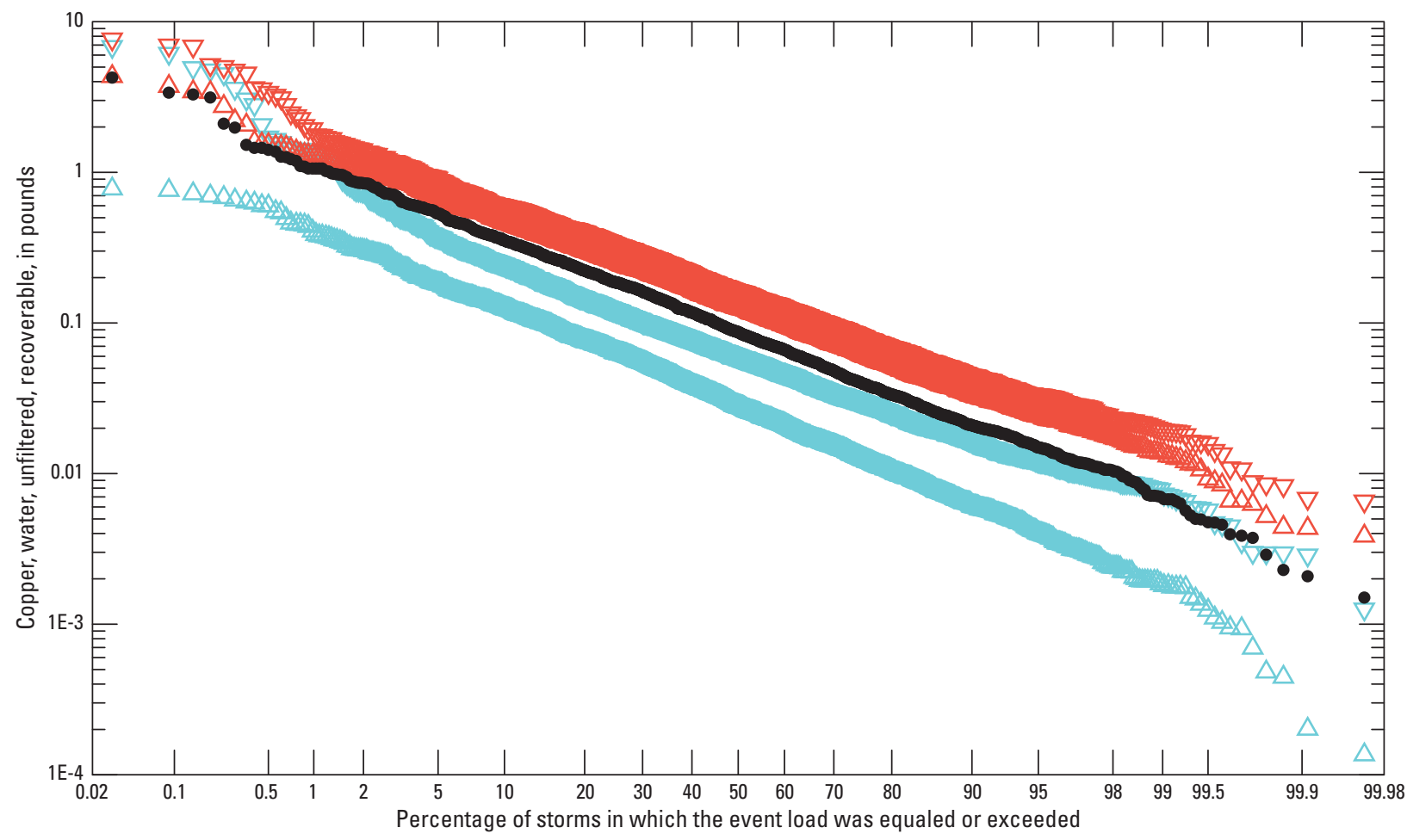

EXPLANATION
Highway runoff, HRDB site 11, Pennsylvania Interstate 84
Highway runoff, HRDB site 91, Wisconsin Interstate 894
- Upstream stormflow, transport-curve concentrations, USGS streamgage (14206900) on Fanno Creek at Portland, Oregon
$\triangle$ Downstream stormflow by using HRDB site 11, Pennsylvania Interstate 84
$\nabla \quad$ Downstream stormflow by using s HRDB site 91, Wisconsin Interstate 894

Figure 31. Example analyses of the loads of total recoverable copper in highway runoff, upstream stormflows, and downstream stormflows concurrent to the period of highway runoff in Tryon Creek at Interstate 5, at Portland, Oregon. HRDB is Highway-Runoff Database. 


\section{Tyron Creek at Oregon Route 43, at Lake Oswego, Oregon}

The ratio of the highway catchment area to the upstream basin area is much lower for the Tryon Creek at Oregon Route 43 study site (about 0.094 percent) than the Tryon Creek at Interstate 5 study site (about 2.9 percent), so the upstream flow and water-quality has a much bigger influence on downstream values than at the I-5 site (table 2). There is an order-of-magnitude increase in drainage area between these sites. Because most of the riparian corridor between these sites is forested, the percentage of urban land-use cover decreases substantially (from 99.8 to 63.2 percent) as does the impervious fraction (from 0.447 to 0.219 ). The average highway runoff volume was about $5,530 \mathrm{ft}^{3}$ and the average concurrent upstream runoff volume, upstream stormflow, and downstream stormflow volumes were about 1,138,000, $1,010,000$, and 1,593,000 ft ${ }^{3}$, respectively (fig. 32). On average, the upstream runoff comprised about 75 percent of the upstream stormflow during the period concurrent to the highway runoff; this ratio ranged from almost 0 to 99.9 percent among the 1,919 simulated storm events. On average, the highway runoff from OR-43 comprised about 0.5 percent of the downstream stormflow during the period concurrent to the highway runoff; this ratio ranged from about 0.003 to 10 percent. Although I-5 is in the upstream basin, OR-43 was simulated independently because the small increase in flows and loads from I-5 are minor in comparison to the flow accumulation between the upstream site (fig. 29) and the downstream site (fig. 32).

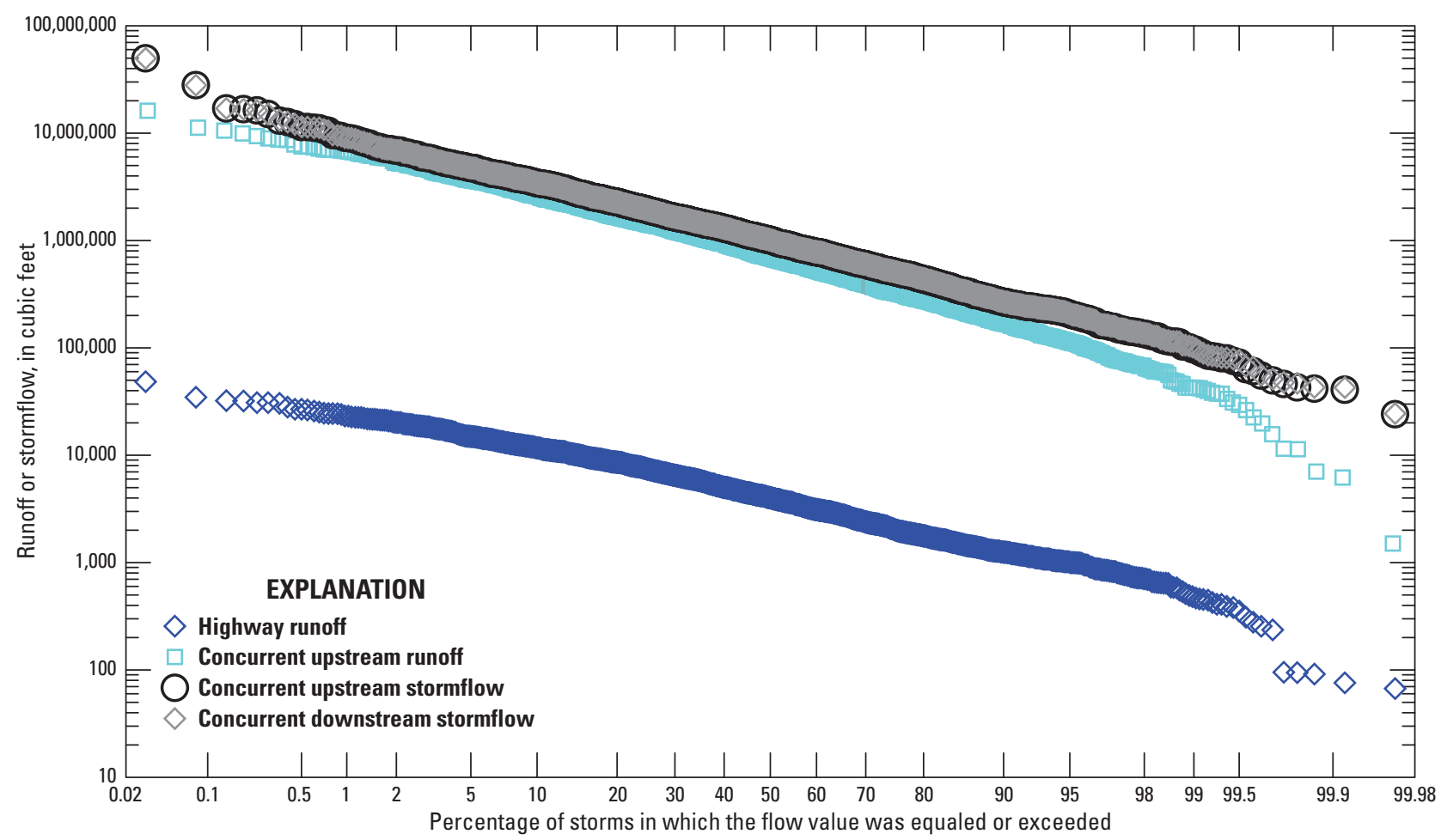

Figure 32. Example analyses of stormflows including highway runoff volumes and the concurrent upstream runoff, upstream stormflow, and downstream stormflow volumes in Tryon Creek at Oregon Route 43, at Portland, Oregon. 
Total recoverable chromium and total recoverable copper were simulated at this site (OR-43) to compare the number of exceedances between these trace metals. Total recoverable copper was also simulated at the OR-43 site so that it could be compared with simulated copper results from the I-5 site. Both the upstream chromium and copper concentrations were simulated by using transport curves created from data monitored at a nearby USGS streamgage on Fanno Creek at Portland, Oregon (14206900) (tables 8 and 10). Total recoverable chromium was simulated by using concentrations from California HRDB site 74 (CA I-5) and Wisconsin HRDB site 24 (WI I-894) site to evaluate the range of chromium statistics among selected highway sites (table 7). Total recoverable copper was simulated by using concentrations from the Pennsylvania HRDB site 11 (PA I-84) site and the Wisconsin HRDB site 91 (WI I-894) site for comparison to the simulations for Tryon Creek at Interstate 5.

The hardness-dependent, whole water aquatic-life criteria for chromium is much higher than for the other trace metals (fig. 13). Consequently, there are relatively few water-quality exceedances for this trace metal even when the upstream and highway-runoff concentrations from ultra-urban areas are used in the simulations. If the average upstream total hardness value of $26 \mathrm{mg} / \mathrm{L}$ is used to calculate a total recoverable criterion for chromium the value would be about $589 \mu \mathrm{g} / \mathrm{L}$, and the percentage of upstream exceedances would be 0 percent. Because the chromium criterion is high there are no upstream exceedances for the stochastic criteria either (fig. 33A). If the CA I-5 or WI I-94 total chromium statistics (table 7) are used, then the percentage of highway runoff exceedances using the stochastic criteria for these two sites would be about 0 and 0.6 percent, respectively (fig. 33A). Highway runoff exceedances for both two sites would be 0 percent using the average-hardness criteria. The percentage of the associated downstream exceedances with the CA I-5 chromium statistics would be 0 percent if either stochastic or average-hardness criteria are used. Similarly, there are no downstream chromium exceedances if the WI I-894 chromium statistics are used in the simulation (fig. 33A). Therefore, if chromium was the only constituent of concern, one might (erroneously) conclude that stormwater quality is not an issue at this site.

The total copper criteria are much lower than the chromium criteria (fig. 13), so there are many more exceedances for total copper than for chromium. The associated total recoverable criterion for copper was $4.89 \mu \mathrm{g} / \mathrm{L}$ and the percentage of upstream exceedances would be about 84 percent (fig. 33B $)$. If the stochastic total recoverable criteria for copper are used, then the percentage of upstream copper exceedances would be about 76 percent. If the PA I-84 or WI I-894 total copper statistics (table 7) are used, then the percentage of highway runoff exceedances using stochastic total recoverable criteria would be about 96.6 and 99.9 percent, respectively (fig. 33B). The percentage of the associated downstream exceedances with the PA I-84 copper statistics would be about 77.3 percent if the stochastic criteria are used and about 85.8 percent if the average-hardness criterion is used. The percentage of the associated downstream exceedances with the WI I-894 copper statistics would be about 79.3 percent if the stochastic criteria are used and about 87.5 percent if the average-hardness criterion is used. Because the upstream concentrations and percentages of exceedances are so high, use of a structural BMP to reduce copper concentrations in runoff from the highway at this site would be ineffective for achieving the 3-year criteria downstream of the highway.

Both the highway storm loads and concurrent instream (upstream and downstream) storm loads vary by about 4 orders of magnitude in this scenario (fig. 34) for total recoverable chromium and total recoverable copper. However the instream storm loads are more than 1 order of magnitude greater than the highway loads on average. The instream values are much higher than the highway values because the upstream drainage area is much larger (by about 1,000 times, table 2) and the upstream concentrations are simulated by using concentration statistics from an urban index station (tables 8 and 10).

Total annual chromium loads with the CA I-5 statistics ranged from 0.0598 to $0.109 \mathrm{lb}$ with an average value of $0.0777 \mathrm{lb}$ during the simulated 27-year period. For the same simulated period, total annual loads with the WI I-894 statistics ranged from about 0.488 to $1.82 \mathrm{lb}$ with an average value of $0.922 \mathrm{lb}$ of chromium. Total annual copper loads with the PA I-84 statistics ranged from about 0.75 to $1.51 \mathrm{lb}$ with an average value of $1.1 \mathrm{lb}$ during the simulated 27-year period. For the same simulated period, total annual loads with the WI I-894 statistics ranged from about 1.47 to $3.99 \mathrm{lb}$ with an average value of $2.45 \mathrm{lb}$ of copper. Differences between the copper loads in this scenario and the Tryon Creek at Interstate 5 scenario are caused by differences in drainage area and stochastic variation from simulation to simulation. 

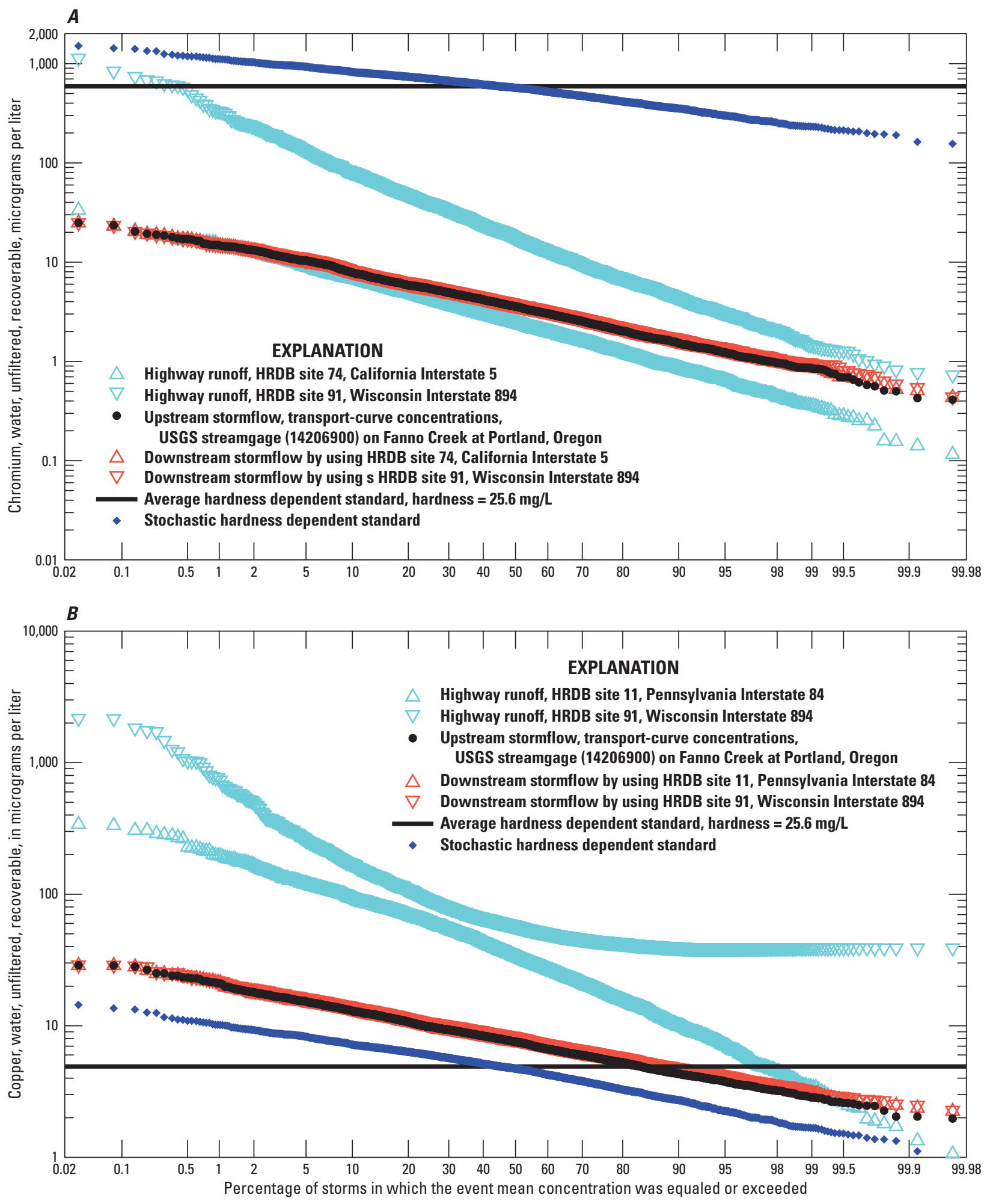

Figure 33. Example analyses of the concentrations of $(A)$ total recoverable chromium and $(B)$ total recoverable copper in highway runoff, upstream stormflows, and downstream stormflows concurrent to the period of highway runoff in Tryon Creek at Oregon Route 43, at Portland, Oregon. Concentrations are ranked independently. In most cases the percentiles for a storm do not match. Stochastic exceedances occur if the concentration for a given storm exceeds the stochastic standard generated for that storm by using the totalhardness transport curve. HRDB is Highway-Runoff Database. 

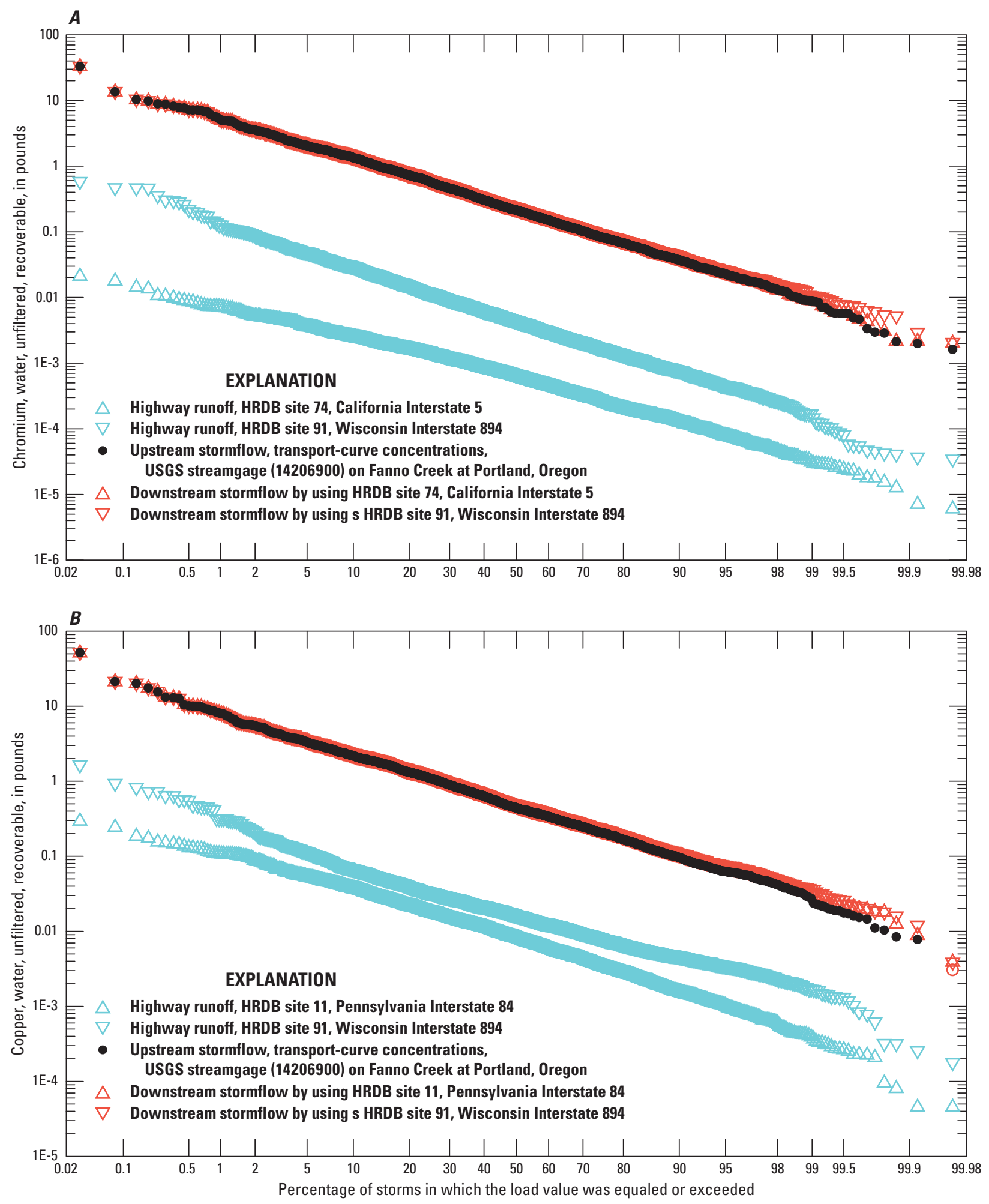

Figure 34. Example analyses of the storm loads of $(A)$ total recoverable chromium and $(B)$ total recoverable copper in highway runoff, upstream stormflows, and downstream stormflows concurrent to the period of highway runoff in Tryon Creek at Oregon Route 43, at Portland, Oregon. HRDB is Highway-Runoff Database. 


\section{Murder Creek at Interstate 5, near Albany, Oregon}

The Murder Creek study site has a low ratio of highway catchment size to upstream basin size (less than 1 percent) and the impervious fraction is 0.0283 (table 2). As a result, simulated highway flow volumes were minimal in comparison to upstream flow volumes (fig. 35). The average highway runoff volume was about $13,600 \mathrm{ft}^{3}$ and the average concurrent upstream runoff volume, upstream stormflow, and downstream stormflow volumes were about 422,000, $1,012,000$, and $1,025,000 \mathrm{ft}^{3}$, respectively. On average, the upstream runoff comprised about 61 percent of the upstream stormflow during the period concurrent to the highway runoff; this ratio ranged from 0.04 to 99.9 percent among the 1,866 simulated storm events. On average, the highway runoff comprised about 2.7 percent of the downstream stormflow during the period concurrent to the highway runoff; this ratio ranged from about 0.0012 to 34 percent.

Concentrations of total recoverable zinc were simulated for the Murder Creek site. The Willamette Valley ecoregion non-urban random water-quality statistics (table 9) were used to simulate upstream concentrations. If data from California HRDB site 74 (CA I-5) and Wisconsin HRDB site 91 (WI I-894) (table 7) are used to simulate highway runoff quality discharging to Murder Creek then the geometric mean zinc concentrations downstream of the outfall would be about 7.41 and $13.1 \mu \mathrm{g} / \mathrm{L}$ for the two highway sites, respectively (fig. 36). If an average total hardness value of $27.3 \mathrm{ml} / \mathrm{L}$ is used to calculate a total recoverable criterion for zinc, then the criterion value would be about $39.9 \mu \mathrm{g} / \mathrm{L}$ and the percentage of downstream exceedances would be 1.93 and 7.12 percent for the CA I-5 and WI I-894 simulations, respectively (fig. 36).

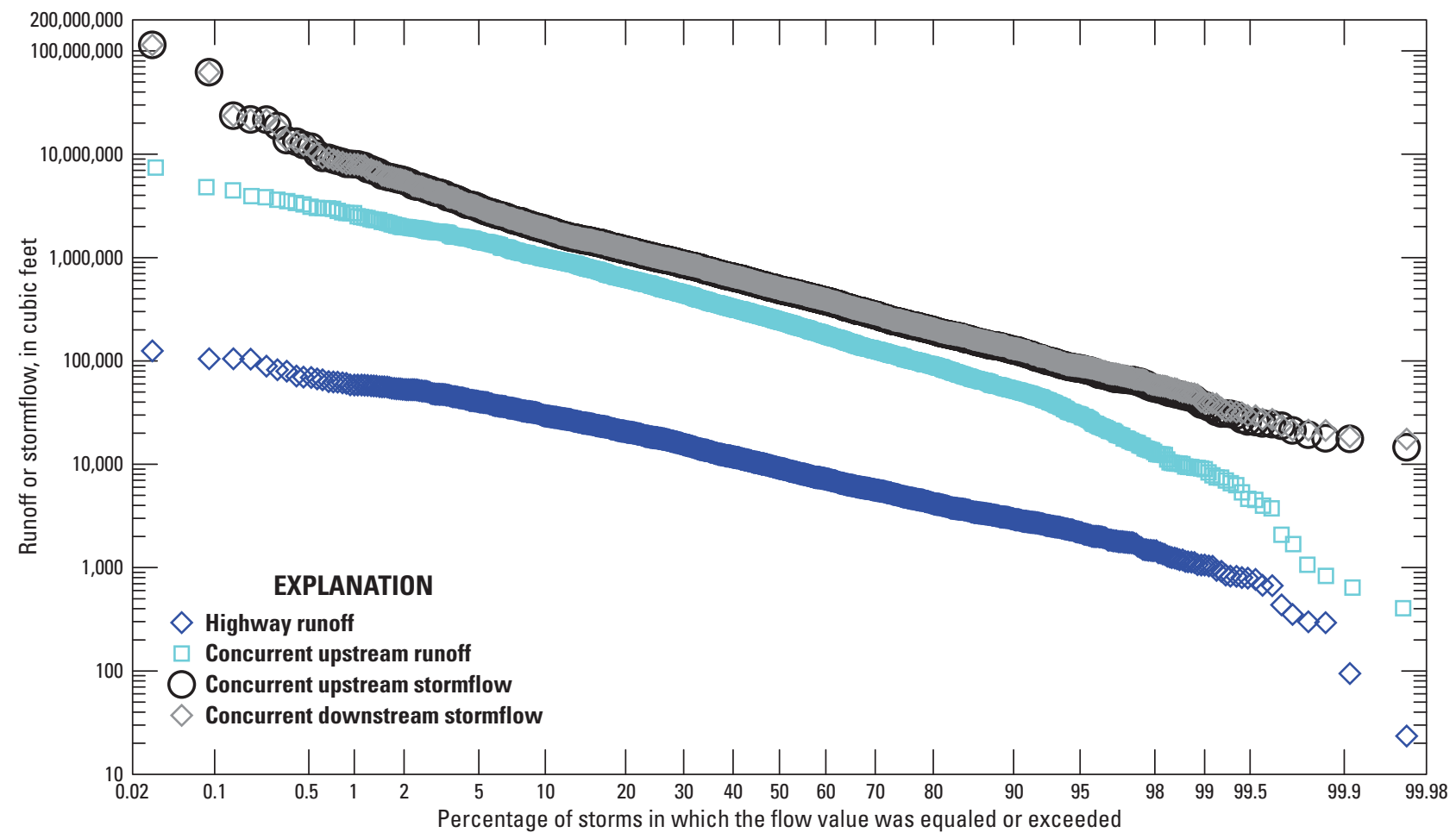

Figure 35. Example analyses of stormflows including highway runoff volumes and the concurrent upstream runoff, upstream stormflow, and downstream stormflow volumes in Murder Creek at Interstate 5, near Albany, Oregon. 


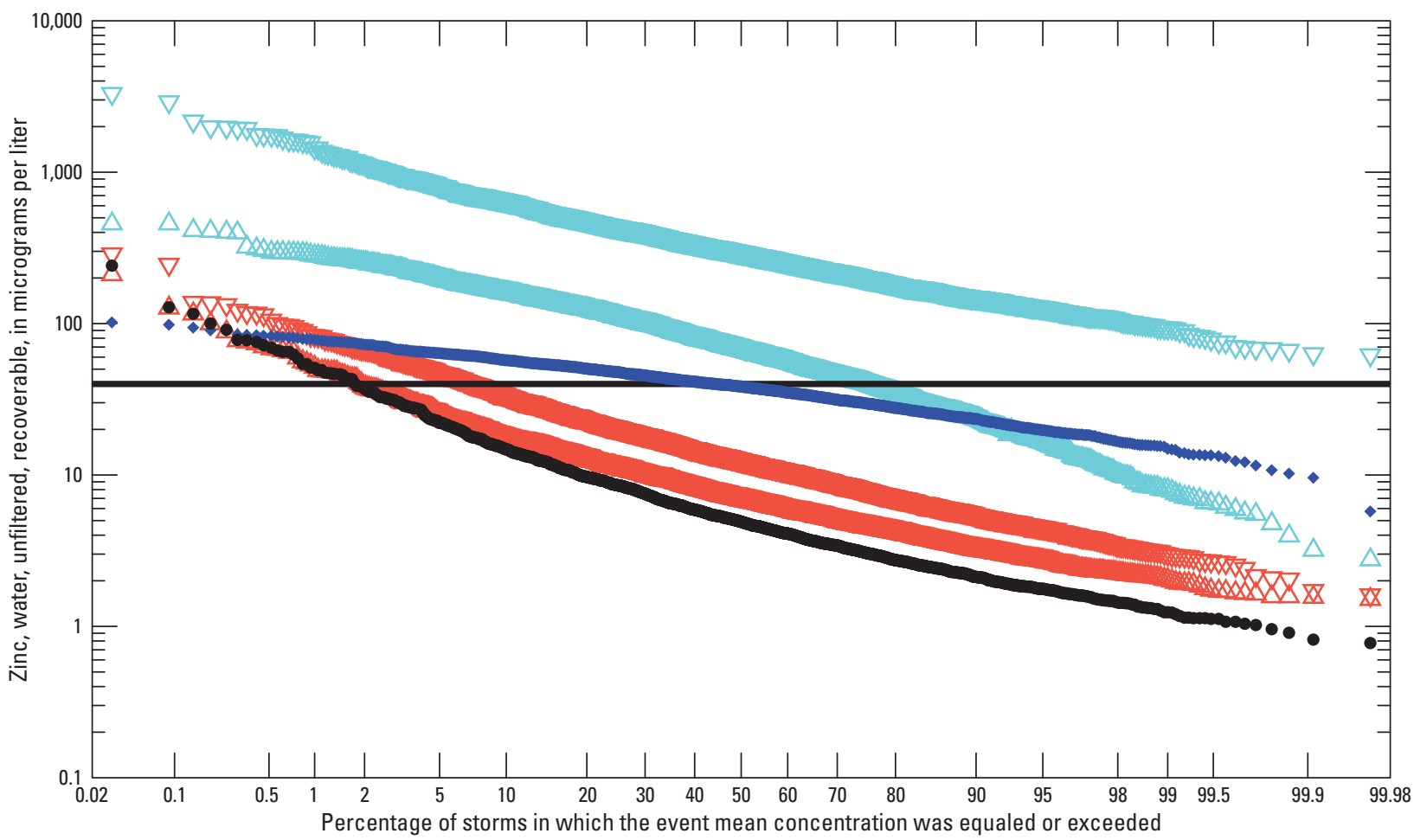

\section{EXPLANATION}

$\triangle$ Highway runoff, HRDB site 74, California Interstate 5

$\nabla \quad$ Highway runoff, HRDB site 91, Wisconsin Interstate 894

- Upstream stormflow, transport-curve concentrations,

USGS streamgage (14206900) on Fanno Creek at Portland, Oregon

$\triangle$ Downstream stormflow by using HRDB site 74, California Interstate 5

$\nabla \quad$ Downstream stormflow by using s HRDB site 91, Wisconsin Interstate 894

Average hardness dependent standard, hardness $=27.3 \mathrm{mg} / \mathrm{L}$

- Stochastic hardness dependent standard

Figure 36. Example analyses of the concentrations of total recoverable zinc in highway runoff, upstream stormflows, and downstream stormflows concurrent to the period of highway runoff in Murder Creek at Interstate 5, near Albany, Oregon. Concentrations are ranked independently. In most cases, the percentiles for a storm do not match. Stochastic exceedances occur if the concentration for a given storm exceeds the stochastic standard generated for that storm by using the total-hardness transport curve. HRDB is Highway-Runoff Database. 
If the stochastic total recoverable criteria for zinc, based on the Willamette Valley ecoregion transport curve for total hardness are used, then the percentage of downstream exceedances also would be 3.21 and 8.52 percent for the CA I-5 and WI I-894 simulations, respectively. Statistics from the WI I-894 site were used to provide a wide range of conditions that may occur depending on the highway inputs. It should be noted, however, that the WI I-894 site would represent a gross over estimate of zinc concentrations because this site is located in an ultra-urban area with a long history of industrial production of metal products while the upstream basin at the Murder Creek site is largely agricultural upstream of the highway. Even so, the simulation using concentration statistics from the CA I-5 site and the Willamette Valley ecoregion statistics indicates that the downstream zinc EMCs may exceed the average criterion in about 1.3 storms per year and the stochastic criteria in about 2.1 storms per year on average.

Storm loads vary by about 4 orders of magnitude in this scenario (fig. 37). About 15 percent of the simulated CA I-5 storm loads from highway runoff exceed the simulated upstream storm load values. About 55 percent of the simulated WI I-894 storm loads from highway runoff exceed the simulated upstream storm load values. As with the concentrations, however, the percentile values in figure 37 are not paired with the upstream or downstream loads for any given storm.

Total annual zinc loads with the CA I-5 site statistics ranged from 3.15 to $6.44 \mathrm{lb}$ with an average value of $4.67 \mathrm{lb}$ during the simulated 28-year period. For the same simulated period, total annual loads with the WI I-894 site statistics ranged from about 12.3 to $24.9 \mathrm{lb}$ with an average value of $19.5 \mathrm{lb}$ of zinc.

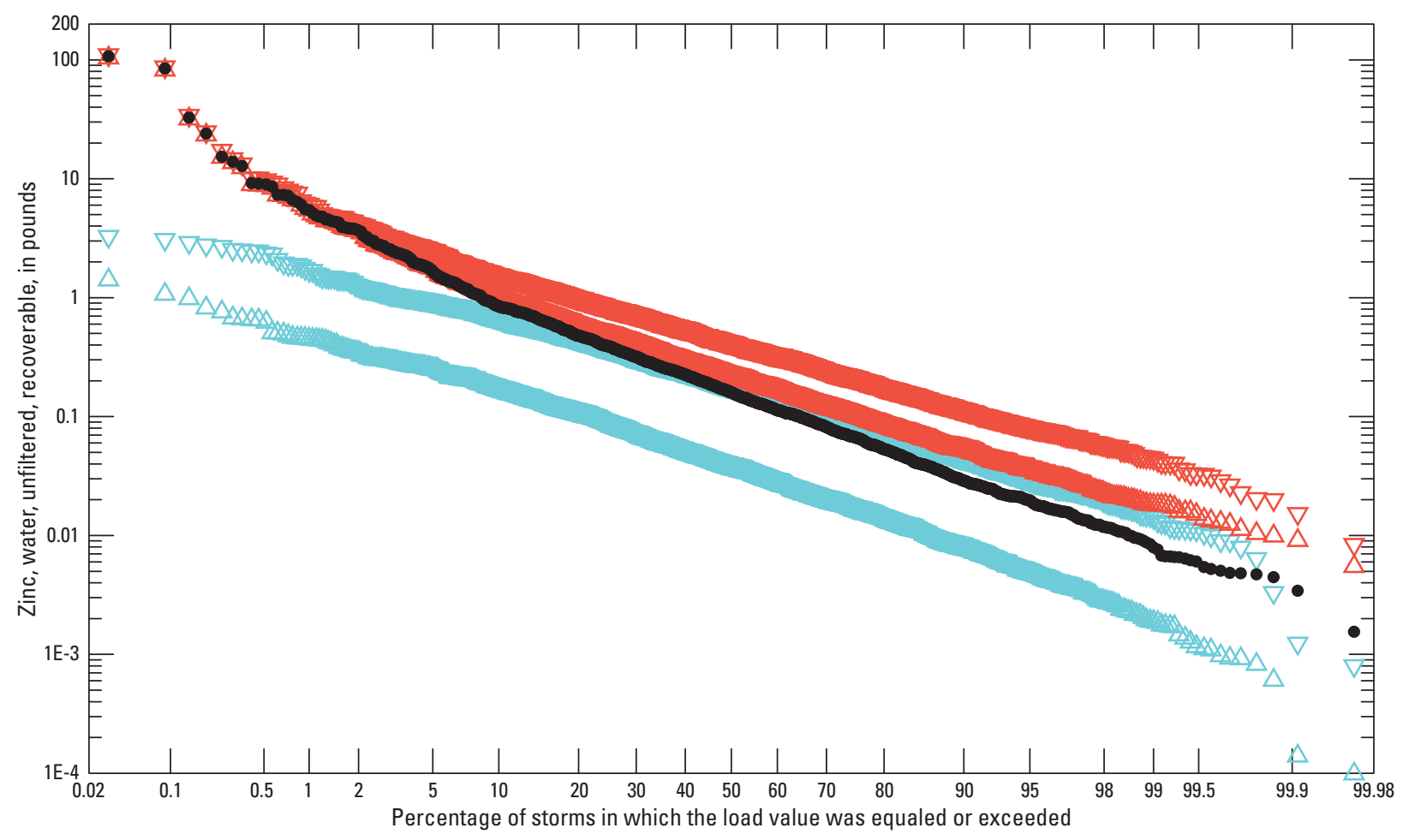

\section{EXPLANATION}

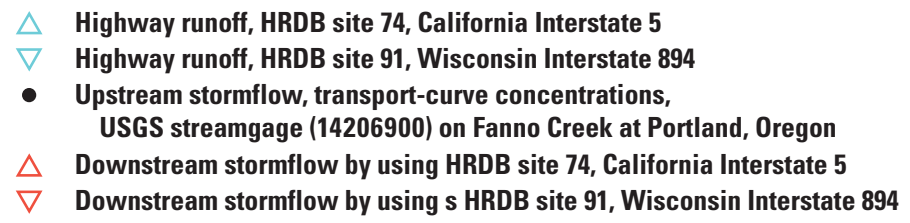

Figure 37. Example analyses of the loads of total recoverable zinc in highway runoff, upstream stormflows, and downstream stormflows concurrent to the period of highway runoff in Murder Creek at Interstate 5, near Albany, Oregon. HRDB is Highway-Runoff Database. 


\section{Wall Creek at Interstate 5, near Ashland, Oregon}

The Wall Creek at I-5 study site highway catchment is approximately 1.3 percent of the upstream drainage basin and the impervious fraction is 0.0082 (table 2). The average highway runoff volume was about $12,200 \mathrm{ft}^{3}$ and the average concurrent upstream runoff volume, upstream stormflow, and downstream stormflow volumes were about 143,000, 205,000, and $217,000 \mathrm{ft}^{3}$, respectively (fig. 38). On average, the upstream runoff comprised about 85 percent of the upstream stormflow during the period concurrent to the highway runoff; this ratio ranged from almost 0 to 100 percent among the 1,360 simulated storm events. On average, the highway runoff comprised about 10 percent of the downstream stormflow during the period concurrent to the highway runoff; this ratio ranged from about 0.001 to 96 percent.

Concentrations of chloride were simulated for the Wall Creek site because ODOT began a program of winter weather road salt applications to I-5 in the mountains near northern California. In these simulations, the random water-quality statistics for chloride from Pennsylvania HRDB site 11 (PA I-84) were used to simulate highway runoff (table 7), and two upstream chloride definitions were used for comparison. In this case, data from selected sites in the Klamath Mountains ecoregion (table 8) were used to generate the random water-quality statistics (table 9 ) and a water-quality transport curve (table 10) for chloride. Highway runoff concentrations ranged from 6.98 to $12,200 \mathrm{mg} / \mathrm{L}$ with a median of 75.6, a geometric mean of 83.5, and a mean value of $189 \mathrm{mg} / \mathrm{L}$. About 17 percent of the highway runoff concentrations exceeded the ODEQ aquatic criterion of $230 \mathrm{mg} / \mathrm{L}$ for chloride (table 1, fig. 39). The random upstream concentrations ranged from 0.53 to $12.2 \mathrm{mg} / \mathrm{L}$ with a median of 1.9 , a geometric mean of 1.96, and a mean value of $2.21 \mathrm{mg} / \mathrm{L}$. Similarly, the transport-curve concentrations ranged from 0.242 to 16.2 with a median of 1.77 , a geometric mean of 1.78 , and a mean value of $2.31 \mathrm{mg} / \mathrm{L}$. None of the upstream concentrations are close to the ODEQ aquatic criterion for chloride. Highway runoff concentrations have a substantial influence on runoff concentrations downstream of the highway because, on average, highway runoff concentrations are about 100 times the random upstream concentrations and 120 times the transport curve upstream concentrations

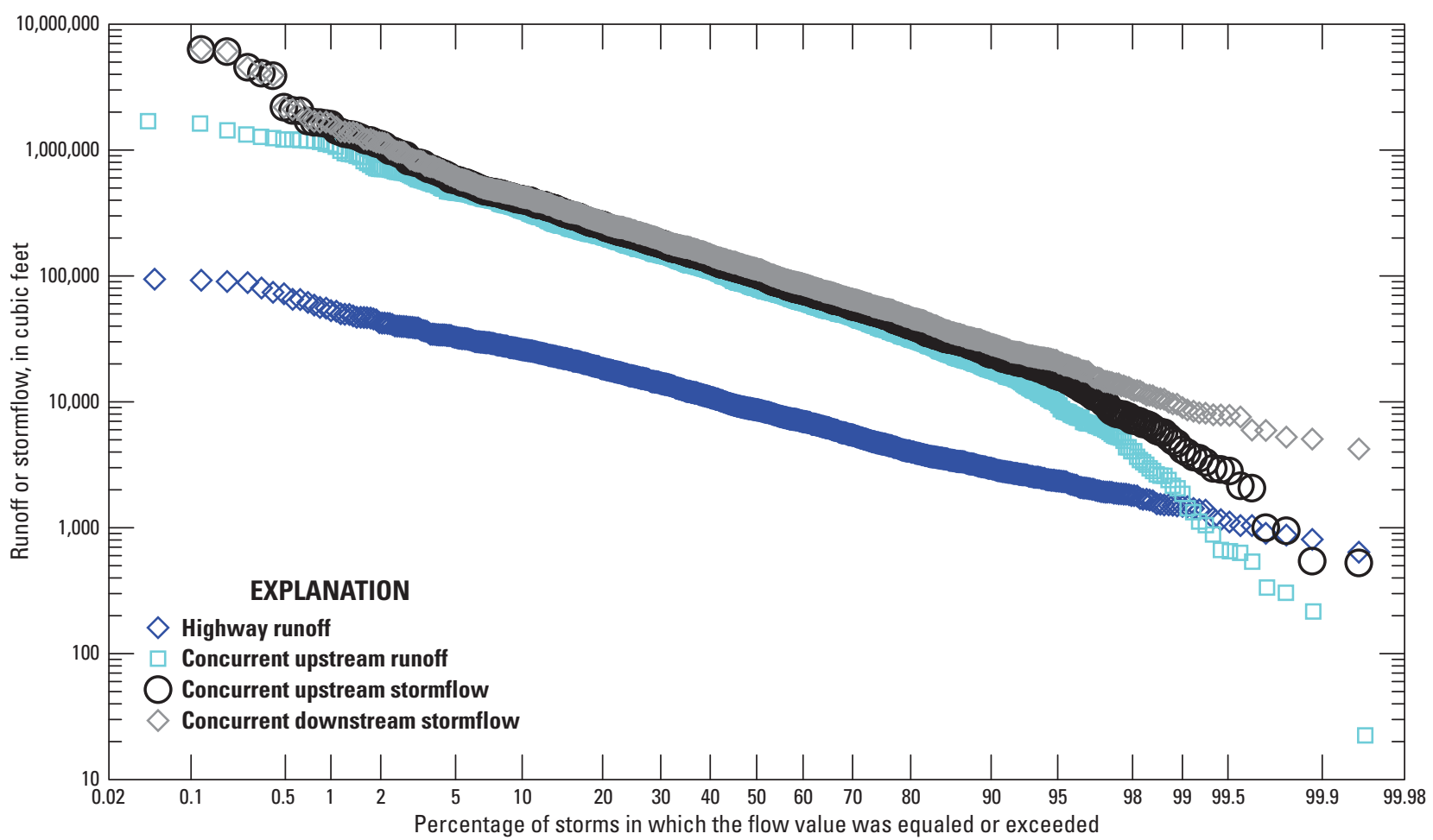

Figure 38. Example analyses of stormflows including highway runoff volumes and the concurrent upstream runoff, upstream stormflow, and downstream stormflow volumes in Wall Creek at Interstate 5, near Ashland, Oregon. Values of $15,600,000$ and $15,700,000$ cubic feet for upstream and downstream stormflow at the 0.05 percent exceedance, respectively, are not shown. 


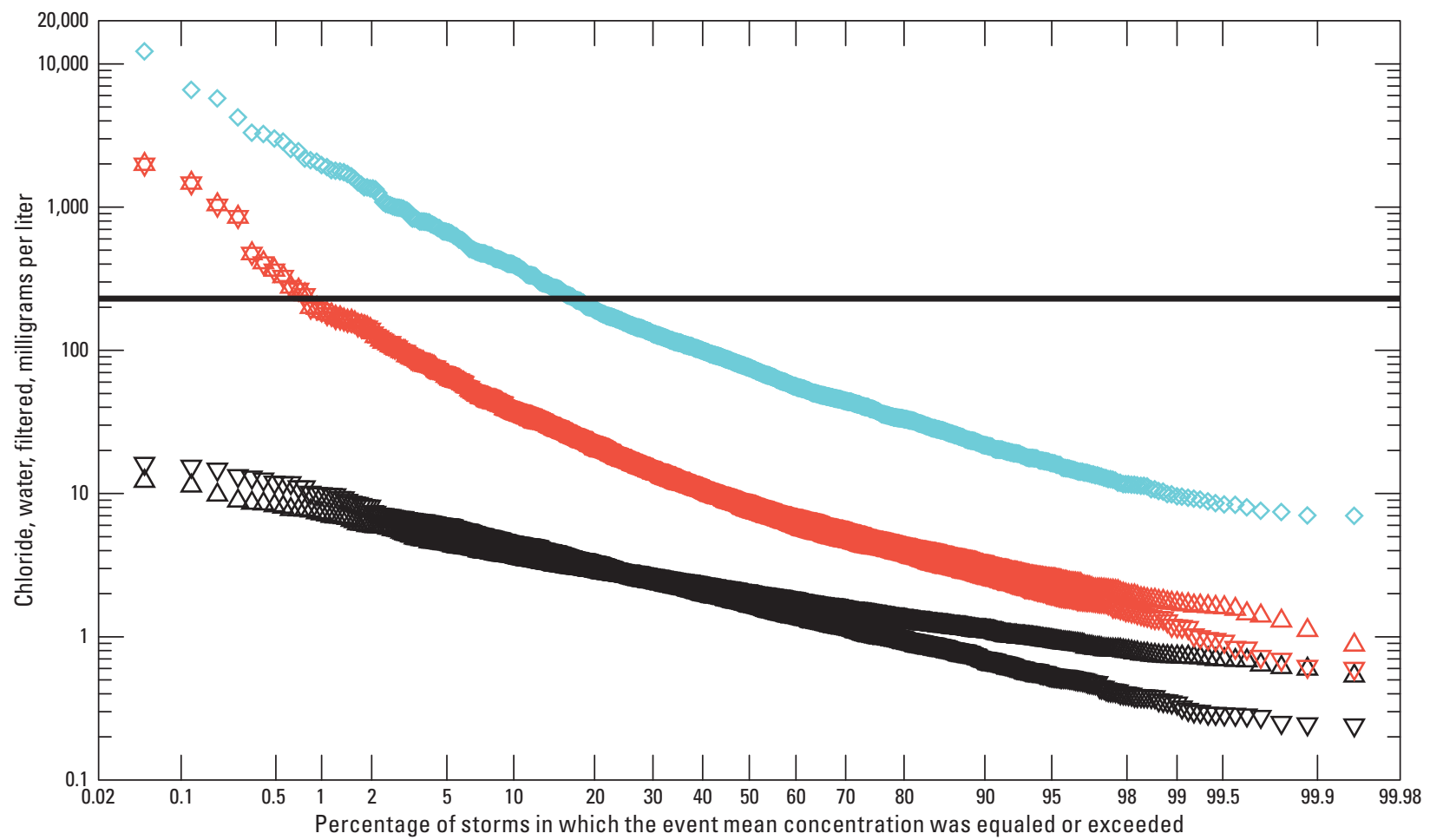

\section{EXPLANATION}

$\diamond \quad$ Highway runoff, HRDB site 11, Pennsylvania Interstate 84

$\triangle$ Upstream stormflow, random concentrations, Klamath Mountains ecoregion

$\nabla$ Upstream stormflow, transport-curve concentrations, Klamath Mountains ecoregion

$\triangle$ Downstream stormflow by using upstream random concentrations

$\nabla \quad$ Downstream stormflow by using upstream transport curve concentrations

Water-quality criterion $(230 \mathrm{mg} / \mathrm{L})$

Figure 39. Example analyses of the concentrations of chloride in highway runoff, upstream stormflows, and downstream stormflows concurrent to the period of highway runoff in Wall Creek at Interstate 5, near Ashland, Oregon. Concentrations are ranked independently. In most cases, the percentiles for a storm do not match.

(fig. 39). About 0.81 percent of downstream concentrations in both scenarios exceed the criterion. This risk meets the criterion because it is equivalent to about one storm every 3.5 years in this simulation, which includes 1,360 storms in a 39-year period. However, if highway-runoff concentrations are better represented by statistics from the Massachusetts or Wisconsin sites (table 7, fig. 18), then the downstream concentrations far exceed the results shown in figure 39, and the number of exceedances would rise to about 6 percent, which is about 2.25 storms per year on average.

In these scenarios, upstream chloride loads are insubstantial in comparison to highway loads. The random upstream values ranged from 0.13 to $3,470 \mathrm{lb}$ with a median of 12.3, a geometric mean of 12.2, and a mean value of $28.5 \mathrm{lb}$ of chloride per storm. The upstream transport curve values ranged from 0.21 to $535 \mathrm{lb}$ with a median of 10.7 , a geometric mean of 11.1, and a mean value of $19.9 \mathrm{lb}$ of chloride per storm. In comparison, the PA I-84 load values ranged from 1.18 to $35,800 \mathrm{lb}$ with a median of 43.0 , a geometric mean of 45.3, and a mean value of $161 \mathrm{lb}$ of chloride per storm. The lognormal load values for MA-495 highway site ranged from 0.015 to $329,000 \mathrm{lb}$ with a median of 31.0, a geometric mean of 30.4, and a mean value of $694 \mathrm{lb}$ of chloride per storm. The annual loads for the PA I-84 highway site ranged from 1,740 to 39,400 lb per year with a median of 4,140 , a geometric mean of 4,410 , and a mean value of 5,600 lb of chloride per year. The annual loads for the MA I-495 highway site (with lognormal concentrations) ranged from 2,360 to 341,000 lb per year with a median of 9,680, a geometric mean of 11,800 , and a mean value of 24,200 lb of chloride per year during the simulated 39-year period. 


\section{Summary}

Water-resource managers are concerned about the frequencies, magnitudes, and durations of concentrations and loads (the products of measured stormflow and concentration) that may have an adverse effect on the quality of receiving waters. Runoff from impervious areas such as parking lots, local roads, and highways can increase stormflows and increase concentrations of sediment, nutrients, deicers, trace elements, and organic constituents in receiving water bodies. Intermittent and highly variable concentrations, flows, and loads complicate the monitoring, characterization, and evaluation of potential effects of runoff on receiving waters. These factors also affect efforts to evaluate runoffmitigation measures, such as structural best management practices (BMP). Therefore decision makers need tools to help transform complex scientific data into meaningful information about the risk of adverse effects of runoff on receiving waters, the potential need for mitigation measures, and the potential effectiveness of such management measures for reducing these risks.

In 2012, the U.S. Geological Survey (USGS) and Oregon Department of Transportation (ODOT) began a cooperative study to demonstrate the Stochastic Empirical Loading and Dilution Model (SELDM). ODOT is responsible for providing a safe, efficient transportation system while balancing economic, environmental, and community well-being needs. To meet this mission, ODOT needs tools to evaluate potential effects of runoff to help target limited resources for mitigation measures at sites where mitigation measures are needed and where they can improve receiving-water quality. The potential need for such mitigation measures in Oregon is driven by the Endangered Species Act (ESA) and by water quality regulations that are implemented and enforced by the Oregon Department of Environmental Quality (ODEQ). The purpose of this study is to demonstrate how SELDM can be used as a decision making tool in Oregon. SELDM is, nominally, a highway-runoff model, but it also is well suited for analysis of runoff from other land uses. This report documents analyses for estimating the quantity and quality of runoff and potential effects of runoff on downstream water quality. The report demonstrates the model's capability for simulating the quality and quantity of stormflows and the potential effectiveness of mitigation measures to reduce or eliminate risks for adverse effects of runoff.

This project was designed to apply the model by using example sites, datasets, and information specific to local conditions in Oregon. The information that was compiled includes:
1. Basin properties for six study sites with a range of basin properties-Study sites selected for the study included Miller Creek at U.S. Route 30 near Linnton, Oregon (north of Portland, Oregon). The upstream basin of this site is mostly forested and flows directly to the Willamette River. Another study site, south of Miller Creek and also located on U.S. Route 30, is at an unnamed creek that is almost entirely forested and also drains into the Willamette River. Two other study sites located in the Portland area are both on Tryon Creek at Interstate 5 in Portland proper and at Oregon Route 43 in Lake Oswego, Oregon. South of Portland, the Murder Creek study site is located on Interstate 5 near Albany, Oregon. Further south, close to the California state line the Wall Creek study site is also located on Interstate 5 near Ashland, Oregon. As input to SELDM, it was critical to accurately define the hydraulic characteristics of highway catchments and the upstream drainages. Highway catchment and upstream basin drainage areas for the study sites range from 3.85 to 11.83 acres and from 0.16 to 6.56 square miles, respectively. Although the upstream basins of the two Tryon Creek sites are urbanized, the upstream basins of all the other sites have less than 5 percent impervious surface area.

2. Interpolated data layers of storm-event precipitation and pre-storm streamflow statistics —-Spatially-interpolated data layers containing storm-event precipitation and pre-storm streamflow statistics were produced by using geographic information system Kriging techniques to facilitate selection of representative statistics within the State. Storm-event precipitation statistics include mean and covariance of storm-event volume, duration, time between storms, number of storms per year, and average annual precipitation. Pre-storm streamflow statistics include average, standard deviation, skew, and median of streamflow, the 7-day, 10-year low flow, and the 1-day, 3 -year and 4-day, 3-year biological flows.

3. Best-fit triangular-hydrograph recession ratios-The triangular hydrograph is used in SELDM to determine the timing and duration of storm runoff from the upstream basin of a study site. The shape of the hydrograph is defined by the ratio of the falling limb to the rising limb. For this study, best-fit triangular-hydrograph recession ratios were computed for two study sites using instantaneous flow data measured at USGS streamgages on Tryon Creek (14211315) and West Fork Ashland Creek (14353000). For the other four study sites, surrogate recession ratios were selected from the recession ratios of 41 streamgages based on similarities between the surrogate and study site basin characteristics. These characteristics included drainage area, basin length, basin slope, imperviousness, and dominant land use. 
4. U pstream basin water-quality characterization-To simulate water-quality concentration and load for the study site upstream basins, water-quality datasets (cadmium, chloride, chromium, copper, iron, lead, nickel, phosphorus, and zinc) measured at similar basins in the vicinity of the study sites were selected and compiled. For this study these constituents were specified in SELDM as a random water-quality definition or as a transport curve. Based on monitoring data, a random water-quality definitions were created by entering the mean, standard deviation, and coefficient of skew for each constituent (or the logarithm of each constituent) as input to SELDM. A water-quality transport curve is a relation between streamflow and the concentration of a constituent. The slopes and intercepts of a one or more than one line regression model were entered into SELDM. For this study, almost all of the constituents for most of the study sites were specified as a random water-quality definition. Transport curves were created for the urban site (Tryon Creek at Interstate 5 and Tryon Creek at Oregon Route 43) constituents and for chloride at the Wall Creek study site.

5. Selection of surrogate highway-runoff quality statisticsAvailability of highway runoff-quality statistics for sites in Oregon are limited, so surrogate datasets that include cadmium, chloride, chromium, copper, iron, lead, nickel, phosphorus, and zinc were selected for the SELDM simulations done for this project. The highway-water-quality datasets were downloaded from the Federal Highway Administration Highway-Runoff Database. The selection of surrogate sites was based on similarities between the surrogate and study sites. Characteristics used to evaluate site similarity, in their order of importance, included average daily traffic load, total annual precipitation, surrounding setting (urban or non-urban), number of lanes, highway catchment area size, and impervious fraction of the highway catchment.

Seven types of stochastic analyses were done to demonstrate use of SELDM and to illustrate the types of information that stochastic analyses may provide. These analyses may help users apply the model to different situations and to help guide the decision making process. These example analyses are:

1. Dilution factors-SELDM's dilution factor output files provide information that can be used as an initial reconnaissance tool for comparing relative risk among sites. Dilution factors are the ratio of highway runoff to downstream flows. If dilution factors are low, the highway runoff volumes are a small proportion of downstream flows. If a decision maker must evaluate potential effects of runoff from many different sites, then they can use basin properties to quickly generate a set of dilution factors for each site. Comparison of dilution factors can be used to identify sites that have the greatest (or least) potential for adverse effects from runoff. This analysis also demonstrated that use of deterministic measures of upstream stormflows such as the average annual, average monthly streamflows may substantially over represent the highway contribution to downstream flows. Therefore, models that use such methods may provide misleading results.

2. Hardness-dependent water-quality criteria-An analysis of hardness-dependent water-quality criteria was done to illustrate the effects of variations in hardness and flow on the application and interpretation of such criteria. The ODEQ has adopted a series of hardness dependent waterquality criteria for trace metals in receiving waters and provides a table of metal criteria values calculated by using a hardness concentration of $100 \mathrm{mg} / \mathrm{L}$, but this hardness concentration is not representative of water quality in many areas of Oregon. Water-quality transport curves, which are relations between flow and concentrations, indicate that total hardness concentrations generally decrease with increasing flows. Use of SELDM with these transport curves indicate that the average hardness concentration in stormwater is about $24 \mathrm{mg} / \mathrm{L}$ in the Willamette Valley ecoregion and about $41 \mathrm{mg} / \mathrm{L}$ in the Klamath Mountains ecoregion. Total hardness concentrations range from 5 to $110 \mathrm{mg} / \mathrm{L}$ and from about 20 to $160 \mathrm{mg} / \mathrm{L}$ in these two ecoregions, respectively. This analysis shows that hardness-dependent criteria for each of these trace metals can vary by an order of magnitude among storm events because hardness in the receiving water is diluted by increasing stormflows. These analyses also indicate that use of stochastic hardness criteria may be necessary to assess risks when concentrations of trace metals, and therefore the risk of exceedances are low. The risk of exceedances estimated by using stochastic hardness values and the average hardness value converge as concentrations of metal (and therefore the percentage of exceedances) increase.

3. Uncertainties in input and output values-An analysis of uncertainties in input and output values was done to demonstrate that properly selected robust datasets are needed to represent conditions at a site of interest. There are two types of uncertainty for input values; there is uncertainty associated with the sample size and uncertainty associated with selection of statistics from a surrogate site. The uncertainty in calculated statistics from environmental datasets decrease as a function of the square root of the number of samples in the dataset. As the number of samples increase, statistics will converge toward their "true" values, but may vary substantially if sample sizes are small. This analysis shows that the rate of water-quality exceedances that are measured or simulated may depend on sample size and the result of chance. Because of the uncertainties in sample size and site selection, using the medians of statistics from a few well-selected sites may provide a more robust estimate of the conditions at the site of interest than the selection of statistics from a single site. 
4. Generating extreme values-An analysis was done to demonstrate that SELDM and other Monte Carlo models may generate extreme values from input statistics, which may or may not be feasible based on physicochemical or hydrological limits. In this case, use of statistics from sites in Massachusetts resulted in a few concentrations of chloride that were beyond the maximum solubility of chloride in saturated brine solutions. This may occur because short-term datasets are extrapolated for long-term simulations. This is most likely to occur if the standard deviation is large and the skew is strongly positive. In this case, the maximum chloride concentrations were not physicochemically feasible, but some extreme concentrations may be feasible. For example, hyperconcentrated sediment flows can occur and small metal particles, such as a small strand of wire, in highway or urban runoff can produce extremely high total-metal concentrations. Therefore, seemingly extreme results may require careful attention and interpretation.

5. BM P modeling-A simple analysis of BMP modeling methods was done to demonstrate use of the model for estimating treatment requirements for meeting waterquality objectives. Currently (2014) the USGS is working in cooperation with the Federal Highway Administration to develop BMP performance statistics for use with SELDM so a detailed analysis was not done in this report. However, SELDM can be used to iteratively assess the BMP performance metrics that must be achieved to meet criteria at a site of interest. Such information may be used by a designer to select a BMP or a series of BMPs for use at a given site. In this simple case study, 10 scenarios were run to assess the amount of highway-runoff flow reduction that would be needed to meet a maximum exceedance criterion of one storm in 3 years on average. This set of scenarios indicates that a flow reduction target of at least 89 percent must be achieved in every storm during a 28-year period to meet the total-lead criterion downstream of the highway without use of concentration reductions or hydrograph extension.

6. Non-Stochastic Background Concentrations-An analysis of the use of grab sampling and non-stochastic upstream modeling methods was done to evaluate the potential effects of these approaches on modeling outcomes. This analysis shows that there is a small probability that a single grab sample will properly characterize the average of EMC values and that the probability of exceedance may rest entirely on the single value that is used. The pattern of increasing water-quality exceedances that is produced by use of mixing models that do not simulate variations in upstream concentrations does not represent the pattern of exceedances that would occur with actual upstream variation. Therefore, use of such methods would be misleading and could easily be used to mislead decision makers about the risk for adverse effects of runoff on receiving waters.
7. Example sites-Example analyses were provided for six study sites to illustrate the risk-based information that SELDM will produce. These analyses show that the potential effects of highway runoff on receiving-water quality downstream of the outfall depends on the ratio of drainage areas (dilution), the quality of the receiving water upstream of the highway, and the concentration of the criteria for the constituent of interest. Two or more highway-runoff datasets were used to simulate highwayrunoff quality at each study site. These simulations were done to show the potential influence of surrogate data-set selection. These analyses show that the probability of exceedance may depend on the input statistics used, thus careful selection of representative values is important.

\section{Acknowledgments}

The authors thank William Fletcher (ODOT) and Jeff Moore (ODOT) for helping to scope the project, identify sites of interest, evaluate water-quality selections, and providing feedback on this report. The authors also thank Susan C. Jones of the Federal Highway Administration Office of Program Development and Environmental Review for technical support and feedback on this report.

\section{References Cited}

American Association of State Highway and Transportation Officials, 2010, State-of-the-Practice Report-TMDLs: American Association of State Highway and Transportation Officials, Center for Environmental Excellence, 19 p., http://environment.transportation.org/pdf/communities_of_ practice/tmdls.pdf

Athayde, D.N., Shelley, P.E., Driscoll, E.D., and Boyd, G.B., 1983, Results of the nationwide urban runoff program, v. I-Final report: U.S. Environmental Protection Agency Water Planning Division Report WH-554, 186 p.

Bleiwas, D.I., 2006, Stocks and flows of lead-based wheel weights in the United States: U.S. Geological Survey Open-File Report 2006-1111, 6 p.

Bohaboy, Spencer, Matzke, Andrea, Ades, Dennis, and Wigal, Jennifer, 2013, Implementation instructions for dissolved metals water quality criteria in reasonable potential analysis and water quality-based effluent limits calculations: Oregon Department of Environmental Quality Technical Memorandum, $4 \mathrm{p}$. 
Breault, R.F., and Granato, G.E., 2003, A synopsis of technical issues for monitoring trace elements in highway and urban runoff, in Granato, G.E., Zenone, Chester, and Cazenas, P.A., eds., National highway runoff water-quality data and methodology synthesis, v. I-Technical issues for monitoring highway runoff and urban stormwater: Federal Highway Administration Report FHWA-EP-03-054, p. 165-233.

Cunnane, C., 1978, Unbiased plotting positions-A review: Journal of Hydrology, v. 37, p. 205-222.

Di Toro, D.M., 1984, Probability model of stream quality due to runoff: Journal of Environmental Engineering, v. 110, no. 3 , p. 607-628.

Driscoll, E.D., DiToro, D.M., and Thomann, R.V., 1979, A statistical method for assessment of urban runoff: U.S. Environmental Protection Agency, EPA 440/3-79-023, $200 \mathrm{p}$.

Driscoll, E.D., Shelley, P.E., Gaboury, D.R., and Salhotra, Atul, 1989, A probabilistic methodology for analyzing water quality effects of urban runoff on rivers and streams: U.S. Environmental Protection Agency, Office of Water, EPA 841-R89-101, 128 p.

Driscoll, E.D., Shelley, P.E., and Strecker, E.W., 1990a, Pollutant loadings and impacts from highway stormwater runoff, Volume I-Design procedure: U.S. Federal Highway Administration Final Report, FHWA-RD-88-006, 67 p.

Driscoll, E.D., Shelley, P.E., and Strecker, E.W., 1990b, Pollutant loadings and impacts from highway stormwater runoff, Volume III-Analytical investigation and research report: Federal Highway Administration Final Report, FHWA-RD-88-008, $160 \mathrm{p}$.

Dupuis, T.V., 2002, Assessing the impacts of bridge deck runoff contaminants in receiving waters, v. 2, Practitioner's handbook: Transportation Research Board, National Cooperative Highway Research Program NCHRP Report 474, 93 p.

Elshorbagy, A., Parasuraman, K., Putz, G., and Ormsbee, L., 2007, Deterministic and probabilistic approaches to the development of $\mathrm{pH}$ total maximum daily loads - $\mathrm{A}$ comparative analysis: Journal of Hydroinformatics, v. 9, no. 3, p. 203-213.

Falcone, J.A., Carlisle, D.M., Wolock, D.M., and Meador, M.R., 2010, GAGES - A stream gage database for evaluating natural and altered flow conditions in the conterminous United States: Ecological Archives E091-045-D1, accessed April 28, 2012, at http://esapubs. org/Archive/ecol/E091/045/default.htm.
Granato, G.E., 2006, Kendall-Theil Robust Line (KTRLineversion 1.0)—A visual basic program for calculating and graphing robust nonparametric estimates of linearregression coefficients between two continuous variables: U.S. Geological Survey Techniques and Methods, book 4, chap. A7, 31 p. http://pubs.usgs.gov/tm/2006/tm4a7/.

Granato, G.E., 2009, Computer programs for obtaining and analyzing daily mean streamflow data from the U.S. Geological Survey National Water Information System Web Site: U.S. Geological Survey Open-File Report 2008-1362, 5 appendixes, 123 p., CD-ROM.

Granato, G.E., and Cazenas, P.A., 2009, Highway-Runoff Database (HRDB Version 1.0)—A data warehouse and preprocessor for the stochastic empirical loading and dilution model: Federal Highway Administration, FHWAHEP-09-004, 57 p., http://webdmamrl.er.usgs.gov/g1/ FHWA/FHWA-HEP-09-004/FHWA-HEP-09-004.pdf.

Granato, G.E., Carlson, C.S., and Sniderman, B.S., 2009, Methods for development of planning-level estimates of water quality at unmonitored sites in the conterminous United States: Federal Highway Administration, FHWAHEP-09-003, 53 p., http://webdmamrl.er.usgs.gov/g1/ FHWA/FHWA-HEP-09-003/FHWA-HEP-09-003.pdf.

Granato, G.E., 2010, Methods for development of planninglevel estimates of stormflow at unmonitored stream sites in the conterminous United States: Federal Highway FHWAHEP-09-005, 101 p., http://webdmamrl.er.usgs.gov/g1/ FHWA/FHWA-HEP-09-005/FHWA-HEP-09-005.pdf.

Granato, G.E., 2012, Estimating basin lagtime and hydrograph-timing indexes used to characterize stormflows for runoff-quality anlaysis: U.S. Geological Survey Scientific Investigations Report 2012-5110, 47 p., with digital media at http://pubs.usgs.gov/sir/2012/5110/.

Granato, G.E., 2013, Stochastic empirical loading and dilution model (SELDM) Version 1.0.0: U.S. Geological Survey Techniques and Methods, book 4, Chapter C3, 112 p., http:// pubs.usgs.gov/tm/04/c03/.

Haan, C.T., 1977, Statistical methods in hydrology: Ames, Iowa, Iowa State University Press, 378 p.

Helsel, D.R., 2005, Nondetects and data analysis: New York, Wiley, $250 \mathrm{p}$.

Helsel, D.R., and Hirsch, R.M., 2002, Statistical methods in water resources-Hydrologic analysis and interpretation: U.S. Geological Survey Techniques of Water-Resources Investigations, book 4, chap. A3, $510 \mathrm{p}$. 
Herrera Environmental Consultants, Inc., 2009, HI-RUN Highway runoff dilution and loading model documentation-Analysis of highway stormwater water quality effects for Endangered Species Act consultations: Washington State Department of Transportation, accessed October 15, 2013, at http://www.wsdot. wa.gov/NR/rdonlyres/03BC9C1B-7376-431A-A99F340BD456AFFA/0/BA_HiRunTechDoc.pdf.

Herrera Environmental Consultants, Inc., 2011a, HI-RUN Highway runoff dilution and loading model user's guide-Analysis of highway stormwater runoff effects for Endangered Species Act consultations: Washington State Department of Transportation, accessed October 15, 2013, at http://www.wsdot.wa.gov/NR/rdonlyres/85B43C71DEBE-478C-A468-C6BF64D86B64/0/BA HIRUNUsersGuide.pdf.

Herrera Environmental Consultants, 2011b, Highway runoff characterization monitoring study: Portland, Oregon, Herrera Environmental Consultants Report 05-03287-003, $812 \mathrm{p}$.

Interagency Advisory Committee on Water Data, 1982, Guidelines for determining flood-flow frequency: U.S. Geological Survey Bulletin 17B of the Hydrology Subcommittee, Office of Water Data Coordination, Reston, Va., 183 p.

Kirby, W.H., 1972, Computer-oriented Wilson-Hilferty transformation that preserves the first three moments and the lower bound of the Pearson type 3 distribution: Water Resources Research, v. 8, no. 5, p. 1251-1254.

Kuzin, S.A., and Adams, B.J., 2010, Probabilistic approach to estimation of urban storm-water TMDLs-Regulated catchment: Journal of Irrigation and Drainage Engineering, v. 136 , no. 9 , p. 627-636.

Lau, Sim-Lin, Han, Younghan, Kang, Joo-Hyon, Kayhanian, Masoud, and Stenstrom, M.K., 2009, Characteristics of highway stormwater runoff in Los Angeles-Metals and polycyclic aromatic hydrocarbons: Water Environment Research, v. 81, no. 3, p. 308-318.

Leisenring, M., Clary, J., Stephenson, J., and Hobson, P., 2010, International stormwater best management practices (BMP) database pollutant category summary-Nutrients: Water Environment Research Foundation, accessed September 30, 2013 at http://www.bmpdatabase.org/.

Litke, D.W., 1999, Review of phosphorus control measures in the United States and their effects on water quality. U.S. Geological Survey Water-Resources Investigations Report 99-4007, 38 p.
National Cooperative Highway Research Program, 2006, Evaluation of best management practices for highway runoff control: Transportation Research Board NCHRP Report 565, 143 p.

Natural Resources Conservation Service, 1998, Tables of percentage points of the Pearson Type III distribution: Natural Resources Conservation Service, Conservation Engineering Division Technical Release 38, 17 p.

Novotny, Vladimir, 2004, Simplified data based total maximum daily loads, or the world is log-normal: Journal of Environmental Engineering, v. 130, no. 6, p. 674-683.

Omernik, J.M., 1987, Ecoregions of the conterminous United States: Annals of the Association of American Geographers, v. 77 , no. 1 , p. 118-125, scale 1:7,500,000.

Oregon Department of Environmental Quality, 2007, TMDL implementation plan guidance-For state and local government designated management agencies: Oregon Department of Environmental Quality, Water Quality Division Document \#07-WQ-004, 30 p., http://www.deq. state.or.us/wq/tmdls/docs/impl/07wq004tmdlimplplan.pdf.

Oregon Department of Environmental Quality, 2013, Water quality standards for toxic pollutants: Oregon Department of Environmental Quality, Water Quality Standards, accessed September 26, 2013, at: http://www.deq.state. or.us/wq/standards/toxics.htm\#Cur.

Park, Daeryong, Loftis, J.C., and Roesner, L.A., 2011, Modeling performance of storm water best management practices with uncertainty analysis: Journal of Hydrologic Engineering, v. 16, no. 4, p. 332-344.

Rice, K.C., 1999, Trace-element concentrations in streambed sediment across the conterminous United States: Environmental Science Technology, v. 33, p. 2,499-2,504.

Ries, K.G., Guthrie, J.G., Rea, A.H., Steeves, P.A., and Stewart, D.W., 2008, StreamStats-A water resources web application: U.S. Geological Survey Fact Sheet 2008-3067, 6 p., http://pubs.usgs.gov/fs/2008/3067/.

Rossman, L.A., 1990, DFLOW User's manual: U.S. Environmental Protection Agency Office of Research and Development, Risk Reduction Engineering Laboratory, $26 \mathrm{p}$.

Schwartz, S.S., and Naiman, D.Q., 1999, Bias and variance of planning-level estimates of pollutant loads: Water Resources Research, v. 35, no. 11, p. 3475-3487.

Smith, K.P., 2002, Effectiveness of three best management practices for highway-runoff quality along the Southeast Expressway, Boston Massachusetts: U.S. Geological Survey Water-Resource Investigation Report 02-4059, 62 p. 
Smith, K.P., and Granato, G.E., 2010, Quality of stormwater runoff discharged from Massachusetts highways, 2005-07: U.S. Geological Survey Scientific Investigations Report 2009-5269, 198 p., with CD-R, http://pubs.usgs.gov/ sir/2009/5269/.

Strecker, Eric, Mayo, Lynn, Quigley, Marcus, and Howell, James, 2001, Guidance manual for monitoring highway runoff water quality: Federal Highway Administration Report FHWA-EP-01-022, 206 p.

Stricker, V.A., and Sauer, V.B., 1982, Techniques for estimating flood hydrographs for ungaged urban watersheds: U.S. Geological Survey Open-File Report 82-365, 24 p.

U.S. Environmental Protection Agency, 2004a, Flow 101Basic Information provides information on the development and uses of DFLOW and the differences between DFLOW3.0 and earlier versions: U.S. Environmental Protection Agency Water Wuality Models, accessed August 4, 2013, at http://epa.gov/waterscience/models/ dflow/flow 101.htm.

U.S. Environmental Protection Agency, 2004b, Level III Ecoregions: U.S. Environmental Protection Agency Western Ecology Division, accessed August 4, 2013, at http://www. epa.gov/wed/pages/ecoregions/level_iii.htm.

U.S. Environmental Protection Agency, 2005, National management measures to control nonpoint source pollution from urban areas: U.S. Environmental Protection Agency Report EPA 841-B-05-004, 518 p.
U.S. Environmental Protection Agency, 2009, National Pollutant Discharge Elimination System (NPDES) - MultiSector General Permit (MSGP) for stormwater discharges associated with industrial activity authorization to discharge under the national pollutant discharge elimination system: accessed September 30, 2013, at http://cfpub.epa.gov/npdes/ stormwater/msgp.cfm.

U.S. Environmental Protection Agency, 2013, National summary of impaired waters and TMDL Information: U.S. Environmental Protection Agency, Watershed Assessment, Tracking \& Environmental Results, accessed September 30, 2013, at http://iaspub.epa.gov/waters10/attains_nation_ cy.control?p_report_type $=\mathrm{T}$.

Warn, A.E., and Brew, J.S., 1980, Mass balance: Water Research, v. 14, p. 1427-1434.

Weick, Rodney, and Brindle, Frances, 2011, Memorandum of understanding ODOT and DEQ: Oregon Department of Environmental Quality, Miscellaneous Contracts and Agreements No.27323, 11 p. http://www.deq.state.or.us/wq/ pubs/igas/ODOTMOU2011.pdf.

Wong, T.H.F., Fletcher, T.D., Duncan, H.P., and Jenkins, G.A., 2006, Modeling urban stormwater treatment-A unified approach: Ecological Engineering, v. 27, no. 1, p. 58-70. 


\section{Appendix A. Stochastic Empirical Loading and Dilution Model (SELDM) Related Products}

Along with SELDM, a variety of software utility and data products (created prior to this study) are available to assist the user in creating the necessary model inputs. Although they are only briefly described below, the user should be aware of these products when setting up their SELDM application. The software utility and data products and related publications-in addition to the SELDM model and manual (Granato, 2013)currently (2014) are available at: http://webdmamrl.er.usgs. gov/g1/fhwa/SELDM.htm, accessed on March 3, 2014.

\section{SELDM Contained Storm-Event Precipitation and Pre-Storm Streamflow Statistics}

The development of storm-event precipitation, pre storm streamflow, and runoff coefficient statistics described in appendix B, which are already available to the user within SELDM, is described in Granato (2010).

\section{Synoptic Precipitation Analysis Facilitator (SPAF)}

The Synoptic Precipitation Analysis Facilitator is a visual basic shell program that provides a graphical user interface for running the EPA/FHWA programs SYNPREP and SYNOP2000, which are command-line FORTRAN programs. The SYNPREP and SYNOP2000 programs use NOAA precipitation-record text files to calculate the synoptic precipitation statistics used by SELDM. The SPAF program and the latest versions of SYNPREP and SYNOP2000 are published in the FHWA stormflow report (Granato, 2010).

\section{Streamflow Data Analysis Programs}

Five computer programs were developed to obtain and analyze USGS streamflow data for estimation of pre-storm flows in SELDM. These programs, which are listed below, are described in Granato (2009).

\section{Get NWIS WEB Streamflow Files (GNWISO)}

This program is used to obtain and reformat dailymean streamflow data from the USGS National Information System Web (http://waterdata.usgs.gov/usa/nwis/sw, accessed February 13, 2014.) Users are able to download information and data for one or more (batch) streamflow-gaging stations.

\section{Make Plotting Position file (MkPP Version 1.0)}

This program allows users to generate plotting positions and normal scores for daily mean streamflow files from the
USGS NWISWeb site. This program is designed to facilitate analysis of flow duration curves to evaluate hydrologic similarity among nearby streamgages.

\section{Streamflow Record-Extension Facilitator (SREF Version 1.0)}

This program allows users to extend or augment available streamflow data by using long-term streamflow records at hydrologically similar sites. This program is designed to provide the long-term flow statistics used by SELDM from short-term records from USGS streamgages or from individual discharge measurements taken at the site of interest.

\section{Streamflow (0) Statistics (QSTATS Version 1.0)}

QSTATS is a program for calculating population statistics for streamflow data. This program calculates the proportion of zero flows and the mean, standard deviation, and skew of the logarithms of non-zero flows, which are used by SELDM to generate pre-storm flows. It also is used to calculate the arithmetic statistics, which are used to assess hydrologic similarity among nearby sites.

\section{Make DFLOW3 Input Files (MkDF Version 1.0)}

This program is used to create preformatted dailymean streamflow input files for the EPA DFLOW3 computer program (U.S. Environmental Protection Agency, 2004b). The DFLOW3 program can be used to compute the 7-day 10-year flow (7Q10), the 1-day 3-year biological flow (1B3), and the 4-day 3-year biological flow (4B3) statistics. These statistics are not used to calculate pre-storm flows, but are used to assess hydrologic similarity among nearby sites. These statistics, which are commonly used to formulate water-quality criteria, also are useful for comparison to the range of stormflows generated by SELDM because commonly used criteria are not suitable for application to stormwater problems (Athayde and others, 1983; Dupuis, 2002).

\section{Basin Lag Time and Triangular Hydrograph Recession Ratio}

Techniques for estimating basin lag time and triangular hydrograph recession ratios are described in Granato (2012). The triangular hydrograph recession ratio of the rising limb over the falling limb is a required input to SELDM to characterize the timing of storm runoff from the upstream basin. Default values of 1, 1.85, and 4.4 for the minimum, most probable value, and maximum recession ratios are available as the pre-defined selection in SELDM (Granato, 2013), but these values were largely based on data from the New England States. 


\section{Highway-Runoff Database (HRDB)}

The highway-runoff database was developed to serve as a data warehouse for current and future highway-runoff data sets (Granato and Cazenas, 2009; Smith and Granato, 2010). The latest version of the HRDB (Smith and Granato, 2010) contains 54,384 EMC measurements (including 194 waterquality constituents) from 4,186 storm events, monitored at 117 highway-runoff monitoring sites in the conterminous United States. The user can get data and statistics from the HRDB to estimate the quality of runoff by use of random runoff-quality statistics or robust regression equations with a stochastic error component. The user can estimate the quantity of runoff by analysis of precipitation and flow data provided by the HRDB. The database is useful for selecting surrogate highway water-quality data if monitored data at a study site are unavailable.

\section{Kendall-Theil Robust Line (KTRLine)}

KTRLine is a visual basic program for calculating and graphing robust nonparametric estimates of linear relations between two continuous variables (Granato, 2006). This program is useful when estimating dependent variable statistics and transport curves, which can be used to characterize the upstream basin concentration component (Granato, 2006; Granato and Cazenas, 2009; Granato and others, 2009). The program also is useful for estimating runoff coefficients and other stormflow variables (Granato, 2010).

\section{Surface Water Quality Data Miner (SWODM)}

SWQDM is a database application used to create preformatted input files of streamflow and chemical constituent data needed for the Kendall-Theil Robust Line program (Granato and others, 2009). Input data sets can be downloaded by site location or by any of the EPA defined level III nutrient ecoregions (Omernik, 1987; U.S. Environmental Protection Agency, 2004b). SWQDM can also compute streamflow statistics used in SELDM by site location or by Ecoregion. The SWQDM database contains over 24,000 sites, so the user can use compiled flow and chemical data to create transport curves using the Kendall-Theil Robust Line program. 


\section{Appendix B. Spatial Data Layers Containing Storm-Event Precipitation and Pre-Storm Streamflow Statistics}

Storm-event precipitation and pre-storm streamflow statistics are required input in SELDM in determining discharge from the highway catchment and the upstream basin. Storm-event precipitation statistics include the event volume (in inches), event duration (in hours), time between events (in hours), number of events per year, and total annual precipitation (in inches). The streamflow statistics used by SELDM to generate pre-storm flows are the proportion of zero flows and the average, standard deviation, and skew of the logarithms of non-zero streamflows. The arithmetic average, standard deviation, and skew; the median of all flows and non-zero flows; and the low-flow statistics (the 7Q10, 4B3, and 1B3) are provided to help assess hydrologic similarity among candidate streamgages. The most accurate method of estimating these statistics is using precipitation and streamflow data measured at the study site when it is available and entering these statistics as user-defined values. However, if measured times-series data are unavailable, the user may select precipitation statistics by rain zone, by ecoregion, or by using statistics from nearby long-term rain gages. Similarly, the user may select streamflow statistics by ecoregion or by using statistics from nearby long-term streamgages. Precipitation or streamflow statistics calculated using data collected from nearby sites that are not in the SELDM database also can be entered as user-defined statistics. For this study, an additional option for estimating storm-event precipitation and pre-storm streamflow statistics for use as user-defined inputs to SELDM was created through a spatial interpolation of the statistics of precipitation and streamflow stations within Oregon using a GIS Kriging algorithm.

\section{Storm-Event Precipitation}

Methods used to compute storm-event precipitation statistics for the 2,610 NOAA stations that are contained within SELDM are described in Granato (2010). For this study, an attempt was first made to increase the number of hourly precipitation stations available in Oregon. Some additional stations where hourly precipitation data are collected were identified. The City of Portland and the Bureau of Reclamation AgriMet program both have a network of hourly precipitation gages. However, none of these additional stations had period of records as lengthy as the 25-year periods of record of the NOAA stations currently in SELDM. For this study, the statistics from the existing set of NOAA stations were selected for the spatial interpolation analyses. To create a data layer covering all of Oregon, all 366 NOAA stations from rain zones 11, 13, 14, and 15, as described in Granato (2010), were selected. The study sites located in the Portland-Salem region are all within rain zone 15 . However, the Wall Creek site, located near Ashland, Oregon, is within rain zone 14. Although many of these stations are located outside of Oregon in neighboring states, they were used in the analysis so as to create a more continuous and robust spatial interpolation at the state lines.

The spatial interpolation was done using Environmental Systems Research Institute (ESRI) ArcMap 10.0 software. Kriging interpolation is a feature under the Spatial Analyst Tools, which was used to create GIS data layers containing interpolated statistics for locations where data are unavailable. Default options were selected to create all the data layers, which included:

- Kriging method: Ordinary

- Semi-variogram model: Spherical

- Search radius: Variable

- Search radius settings: 12 points

GIS data layers created for each of the storm-event precipitation statistics are identified in table B1. Storm-event precipitation statistics downloaded from the interpolated data layers for the six study sites are in table 3 .

Table B1. Spatially interpolated Geographic Information System data layers containing storm-event precipitation statistics.

[Table B1 is a Microsoft ${ }^{\oplus}$ Excel file and can be downloaded at http://pubs. usgs.gov/sir/2014/5099/.]

\section{Pre-Storm Streamflow}

To create spatially interpolated data layers for the prestorm streamflow statistics, a set of 348 USGS streamflow stations covering the Pacific Northwest and northern California was assembled. The main criteria used for selecting the stations was having at least 20 years of continuous daily-mean streamflow record and not being located immediately downstream of a dam or in a highly regulated water way. However, stations with drainages impacted by urbanization or deforestation were included. For all USGS stations in Oregon, the period of record used to compute statistics was extended from 1960 to 2011 when data were available. Many USGS streamflow stations in Oregon were 
transferred to the Oregon Department of Water Resources (OWRD) in the early 1990s for continued operation by OWRD. It was possible to augment the period of record for 36 of these stations by combining USGS and OWRD flow data. With the expanded set of streamflow stations and additional years of streamflow record, pre-storm streamflow statistics for this study were recomputed. These stations and their statistics, which were used to create the spatially interpolated data layers from this study, are included in table B2.

Table B2. Pre-storm streamflow statistics for streamflow-gaging stations used to create data layers.

[Table B2 is a Microsoft ${ }^{\circ}$ Excel file and can be downloaded at http://pubs. usgs.gov/sir/2014/5099/.]

As with the storm-event precipitation statistics, spatial interpolation to create data layers for the pre-storm streamflow statistics was done using ESRI ArcMap 10.0 software. The default Kriging options used to create all the data layers included:

- Kriging method: Ordinary

- Semi-variogram model: Spherical

- Search radius: Variable

- Search radius settings: 12 points
Data layers created for each of the pre-storm streamflow statistics are identified in table B3. However, statistics from the data layers were not used for the six study sites because more accurate statistics were computed using measured streamflow data in the vicinity of the study sites (table 4). Statistics for Miller Creek and the unnamed creek study sites were based on the average of Willamette Valley ecoregion streamgages computed by SELDM. Statistics for the two Tryon Creek study sites were computed using daily-mean streamflow data (WY 2002-11) from the Tryon Creek streamgage (14211315). A MOVE 1 regression was used to extend the period of record of the Tryon Creek low-flow statistics. Tryon Creek statistics were regressed with statistics from the USGS streamflow gage on Fanno Creek at 56th Avenue in Portland (14206900) using an additional eleven years of streamflow record (WY 1991-2011). Statistics for Murder Creek and Wall Creek were based on records from USGS streamflow gages on Mary's River (14171000) and Emigrant Creek (14350000), respectively, and computed by SELDM. However, for many locations around Oregon where the density of streamflow sites is limited, statistics from the spatially interpolated data layers could be more accurate than using data from the nearest streamflow site or the average of streamflow sites within an ecoregion.

Table B3. Spatially interpolated Geographic Information System data layers containing pre-storm streamflow statistics.

[Table B3 is a Microsoft ${ }^{\oplus}$ Excel file and can be downloaded at http://pubs. usgs.gov/sir/2014/5099/.] 


\section{Appendix C. Triangular Hydrograph Recession Ratios}

The triangular hydrograph is used in SELDM to determine the timing and duration of storm-runoff from the study site upstream basin. As described in Granato (2012), it is necessary in water-quality modeling to estimate the volume of upstream flow that occurs concurrently with storm runoff from a highway (or other site of interest). Although stormrunoff timing does not affect the total storm load entering the downstream receiving water body from the highway, it does affect the proportion of the total upstream flow and load used to calculate the downstream flows, concentrations, and loads concurrent to the highway or BMP discharge to the stream. The shape of the hydrograph in SELDM is determined by the ratio of the falling limb to the rising limb. For example, a value of 2 would indicate that the falling limb time period is twice as long as the rising limb time period. In basins where slope is a major factor in runoff, steep sloped basins would be expected to have smaller recession ratios than flatter basins. Methods for determining triangular hydrograph recession ratios are provided in Granato (2012). If an upstream basin has a streamgage upstream of the highway crossing and has a sufficient record of streamflow data, it is possible to compute a best-fit recession ratio using a spreadsheet utility program, "Hydrograph01.xls," included in Granato (2012). The program optimizes a least-squares fit of a triangular hydrograph to the unit hydrograph calculated from the data. A minimum of 20 storm-event data sets containing instantaneous (15-minute) flows are typically used in these analyses. Another spreadsheet from Granato (2012), "FitTriangular. xls", is then used to compute minimum, most probable value (MPV), and maximum recession ratio values based on the set of computed recession ratios, which are used as input to SELDM. If the streamflow gage is not located in the study site upstream basin, it is possible to perform a best-fit recession ratio analysis using streamflow data measured at a nearby basin having similar topographic, geologic, and land use conditions. If local streamflow data are unavailable, guidelines for estimating recession ratios based on basin characteristics are provided in Granato (2012). Table 7 in Granato (2102) contains a list of best-fit triangular-hydrograph recession ratios computed for 41 USGS streamflow gages located in Massachusetts, Pennsylvania, Maryland, North Carolina, Kentucky, and California.
For two of the six sites in this study, Tryon Creek at Oregon Route 43 and Wall Creek, it was possible to estimate best-fit triangular-hydrograph recession ratios with available local streamflow data. Using instantaneous flow data measured at the USGS streamgage on Tryon Creek (14211315) and the "Hydrograph01.xls" program, a recession ratio was estimated for the stream based on 21 storm events that occurred between 2001 and 2012 (table C1). The streamgage is located between Tryon Creek at Interstate 5 and Tryon Creek at Oregon Route 43 . Because the basins above the gage and above the Oregon Route 43 study site have similar characteristics, the estimated recession ratio was used as input to the Oregon Route 43 study site SELDM simulations. However, the estimated recession ratio was not suitable for the Tryon Creek at Interstate 5 study site because that upstream basin is almost entirely urbanized and has a higher impervious fraction than the downstream basins. For the Wall Creek study site it was possible to estimate a recession ratio using instantaneous flow measured at nearby West Fork Ashland Creek near Ashland, Oregon (14353000) (table C2).

For the four other study sites, Miller Creek, Unnamed Creek, Tryon Creek at Interstate 5, and Murder Creek, it was necessary to select surrogate triangular-hydrograph recession ratios from among 41 streamflow gages listed in table 7 in Granato (2012) based on similarities in drainage area, basin length, basin slope, imperviousness, and dominant land use (table 2) . Caldwell Creek (01174600) in Massachusetts, a small forested basin, was selected for the Miller and Unnamed Creek study sites. Castro Valley Creek (11181008) in California, a developed urbanized basin, was selected for the Tryon Creek at Interstate 5 study site. Sevenmile Creek (01175670) in Massachusetts was selected for the Murder Creek study site because both basins are rural and low gradient. 
Table C1. Best-fit triangular storm-event hydrograph recession ratios for streamgage (14211315) Tryon Creek near Lake Oswego, Oregon.

\begin{tabular}{|c|c|c|c|c|c|c|}
\hline \multicolumn{7}{|c|}{\begin{tabular}{|l} 
Best-fit triangular storm-event hydrograph recession ratios \\
14211315 Tryon Creek near Lake Oswego, Oregon
\end{tabular}} \\
\hline Summary: & Start date & End date & $\begin{array}{l}\text { Ratios: } \\
\text { Falling/Rising }\end{array}$ & Rising & Base & Mean \\
\hline Storm 01 & $12 / 22 / 0512: 15$ & $12 / 22 / 0521: 30$ & 2.17 & 7.60 & 24.12 & 10.57 \\
\hline Storm 02 & $1 / 17 / 0610: 00$ & $1 / 17 / 0618: 45$ & 1.54 & 11.35 & 28.87 & 13.41 \\
\hline Storm 03 & $2 / 11 / 1020: 30$ & $2 / 11 / 1023: 15$ & 2.40 & 2.90 & 9.87 & 4.26 \\
\hline Storm 04 & $4 / 26 / 1117: 00$ & $4 / 26 / 1120: 00$ & 2.56 & 2.91 & 10.37 & 4.43 \\
\hline Storm 05 & $5 / 11 / 1116: 45$ & $5 / 11 / 1121: 45$ & 2.12 & 5.44 & 16.95 & 7.46 \\
\hline Storm 06 & $2 / 17 / 1215: 45$ & $2 / 17 / 1222: 15$ & 2.37 & 7.19 & 24.25 & 10.48 \\
\hline Storm 07 & $2 / 24 / 1219: 15$ & $2 / 24 / 1222: 00$ & 2.49 & 2.44 & 8.50 & 3.64 \\
\hline Storm 08 & $3 / 18 / 0223: 00$ & $3 / 19 / 0220: 30$ & 4.81 & 6.87 & 39.86 & 15.57 \\
\hline Storm 09 & $3 / 6 / 024: 00$ & $3 / 6 / 0223: 00$ & 3.52 & 6.60 & 29.80 & 12.13 \\
\hline Storm 10 & $4 / 10 / 0212: 00$ & $4 / 10 / 0216: 30$ & 2.94 & 1.93 & 7.62 & 3.18 \\
\hline Storm 11 & $4 / 9 / 0220: 00$ & $4 / 10 / 022: 30$ & 1.57 & 3.66 & 9.41 & 4.36 \\
\hline Storm 12 & $11 / 13 / 0121: 00$ & $11 / 14 / 0112: 30$ & 1.61 & 9.52 & 24.81 & 11.44 \\
\hline Storm 13 & $12 / 27 / 02 \quad 19: 30$ & $12 / 28 / 021: 30$ & 4.38 & 1.12 & 6.03 & 2.38 \\
\hline Storm 14 & $4 / 12 / 0323: 30$ & $4 / 13 / 038: 00$ & 2.18 & 3.47 & 11.01 & 4.83 \\
\hline Storm 15 & $1 / 12 / 0322: 30$ & $1 / 13 / 032: 00$ & 3.65 & 1.21 & 5.63 & 2.28 \\
\hline Storm 16 & $1 / 2 / 0410: 30$ & $1 / 3 / 042: 00$ & 2.67 & 7.81 & 28.65 & 12.16 \\
\hline Storm 17 & $8 / 25 / 04 \quad 15: 00$ & $8 / 25 / 0422: 00$ & 1.59 & 2.78 & 7.21 & 3.33 \\
\hline Storm 18 & $8 / 26 / 0419: 30$ & $8 / 26 / 0423: 30$ & 1.69 & 2.12 & 5.70 & 2.61 \\
\hline Storm 19 & $11 / 20 / 0316: 45$ & $11 / 20 / 0319: 45$ & 4.97 & 1.76 & 10.49 & 4.08 \\
\hline Storm 20 & $1 / 19 / 049: 00$ & $1 / 19 / 0416: 00$ & 3.53 & 2.71 & 12.27 & 4.99 \\
\hline Storm 21 & $12 / 11 / 042: 30$ & $12 / 11 / 0410: 00$ & 4.04 & 2.81 & 14.18 & 5.67 \\
\hline
\end{tabular}

Computed using 'FitTriangular.xlsm'; used as input to SELDM:

\begin{tabular}{|l|l|l|}
\hline Min & MPV & Max \\
\hline 1.29 & 1.29 & 5.84 \\
\hline
\end{tabular}


Table C2. Best-fit triangular storm-event hydrograph recession ratios for streamgage (14353000) West Fork Ashland Creek near Ashland, Oregon.

\begin{tabular}{|c|c|c|c|c|c|c|}
\hline \multicolumn{7}{|c|}{$\begin{array}{l}\text { Best-fit triangular storm-event hydrograph recession ratios } \\
14350000 \text { West Fork Ashland near Ashland, Oregon }\end{array}$} \\
\hline Summary: & Start date & End date & $\begin{array}{l}\text { Ratios: } \\
\text { Falling/Rising }\end{array}$ & Rising & Base & Mean \\
\hline Storm 01 & 10/19/07 5:15 & 10/19/07 19:30 & 1.88 & 17.66 & 50.89 & 22.85 \\
\hline Storm 02 & $8 / 18 / 0817: 45$ & $8 / 19 / 086: 15$ & 1.88 & 13.54 & 39.05 & 17.53 \\
\hline Storm 03 & $11 / 8 / 08$ 16:45 & $11 / 9 / 086: 15$ & 2.04 & 17.63 & 53.69 & 23.77 \\
\hline Storm 04 & $11 / 11 / 08$ 10:00 & $11 / 12 / 08$ 12:15 & 2.05 & 31.76 & 96.88 & 42.88 \\
\hline Storm 05 & $2 / 22 / 0923: 30$ & $2 / 23 / 098: 30$ & 2.67 & 10.24 & 37.57 & 15.93 \\
\hline Storm 06 & $5 / 4 / 0917: 15$ & $5 / 4 / 0923: 45$ & 2.35 & 7.84 & 26.28 & 11.37 \\
\hline Storm 07 & $12 / 30 / 118: 30$ & $12 / 30 / 1117: 45$ & 5.07 & 6.35 & 38.54 & 14.96 \\
\hline Storm 08 & $9 / 19 / 107: 00$ & $9 / 20 / 102: 00$ & 2.23 & 20.63 & 66.65 & 29.09 \\
\hline Storm 09 & $10 / 24 / 106: 15$ & $10 / 24 / 10 \quad 12: 45$ & 2.17 & 8.71 & 27.60 & 12.10 \\
\hline Storm 10 & $3 / 23 / 0821: 15$ & $3 / 26 / 0823: 00$ & 5.30 & 53.51 & 336.97 & 130.16 \\
\hline Storm 11 & $11 / 3 / 0816: 15$ & $11 / 4 / 080: 30$ & 3.07 & 7.55 & 30.75 & 12.77 \\
\hline Storm 12 & $12 / 26 / 067: 30$ & $12 / 27 / 0620: 30$ & 3.76 & 29.47 & 140.13 & 56.53 \\
\hline Storm 13 & $1 / 6 / 101: 30$ & $1 / 8 / 101: 00$ & 3.48 & 44.15 & 197.88 & 80.68 \\
\hline Storm 14 & $11 / 9 / 08$ 16:45 & $11 / 10 / 082: 30$ & 3.09 & 9.65 & 39.43 & 16.36 \\
\hline Storm 15 & $11 / 6 / 091: 30$ & $11 / 6 / 0918: 15$ & 2.42 & 16.61 & 56.79 & 24.47 \\
\hline Storm 16 & $1 / 22 / 0315: 30$ & $1 / 23 / 037: 30$ & 4.52 & 5.54 & 30.56 & 12.03 \\
\hline Storm 17 & $1 / 27 / 034: 30$ & $1 / 28 / 034: 00$ & 5.36 & 7.26 & 46.15 & 17.80 \\
\hline Storm 18 & $2 / 1 / 031: 30$ & $2 / 1 / 0312: 30$ & 1.94 & 8.00 & 23.48 & 10.49 \\
\hline Storm 19 & $12 / 12 / 0622: 15$ & $12 / 15 / 0620: 30$ & 5.52 & 45.00 & 293.22 & 112.74 \\
\hline Storm 20 & $11 / 3 / 0517: 00$ & $11 / 4 / 058: 00$ & 2.14 & 8.51 & 26.72 & 11.74 \\
\hline \multirow[t]{3}{*}{ Storm 21} & $11 / 13 / 0616: 45$ & $11 / 14 / 0623: 15$ & 3.27 & 20.69 & 88.36 & 36.35 \\
\hline & & & & & & \\
\hline & & & & & & \\
\hline \multicolumn{7}{|c|}{ Computed using 'FitTriangular.xIsm'; used as input to SELDM: } \\
\hline & & & & & & \\
\hline Min & MPV & Max & & & & \\
\hline 1.41 & 1.41 & 6.67 & & & & \\
\hline
\end{tabular}



Publishing support provided by the U.S. Geological Survey Publishing Network, Tacoma Publishing Service Center

For more information concerning the research in this report, contact the Director, Oregon Water Science Center

U.S. Geological Survey

2130 SW 5th Avenue

Portland, Oregon 97201

http://or.water.usgs.gov 


\section{盆}

疋

๗

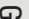

疍

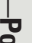

욜.

署

क्षे

을

퐇

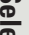

홍 